TE WHARE WĀNANGA O TE ŪPOKO O TE IKA A MĀUI

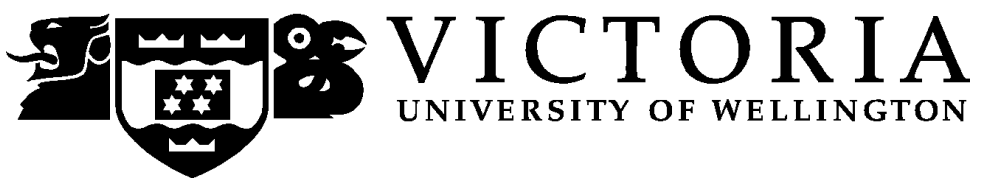

Faculty of Commerce and Administration

School of Information Management

\title{
The challenges of implementing the ITIL Problem Management process in IT support organisations
}

In partial fulfillment of the requirements for the course of

MMIM 592

Research Project in Information Management

By

Michael Hsu

$21^{\text {st }}$ February 2011 


\section{Preface}

First of all, I wish to thank my supervisor Dr. Janet Toland for her superb guidance, support and inspiration for me to conduct the research and complete writing this paper. I am most grateful to Dr. Toland's supervision in making this paper a reality.

As this paper marks the completion of my study in the Masters of Information Management programme at Victoria University of Wellington, New Zealand, I would also like to thank all the teaching and support staff at Victoria University for their excellent efforts and assistance. Both as student and staff of this great institution for the past 11 years, I received far more than education but a unique lifetime experience which I will forever appreciate.

I also wish to thank my current employer for the support for my master's study. I would like to thank my team, my managers and all my colleagues for their knowledge and encouragement which helped me greatly. I am grateful for the exceptional organisational environment they created and deeply humbled by their professionalism and the wealth of experiences and expertise they bring to the workplace on daily basis.

Last but not least, I would like to express my gratitude to my parents, my daughter and my extended families in China and US. The development of my education and career could never be separated from their understanding and long-term support. I would never be able to thank them enough for all the care they have given me and the endeavor they have taken for me thus far in my life. 


\section{Abstract}

Information Technology Infrastructure Library (ITIL) is a framework and an integrated set of process orientated best practices for providing IT infrastructure support, managing and delivering IT services. As organisations in the digital age rely on Information Technology for their daily operations as well as future growth and success, the ITIL framework is widely adopted. The Problem Management process is one of the Service Operation processes defined by the ITIL framework.

Whilst the adoption of the ITIL framework is often for the benefit of both the organisations that provide IT support and services and the organisations which consume them, the challenges of implementing this framework and its processes is often left to the IT support organisations.

This paper focuses on the ITIL Problem Management process; it reviews the principles and objectives of this IT Service Management process from an IT Governance stand point, and its implementation in the context of organisational IT services and operations. This paper collects and presents the views and insights from IT professionals who routinely worked with ITIL processes. As empirical research, this paper seeks to identify and prioritize the challenges associated with implementing the ITIL Problem Management process by the IT support organisations; it also seeks to understand the ways and methods to overcome these challenges.

This paper identifies 23 unique challenges in 6 categories including "the understanding", "the buy-in", "the investment", "the interrelation", the "execution" and "the organisational factors" which are associated with implementing the ITIL Problem Management process. The ranking of these challenges is also finalized. This paper further offers suggestions for IT support organisations to overcome these challenges. It suggests that IT support organisations may first address and overcome the challenges associated with the understanding and the buy-in of the ITIL Problem Management process, and use an overall top-down approach and effective organisational communication as they try to implement the ITIL Problem Management process.

Keywords: ITIL, IT Service Management, IT Governance, Problem Management, IT Support organisation, ITIL Problem Management process, IT Services and Operations 


\section{Table of Contents}

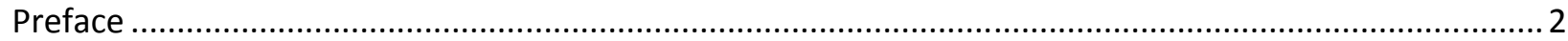

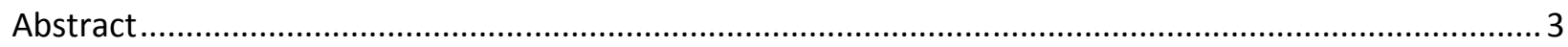

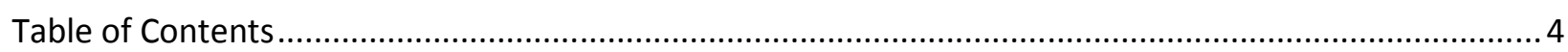

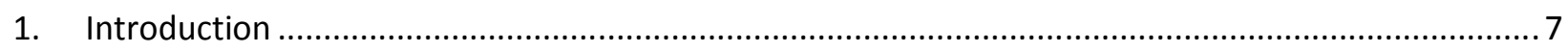

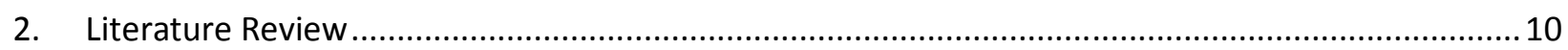

2.1 The background and overview of IT Governance ............................................................ 10

2.2 IT Governance and IT Service Management ...................................................................... 12

2.3 The ITIL Framework and the process-oriented IT Service Management .................................. 15

2.4 IT Service Management and its organisational impact........................................................... 19

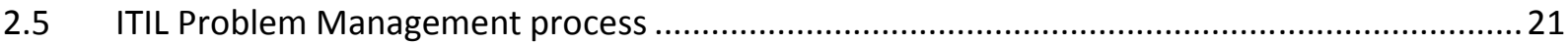

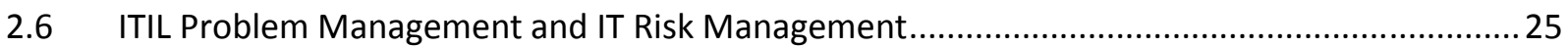

2.7 ITIL Problem Management process, major incident prevention and the improvement of IT

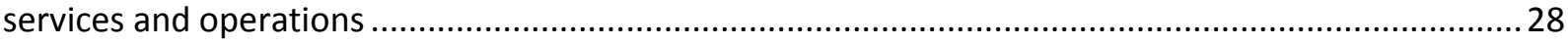

2.8 ITIL Problem Management and the improvement of IT Governance.......................................30

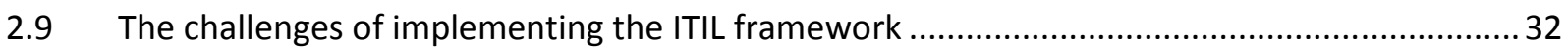

2.10 The challenge of implementing the ITIL Problem Management process ....................................37

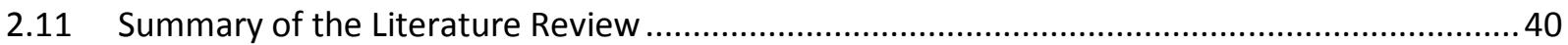

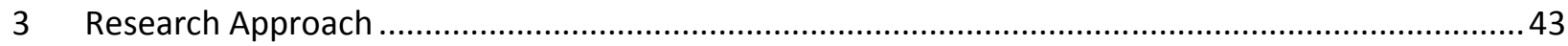

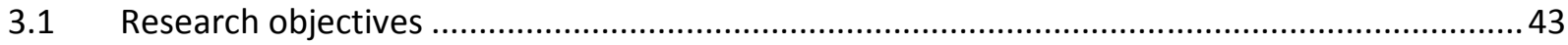

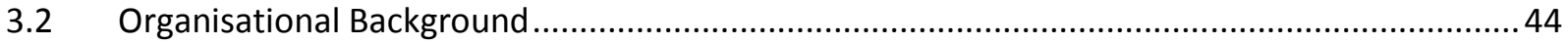

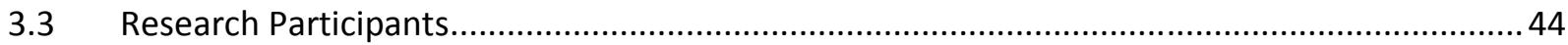

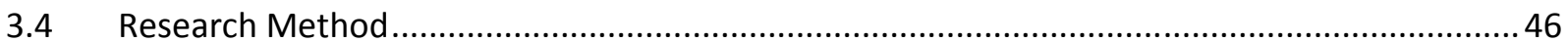

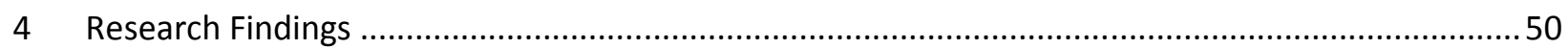

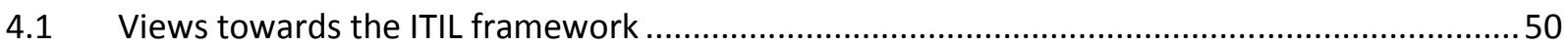


4.2 Views towards the ITIL Problem Management process

4.3 The challenges identified for IT Support organisation to implement the ITIL Problem Management process

4.4 Ways and methods to overcome the challenges.............................................................. 59

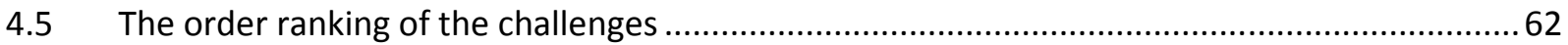

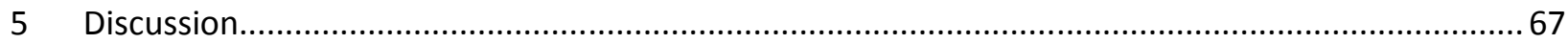

5.1 The understanding of the ITIL Problem Management process …............................................67

5.2 The quantity and quality of the information gathered for the ITIL Problem Management Process and the execution of the Problem Management process .....................................................68

5.3 The management buy-in and support for the ITIL Problem Management process ...................69

5.4 The investment and cost-benefit justification for implementing the ITIL Problem Management

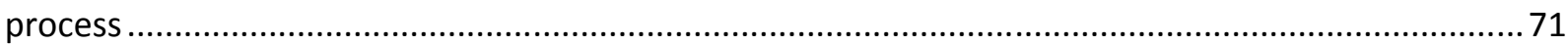

5.5 The relationships and interactions between ITIL Problem Management process and other ITIL processes and functions within the IT support organisation.

5.6 The implementation of the ITIL Problem Management and the change of IT support

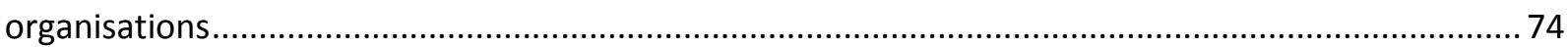

5.7 The ITIL Problem Management implementation strategy....................................................... 75

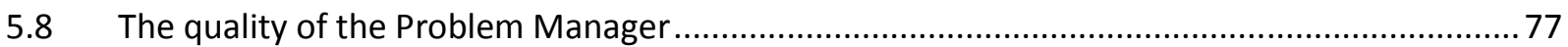

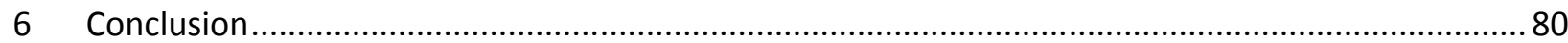

6.1 Summary of the challenges for implementing the ITIL and Problem Management process ..... 80

6.2 Overcome the challenges to implement the ITIL Problem Management process .....................82

6.3 The view towards the ITIL framework and the ITIL Problem Management process..................83

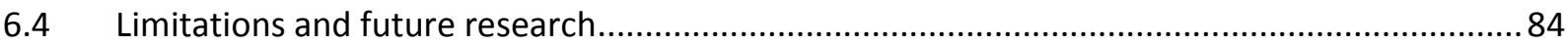

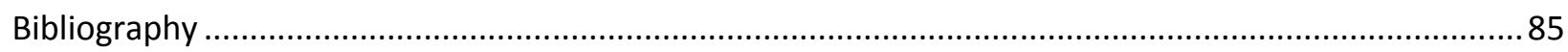

Appendix 1: Human Ethics Committee application form 1 …............................................................. 91

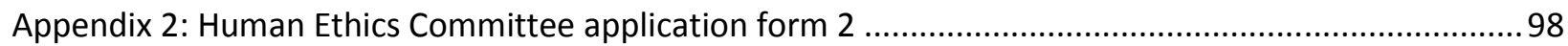


Appendix 3: Letter seeking permission to carry out the proposed research at Fujitsu Australia and New Zealand...

Appendix 4: Letter to SIM Human Ethic Committee 107

Appendix 5: Research recruitment letter to potential research participants at Fujitsu Australia and New Zealand

Appendix 6: Research Information Sheet

Appendix 7: Consent to Participate in Research.

Appendix 8: Importance Rating Questionnaire 


\section{Introduction}

Using Information Technology at the work place has never been as easy as it is made out to be computer glitches, application errors, unexpected network disconnections, data losses, virus infections, system failures ... these are all too familiar to ordinary IT users and businesses. In an organisational environment, where daily operations largely depend on Information Technology, even minor IT issues can reduce the productivity of the employees; large IT failures may bring more significant or even disastrous impacts to the organisation. For example, IBM estimated that an unplanned application outage could cost up to US2.8 million per hour (IBM, 2008). A 2010 study by CA technologies also found out that -

- North American businesses are collectively losing \$26.5 billion in revenue each year through IT downtime and data recovery. On average, each company loses $\$ 159,331$ per year.

- North American businesses collectively suffer from 1,661,321 hours of IT downtime each year. That's an average of 10 hours per company, per year.

- During these periods, when business critical systems are interrupted, companies estimate that their ability to generate revenue is reduced by $29 \%$. (CA Technologies, 2010)

IT issues are indeed business issues, not only do they result in dissatisfied end-users, disrupted business processes and lost revenue, they also bring follow-on affects such as brand damage and can even lower stock value - Investor's Business Daily reported that when Amazon had to go offline for 2 hours on a Friday in 2008 due to unexpected technical issues, not only did the company lose 3.8 million US dollars, its stock also fell 4.6 per cent on the same trading day.

Can organisational IT incidents or IT disasters ever be prevented? Are there any methods to prevent them or are they just part of the real world that we live in? The good news is that, nowadays, no matter whether organisations are getting their IT support from their internal IT departments or from external IT companies, the support is increasingly being provided by following sound best practice guidelines for managing and delivering IT services. 
ITIL - Information Technology Infrastructure Library is one of the most popular best practice frameworks and has been widely adopted by IT support organisations around the world. ITIL is made up of several interrelated IT Service Management processes; not only does it provide IT support organisations with the guidance for managing "incidents" when they occur - mainly, how to restore the normal IT services as soon as possible with "workarounds"; it also offers detailed guidelines as how the impact of the incidents should be minimized or be prevented, namely, the "Problem Management" process. A more detailed introduction of ITIL and its processes is included in section 2.3.

With a service-orientated view, any IT issue that impacts the end-users and also the organisation as a whole, no matter big or small, fits into the ITIL definition of an "Incident", which is "an unplanned interruption to an IT Service or reduction in the Quality of an IT Services" (Office of Government Commerce, 2007; p.19). A "Problem" is defined by ITIL as the root cause of one or more "incidents"; "Problem Management" is the process "responsible for managing the life cycle of all problems" (Office of Government Commerce, 2007; p.29) with the primary objectives being "to prevent problems and resulting incidents from happening, to eliminate recurring incidents and to minimize the impact of incidents that cannot be prevented" (Office of Government Commerce, 2007; p.29). In a complex technological environment which supports the day-to-day organisational operations, "when done well, Problem Management can be a powerful tool to help improve overall service quality and IT value" (Addy, 2008; p.167).

However, the implementation of the ITIL Problem Management process still seems to be at its infancy among IT support organisations, even among the ones which have embraced the ITIL framework extensively. This process has rarely been introduced to the daily organisational IT operations at its full entirety. Previous studies on the implementation of ITIL framework found that the ITIL Problem Management process was often not given the same priority as Service Desk, the Incident Management, Change Management and other ITIL processes. Even once the Problem Management process has been implemented, this important process was "rarely done well" (Addy, 2008; p.167). There has also been very little in-depth empirical research into the implementation of ITIL Problem Management process, i.e. how the implementation of this process could succeed or fail. 
The organisations which mainly provide IT support, whether being internal IT departments or an external IT outsourcing companies or suppliers, are referred to as IT support organisations in this paper. Depending on the contracts and agreements between these organisations and their customers, the support provided by these organisations can vary from supplying specific IT applications or functionalities to maintaining the ongoing or day-to-day enterprise wide IT operations. Whilst the adoption of the ITIL frameworks often aims to benefit both the organisations which receive IT support and the ones who provide them, it is usually the IT support organisations that would have to overcome most of the challenges of implementing this IT Service Management framework and its processes. "To date there has been limited academic research undertaken into ITIL implementation."(Cater-Steel et al, 2009; p.322) and research is needed to understand how organisations are adopting ITIL and identify the factors that influence its success (Hochstein et al, 2005a; Pollard \& Cater-Steel, 2009).

The word "Implementation" means the actions to put a decision or plan into effect or to fulfill an undertaking (Deverson \& Kennedy, 2005). This study focuses on the implementation of the ITIL Problem Management process and takes into consideration of both the initial setup of this process by IT support organisations and the execution of this process as part of the IT services they manage and deliver to their customers. This study seeks to identify and understand the challenges related to these implementations of the ITIL Problem Management process, as well as the ways and methods to overcome these challenges so that both the IT support organisations and the organisations which receive the IT support based on the ITIL framework can utilize the this process to its full potential. For the purpose of this study, empirical research was conducted at one major IT support organisation operating in Australia and New Zealand; 23 IT professionals from this organisation participated in this research. The research data was analysed both quantitatively and qualitatively. This study also explores the participants' views towards the ITIL framework and the ITIL Problem Management process.

This paper begins with a comprehensive literature review of the ITIL Problem Management process as well as its related concepts and benefits from a broad organisational IT governance perspective. Following the empirical research, this paper identifies a number of unique challenges and order-ranks them according to their importance. A discussion of the research findings is also included in this paper as well as the suggestions to overcome the challenges identified. 


\section{Literature Review}

\subsection{The background and overview of IT Governance}

The background of the topic for this study can be traced to the early days of using Information Technology in the organisational field. It is necessary to first look at Information Technology from an organisational perspective in order to develop the various concepts for this study.

Information Technology made significant progress from the 1950's to the 1980's, with computers developing from huge machinery units used for solving complex mathematical problems and automating traditional clerical tasks to information process devices such mini workstations. By the early 1980 's, with the invention of microprocessor and the sharp reduction of the hardware cost, personal computers started emerging in millions of households as well as the offices of organisations.

A number of studies have looked into the history of Information Technology in the organisational environment, for example, Porra, Hirschheim and Parks (2006) examined 40 years' IT history at Texaco Inc; Palmquist (2003) reviewed the history of computer support for writing centres at a number of universities in US. Most of these studies confirmed that during the early 1980's desktop computers were being introduced into daily organisational life.

Once personal computers became common within organisations, the power of corporate or organisational computing was largely dispersed to individual employees and the end-user base of Information Technology expanded widely. This fact also led to further technology development such as organisational computer networks and computer-mediated communication. In the 1990's, client - server architecture became dominant in the organisational Information Technology field and pushed computing power even further outwards towards the organisational departments and end-users. Then with the development of enterprise-wide applications, Local Area Networks, Wide Area Networks, Intranet and the internet, hundreds and thousands of organisations have firmly based their communications and business processes on their Information Technology capabilities.

Throughout the organisational Information Technology history of the last few decades, there have been two continuing trends: firstly, IT has become more pervasive and more permanently intertwined with all aspects of modern organisations; and secondly, the support of IT has become increasingly serviceorientated. 
The first trend sees Information Technology providing an increasingly crucial, complex and integrated backbone and platform which organisational routines, activities and functions, and most importantly, the business processes need to rely on. IT now has a greater impact on the organisational performance than ever before. With the growing strategic role of Information Technology in the organisational environment, IT has become an area that demands great attention and oversight from the top of the organisational hierarchy. This reality was reflected on the establishment of "IT Governance" as an integral part of the organisational or corporate governance (Buckby et al, 2008). According to Information Technology Governance Institution (2007), IT Governance is "the responsibility of executives and board of directors, and consists of the leadership and organisational structures and processes that ensure that the organisation's IT sustains and extends the organisation's strategies and objectives" (ITGI, 2007). IT Governance is "the management process which ensures delivery of the expected benefits of IT in a controlled way to enhance the long-term success of the enterprise" (ITGI, 2000).

ITGI further specified the following five key focus areas of organisational IT governance -

\begin{tabular}{|l|l|}
\hline $\begin{array}{l}\text { STRATEGIC } \\
\text { ALIGNMENT }\end{array}$ & $\begin{array}{l}\text { Ensuring the linkage of business and IT plans, on defining, maintaining and validating the } \\
\text { IT value proposition, and on aligning IT operations with enterprise operations. }\end{array}$ \\
\hline VALUE DELIVERY & $\begin{array}{l}\text { Executing the value proposition throughout the delivery cycle, ensuring that IT delivers } \\
\text { the promised benefits against the strategy, concentrating on optimizing costs and } \\
\text { proving the intrinsic value of IT. }\end{array}$ \\
\hline $\begin{array}{l}\text { RESOURCE } \\
\text { MANAGEMENT }\end{array}$ & $\begin{array}{l}\text { Optimizing investment in, and the proper management of, critical IT resources: } \\
\text { processes, people, applications, infrastructure and information. Key issues relate to the } \\
\text { optimization of knowledge and infrastructure. }\end{array}$ \\
\hline RISK MANAGEMENT & $\begin{array}{l}\text { Promoting risk awareness by senior corporate officers, a clear understanding of the } \\
\text { enterprise's appetite for risk, transparency about the significant risks to the enterprise, } \\
\text { and embedding of risk management responsibilities into the organisation. }\end{array}$ \\
\hline $\begin{array}{l}\text { PERFORMANCE } \\
\text { MEASUREMENT }\end{array}$ & $\begin{array}{l}\text { Tracking and monitoring strategy implementation, project completion, resource usage, } \\
\text { process performance and service delivery, using, for example, balanced scorecards that } \\
\text { translate strategy into action to achieve goals measurable beyond conventional } \\
\text { accounting. }\end{array}$ \\
\hline
\end{tabular}

Table 2.1 the 5 key focus areas of IT Governance (ITGI, 2007).

IT Governance, in practice, involves activities which exercise power and control over IT related decision making in an organisation; these activities often include board members and directors assessing the 
impact and benefit of Information Technology, exercising oversight and control on IT investments, developments and operations, designing, formulating and implementing enterprise-wide IT policies, making long-term and strategic plans for IT infrastructure, resources and services, facilitating IT-enabled changes, defining IT related roles and activities as well as ensuing compliances with related laws and regulations and safeguarding the interest of all stakeholders. "Just as corporate governance has been driven by the imperative to manage firms' operations to more effectively meet shareholder expectations for financial and environmental prudence, reputation, competitive edge, and risk management, so have firms focused on ITG to achieve similar IT accountabilities" (Wilkin \& Chenhall, 2010; $p, 108)$.

\subsection{IT Governance and IT Service Management}

The second notable trend for organisational IT during the past few decades is that the support of IT has moved on from being strictly technical and being provided in ad-hoc fashion to becoming increasingly dynamic and service-orientated.

"Service-oriented thinking is one of the fastest growing paradigms in IT" (Demirkane et al, 2008; p.356). A service can be described as "how certain functionality is provided to a customer by a provider" (Brenner et al, 2006; p.856). It must be recognised that most organisations do not simply rely on technology, but essentially the "communications capabilities and information processing capacity that they need to conduct their businesses" (Youtie et al, 2005; p.349).These IT functionalities and capabilities facilitate information and information handling (Peppard, 2003) for the day-to-day operations of organisations in the information age.

As organisational IT functionalities, capabilities and the infrastructures they are based on are being increasingly closely and constantly monitored, maintained, planned, customized, analysed and measured, and the organisational IT end-users are increasingly being assisted, guided and educated, the provisioning of organisational IT support and the related activities demand higher levels of competency and knowledge (Spohrer et al, 2007). In searching for more integrated, mature and cost-effective IT management and support in an increasingly complex technical environment, "companies developed a service perspective towards IT" (Conger, Winniford and Erickson-Harris, 2007; p.2). The following are 
some of the services that organisations can expect from either their internal IT departments or external IT service providers -

- Help desk services

- Hardware and software maintenance services

- Procurement and logistics services

- Network management and remote diagnosis services

- Asset management services

- Change management services (Kumbakara, 2008)

As the service-orientated trend continues for organisational Information Technology, Carr (2005) argued that IT had shifted from being an asset that organisations own in the forms of computers, software and technical components to being a service that they purchase (Carr, 2005).

With a service-centric view, IT support organisations are increasingly seen as service providers rather than technology providers. Today, IT support organisations are not only facing the challenges of managing IT infrastructure, functionalities and capabilities to meet their customers and the end-users' requirements in daily operations, but also the challenges of providing services that would create organisational value (Spohrer et al, 2007) and assist their customers to achieve their business objectives and contribute to their future success and growth.

"This transformation from a technology oriented IT shop towards a customer oriented service provider that engineers its IT processes in a systematic, methodical manner can only be achieved in terms of service oriented IT management" (Hochstein et al, 2005b; p.2). At a practical level, IT Service Management can be defined as the "management of all processes that co-operate to ensure the quality of live IT Services, according to the levels of service agreed with the customer" (Office of Government Commerce, 2007; p.30). At an organisational or strategic level, IT services should be managed and delivered appropriately to the business requirements of the organisation (Office of Government Commerce, 2000).

For organisations which receive IT services, IT Service Management should be regarded as a crucial part of the organisational IT governance. Whilst IT Governance sets the goals and objectives (Bartolini and 
Salle, 2004) and "provides a controlled environment for IT services and enable organisations to align their IT services with their objectives" (ITGI, 2004; Grewal and McDonald, 2006; P.252), IT Service Management, by focusing on " the efficient and effective supply of IT services and products, and the management of IT operations" (Bartolini and Salle, 2004; p.64), supports each of the five key focus areas of IT Governance as outlined in table 2.1 and ultimately the goals and objectives of the organisational IT governance.

In recent decades, IT services have not only been provided by organisations' internal IT departments, but also increasingly by external vendors and service providers (Peppard, 2003). Even when the economy is weak, this trend continues with a recent survey by Gartner showing 85 percent of organisations anticipate that spending on external service providers would increase or stay the same (Gartner, 2010).

The fact that IT services are provided by external parties should not prevent the management of the IT services becoming an integral part of the organisational IT governance, nor should it prevent the services being managed and delivered by following standard IT Service Management frameworks and processes. The organisations which receive IT services and rely on them for its daily operations can also be regarded as following the management frameworks and processes that the IT services are based on.

By providing IT support based on well-known IT Service Management frameworks in the industry, external IT support organisations not only work as the external service providers for their customer organisations but also the business process outsourcer of the customers' own IT departments, and therefore are able to align their services with the customers' business requirements and objectives. In a strategic partnership based on value propositions, external IT service providers with resources, competencies and knowledge are able to deliver the value sought by their customers and in return receive their own business value (Saxena and Bharadwaj, 2009). IT Service Management frameworks such as ITIL provide a common language and enable such strategic partnerships between external IT support organisations and the organisations which they manage and deliver services to. 


\subsection{The ITIL Framework and the process-oriented IT Service Management}

ITIL, known as the Information Technology Infrastructure Library, was originally designed in 1980's by the British Office of Commerce and is regarded as one of the most popular frameworks and best practices for IT Service Management. ITIL defines IT services as being based on the use of Information Technology and supports the customer's business processes; it regards IT Service Management as the implementation and management of Quality IT Services that meet the needs of the business (Office of Government Commerce, 2007).

Since being first published, ITIL went through 2 revisions which started in the mid 1990's and 2004. The refresh in 2004, initialised by the recognition of "the massive advancements in technology and emerging challenges for IT service providers" (Office of Government Commerce, 2007; p.3), resulted in the upgrade of ITIL version 2 to ITIL version 3. The upgrade introduced a new overall structure made up of "Service Strategy", "Service Design", "Service Transaction", "Service Operation" and "Continual Service Improvement" as shown in figure 2.3.1. The concepts used in this paper are mostly based on ITIL version 3. 


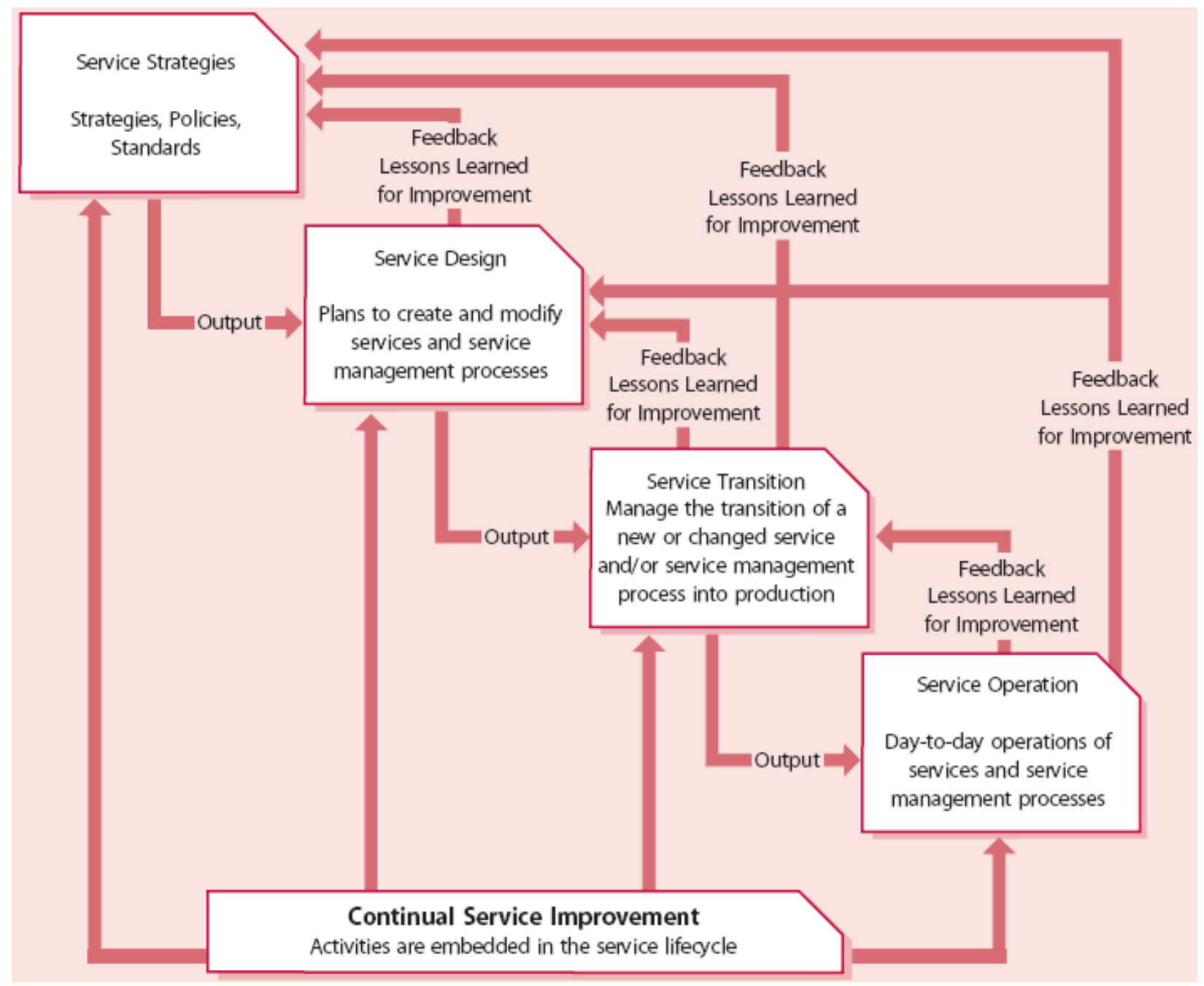

Figure 2.3.1 the core ITIL set and the continual feedback loop (Office of Government Commerce, 2007; p.22)

ITIL specifies a set of interrelated processes embedded in the above structure and presents an integrated approach to manage and deliver IT services. "ITIL exemplifies the roadmap and the description of ITSM practices ....and provides standard practices for planning and executing an ITSM programme"(Mohamed et al, 2008; p.322). "Whether it is the internal IT organisation or the external service provider, each organisation should adopt the guidelines, principles and concepts of ITIL and adapt them to suite their organisation context." (Kumbaraka, 2008; p.337). Today, the adoption of mature and structured ITS Service Management framework such as ITIL by IT support organisations is often seen as an essential step to become service-orientated in managing IT operations and providing IT support. Table 2.3 further provides the details of a number of key ITIL Service Management processes. 


\begin{tabular}{|c|c|c|}
\hline Process title & Process definition & Key concept \\
\hline $\begin{array}{l}\text { Incident } \\
\text { Management } \\
\text { (Service } \\
\text { Operation) }\end{array}$ & $\begin{array}{l}\text { The Process responsible for managing the Lifecycle } \\
\text { of all Incidents. The primary Objective of Incident } \\
\text { Management is to return the IT Service to } \\
\text { Customers as quickly as possible. }\end{array}$ & $\begin{array}{l}\text { Incident - An unplanned interruption to an } \\
\text { IT Service or reduction in the Quality of an } \\
\text { IT Service. }\end{array}$ \\
\hline $\begin{array}{l}\text { Problem } \\
\text { Management } \\
\text { (Service } \\
\text { Operation) }\end{array}$ & $\begin{array}{l}\text { The Process responsible for managing the Lifecycle } \\
\text { of all Problems. The primary objectives of Problem } \\
\text { Management are to prevent Incidents from } \\
\text { happening, and to minimize the Impact of } \\
\text { Incidents that cannot be prevented. }\end{array}$ & $\begin{array}{l}\text { Problem - A cause of one or more } \\
\text { Incidents. } \\
\text { Known Error - A Problem that has a } \\
\text { documented Root cause and a } \\
\text { Workaround. Known Errors are created and } \\
\text { managed throughout their Lifecycle by } \\
\text { Problem Management. }\end{array}$ \\
\hline $\begin{array}{l}\text { Configuration } \\
\text { Management } \\
\text { (Service } \\
\text { Transition) }\end{array}$ & $\begin{array}{l}\text { The Process responsible for maintaining } \\
\text { information about Configuration Items required to } \\
\text { deliver an IT Service, including their Relationships. } \\
\text { This information is managed throughout the } \\
\text { Lifecycle of the } \mathrm{Cl} \text {. Configuration Management is } \\
\text { part of an overall Service Asset and Configuration } \\
\text { Management Process. }\end{array}$ & $\begin{array}{l}\text { Configuration Item - Any Component that } \\
\text { needs to be managed in order to deliver an } \\
\text { IT Service. Information about each Cl is } \\
\text { recorded in a Configuration Record within } \\
\text { the Configuration Management System and } \\
\text { is maintained throughout its Lifecycle by } \\
\text { Configuration Management. Cls are under } \\
\text { the control of Change Management. Cls } \\
\text { typically include IT Services, hardware, } \\
\text { software, buildings, people, and formal } \\
\text { documentation such as Process } \\
\text { documentation and SLAs. }\end{array}$ \\
\hline $\begin{array}{l}\text { Change } \\
\text { Management } \\
\text { (Service } \\
\text { Transition) }\end{array}$ & $\begin{array}{l}\text { The Process responsible for controlling the } \\
\text { Lifecycle of all Changes. The primary objective of } \\
\text { Change Management is to enable beneficial } \\
\text { Changes to be made, with minimum disruption to } \\
\text { IT Services. }\end{array}$ & $\begin{array}{l}\text { Change - The addition, modification or } \\
\text { removal of anything that could have an } \\
\text { effect on IT Services. The Scope should } \\
\text { include all IT Services, Configuration Items, } \\
\text { Processes, Documentation, etc. }\end{array}$ \\
\hline $\begin{array}{l}\text { Release } \\
\text { Management } \\
\text { (Service } \\
\text { Transition) }\end{array}$ & $\begin{array}{l}\text { The Process responsible for Planning, scheduling } \\
\text { and controlling the movement of Releases to Test } \\
\text { and Live Environments. The primary Objective of } \\
\text { Release Management is to ensure that the } \\
\text { integrity of the Live Environment is protected and } \\
\text { that the correct Components are released. Release } \\
\text { Management is part of the Release and } \\
\text { Deployment Management Process. }\end{array}$ & $\begin{array}{l}\text { Release - A collection of hardware, } \\
\text { software, documentation, Processes or } \\
\text { other Components required to implement } \\
\text { one or more approved Changes to IT } \\
\text { Services. The contents of each Release are } \\
\text { managed, tested, and deployed as a single } \\
\text { entity. }\end{array}$ \\
\hline
\end{tabular}

Table 2.3 a number of ITIL processes (Office of Government Commerce, 2007). 
In general, processes can be defined as a structured and measured set of activities designed to produce a specified outcome for a particular customer or market (Davenport, 1993). Regev and Wegmann (2009) associated the ITIL framework with the business process reengineering movement in the early 1990's which was created "due to a perceived need to dramatically increase the efficiency of large organisations" (Regev \& Wegmann, 2009). Traditionally goods and services are produced and provided via organisational divisions based on specialties and functions, which can be described as being "departmentalised", "un-integrated" and being managed "vertically"; with business processes, organisational divisions could be integrated with higher efficiency towards common goals.

The adoption of ITIL framework and its processes represents a "horizontal" and integrated approach by the IT support organisations in managing and delivering services. As IT support is increasingly provided with a service-orientated mindset, the implementation of IT Service Management processes such as the ones prescribed by the ITIL framework allows IT support organisations to break down its IT functional silos and organise its specialties in a more efficient way. The implementation of ITIL processes can therefore be seen as business process engineering in the IT support industry.

As IT Service Management is regarded as a strategic integral part of organisational IT governance, the ITIL framework is also compatible with some of the widely adopted IT Governance frameworks such as COBIT (Control Objectives for Information and Related Technology). COBIT has a broader focus and includes the strategic IT leadership of the organisation. As an IT Governance framework, COBIT primarily addresses efficiency and strategy of IT in the context of an organisation and provides processes, measures and indicators to facilitate the adoption of appropriate IT Governance and control (Knahl, 2009). In terms of daily IT services and operations, COBIT provides less practical details and "articulates what has to be done, whereas ITIL provides the practical steps and processes to answer how it should be done and who should perform each task" (Ko and Fink, 2010; p.664). Both COBIT and ITIL formulate and formalize both the understanding and application of IT Governance and IT Service Management in a practical business environment (Demirkan et al, 2008).

Figure 2.3.2 shows IT Governance in a top-down order. The power of organisational IT governance reside with the organisational leadership; from there, it penetrates vertically through different organisational and IT layers which include IT Service Management and related activities. 


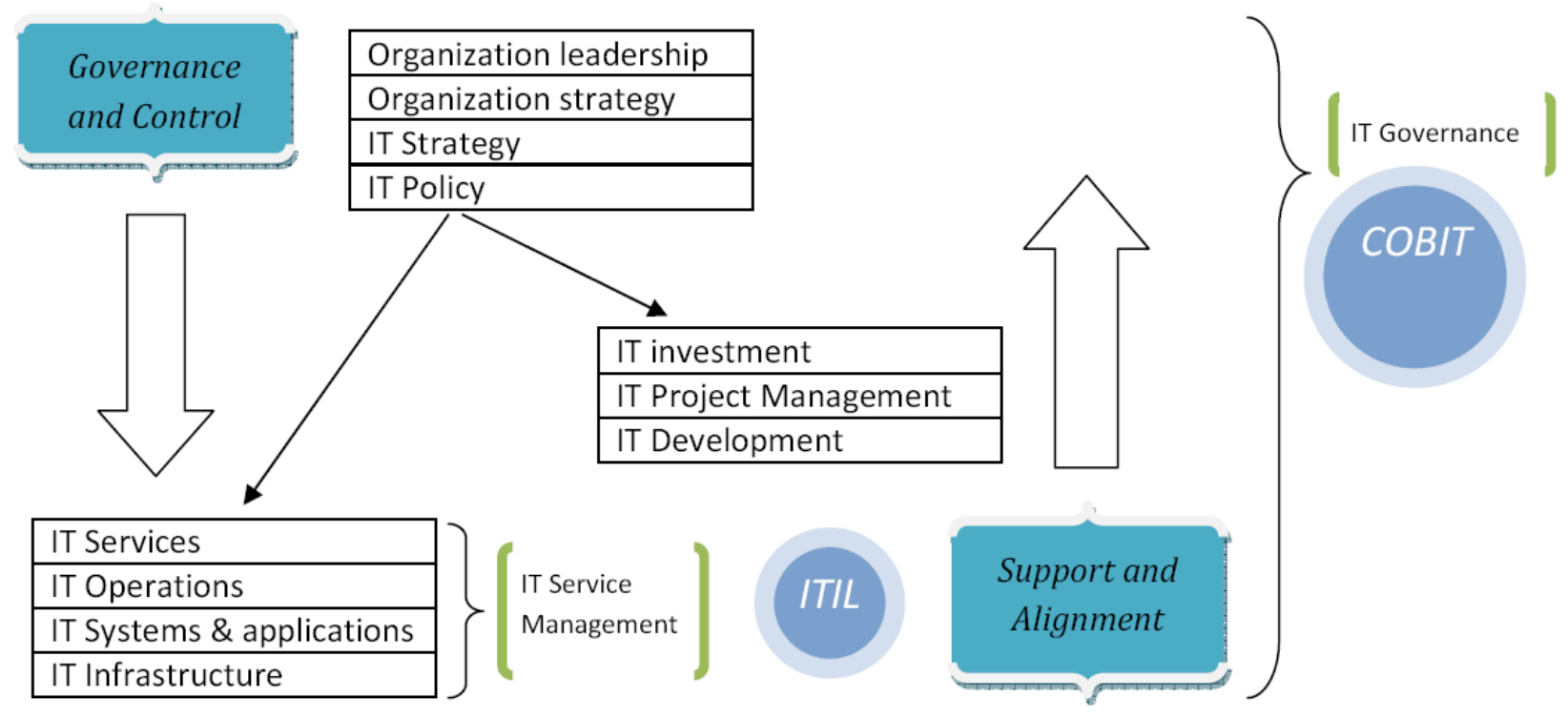

Figure 2.3.2 IT Governance and IT Service Management and their designated best practice frameworks

Whilst IT Governance can be described as an overall top-down exercise; the benefits of IT Service Management are usually realised through a bottom-up approach. Regardless of how it is implemented by either the organisation's internal IT departments or external IT service providers, all of the ITIL Service Management processes, including both Service Transition processes and Service Operation processes, are able to provide strategic and significant inputs to organisational IT governance, and by doing so, contribute to the organisation's long term growth and success.

\subsection{IT Service Management and its organisational impact}

Research by Gorla, Somers and Wong (2010) found that Information Technology service quality is the most important variable affecting business performance. This research considered IT services to an organisation as something primarily consumed by the end-users; "reliability, responsiveness, assurance, empathy" were pointed out as the most important attributes of the IT services. According to Gorla, Somers and Wong (2010), the better IT services are, the more productive the end-users will be which leads to better organisational performance. The researchers also used the following model to illustrate the impact that IT service quality has on organisational performance. 


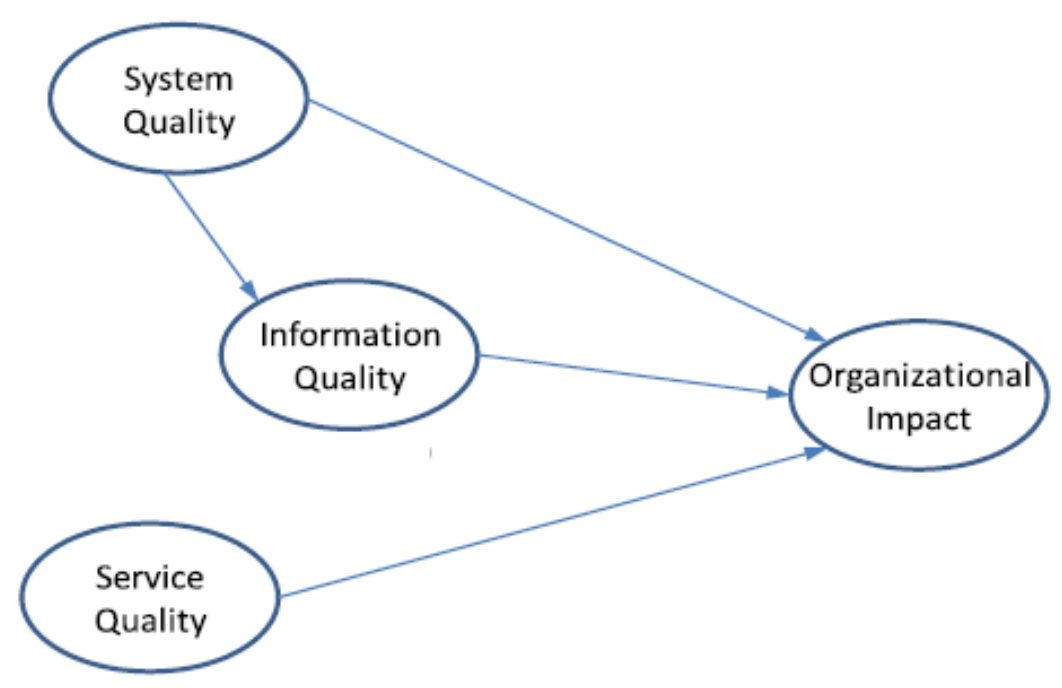

Figure 2.4 IT Service organisational impact model. Gorla, Somers and Wong (2010)

In an organisational environment, IT services are usually also provided to enhance "system quality" and "information quality" which in turn have positive impacts on organisational performance. Gorla, Sombers and Wong (2010) in their study further recommended that organisations should undertake an IT Service Management programme and framework such as ITIL to improve IT service quality and lower its cost.

IT services are also believed to enable organisations to provide better products and services, and hence increase their competitive advantage in the market. Traditionally organisational competitive advantage often came from new IT developments; however new IT systems can be easily replicated by competitors. "Sustainable competitive advantage is difficult to achieve through information systems because they can be copied. Even with patent or trade secret protection, competitors can eventually achieve the same functionality" (Gray, 2006; p.16). One example is when ATM machines were first introduced, they gave the banks which first utilised them a strategic competitive advantage, but soon they became "strategic necessity" for all major banks (Gray 2006). However, even as a "necessity", systems such as ATM machines or internet banking would still require IT services to ensure their operational quality and availability. A better maintained IT system with more efficient back-end processes would most certainly have the competitive edge over the same system but without the same level of services.

In the resource-based theory model of organisational competitive advantage (Barney, 1991), the IT services that an organisation receives can be counted as one of the organisation's "Idiosyncratic 
resources that provide operational superiority or help create a superior market position allow the firm to generate superior returns" (Reed, Lemak \& Mero, 2000; p.9). Compared to IT systems, the benefits provided by IT services are mostly intangible and depend largely on the people and the processes of the IT service provider; the organisational advantages that come from these benefits are much harder for competitors to replicate. By becoming strategic partners with their customers, IT support organisations or IT service providers are able to provide their resources, competencies and knowledge in a unique way and assist the organisation to obtain advantages over their competitors.

As pointed out by Nordin (2008) in a paper exploring the linkages between strategic service sourcing decisions and competitiveness, the advantages provided by IT services to an organisation can be described as something "different on the outside and efficient on the inside" (Nordin, 2008; p.53). With its largely intangible benefits, IT services are able to make a difference within organisations and also benefit the organisations in a competitive market. This reaffirms the point of the previous section that IT Service Management should be regarded as a strategic part of organisational IT governance which supports the goals and objectives of IT Governance.

\subsection{ITIL Problem Management process}

In ITIL version 3, the Problem Management process is one of the five "Service Operation" processes of the ITIL framework. A problem is defined by ITIL as the "root cause" for IT service disruptions or incidents. The ITIL Problem Management process is responsible for identifying, investigating and removing such root causes, and by doing so, preventing and minimizing their impact (Office of Government Commerce, 2007).

The ITIL Problem Management process also consists of reactive Problem Management and proactive Problem Management; reactive Problem Management is generally executed as part of Service Operation; proactive Problem Management may be initiated in Service Operation, but is generally driven as part of Continual Service Improvement (Office of Government Commerce, 2007). Proactive Problem Management identifies problems by proactively trending incidents and monitoring IT service operations, and focuses primarily on the preventive measures towards potential service disruptions. The 
principles and objectives of the Problem Management process remain largely unchanged in ITIL version 3 compared to ITIL version 2.

To achieve its objectives, the ITIL Problem Management interacts with the other ITIL processes especially Incident and Change Management, and carry out activities such as problem "detection", "categorization", "prioritization" and "investigation and diagnosis" as prescribed by the ITIL framework. Various techniques such as the Chronological analysis, Pain Value analysis, Kepner and Tregoe, brainstorming, Shikawa diagrams, Pareto analysis and etc can all be utilized by the Problem Management process. Once the root cause is identified, the ITIL Problem Management process "is also responsible for ensuring that the resolution is implemented through the appropriate control procedures, especially Change Management and Release Management" (Office of Government Commerce, 2007; p.80); its related activities for this purpose also include "workarounds", "raising known errors", "resolution", "review" and "closure".

A "Problem Case" or "Problem Record" is usually used to log or register an "underlying issue" or "root cause" of incidents in IT services and operations. A "Problem Case" or "Problem Record" usually contains information such as workarounds, permanent fixes, configuration items and the references of related incidents and changes; and is updated throughout the problem life cycle. "Problem Case" provides the base to launch Problem Management related activities. Incident Management and Service Desk are probably the most common sources for problem detection and identification - similar IT service disruptions, service disruptions with matching symptoms and severe and unprecedented IT service disruptions can all lead to the creation of problem cases.

Figure 2.5.1 offers a description of the ITIL Problem Management process and some of the related activities, and also an example of how this process works with Incident and Change Management. 


\begin{tabular}{|c|c|c|c|}
\hline & Inputs & Activities & Outputs \\
\hline 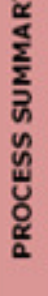 & $\begin{array}{l}\text { 1. CMOB } \\
\text { 2. Known Errors } \\
\text { 3. Detected issues } \\
\text { 4. existing and potential } \\
\text { 5. Reblems } \\
\text { 6. Work arounds } \\
\text { 7. Recognized trends } \\
\text { 8. Concems from Support } \\
\text { 9. SLaff } \\
\text { 9. SLequirements }\end{array}$ & $\begin{array}{l}\text { 1. Problem control } \\
\text { 2. Error control } \\
\text { 3. The proactive prevention of Problems } \\
\text { 4. Identifying trends } \\
\text { 5. Obtaining management information from Problem } \\
\text { 6. The completion of major Problem reviews }\end{array}$ & $\begin{array}{l}\text { 1. Known Errors } \\
\text { 2. Requests for Change } \\
\text { 3. Knowledge record } \\
\text { 4. Management information } \\
\text { 5. Accurate Work Around } \\
\text { 6. Insight into infrastructure } \\
\text { 7. Proknesses } \\
\text { 8. Less support cost because } \\
\text { of better IT staff utilization }\end{array}$ \\
\hline
\end{tabular}

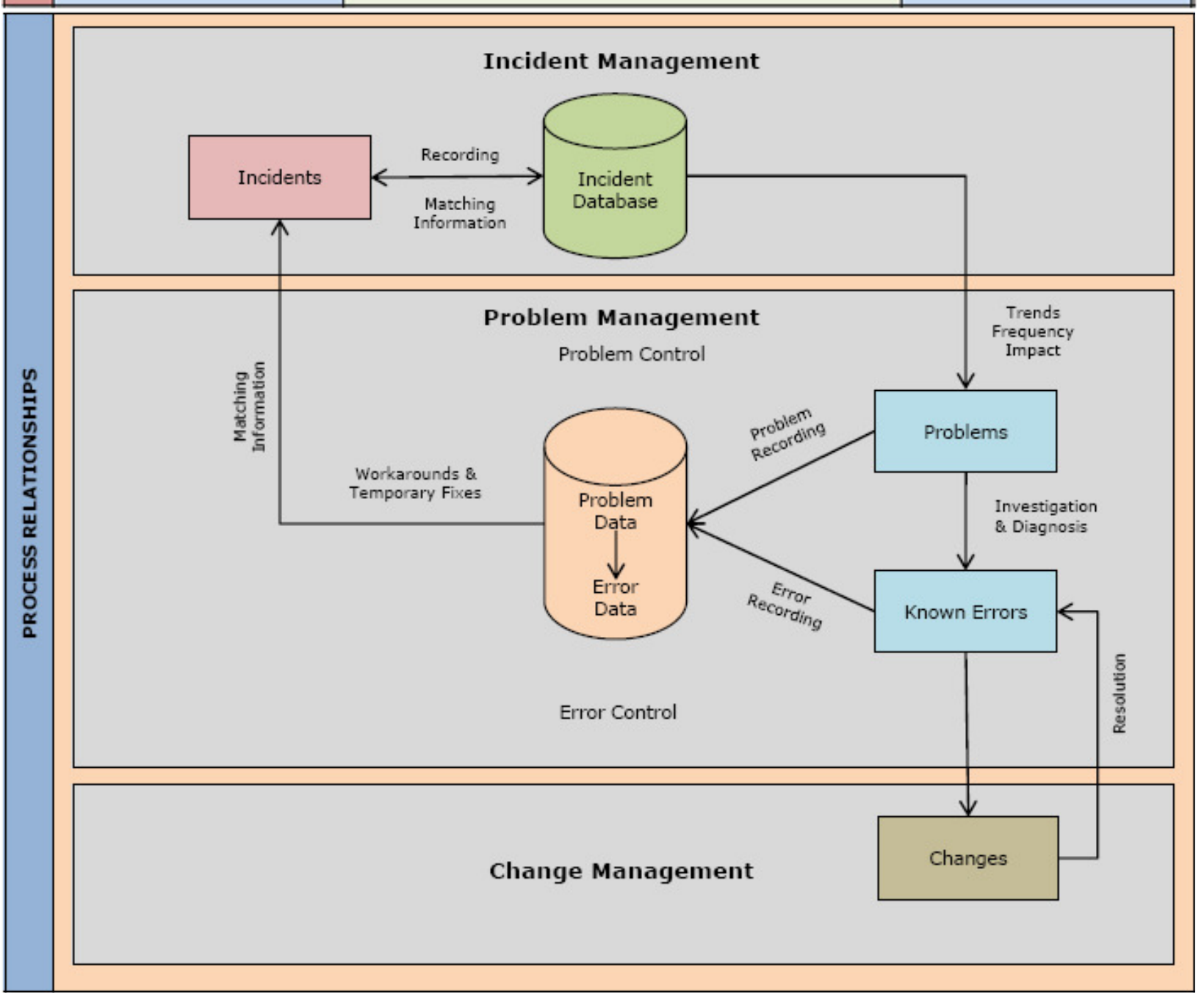

Figure 2.5.1 ITIL Problem Management descriptions (Advanced business concepts, 2008)

"Problem Management works together with Incident Management and Change Management to ensure that IT service availability and quality are increased. When incidents are resolved, information about the resolution is recorded. Over time, this information is used to speed up the resolution time and identify permanent solutions, reducing the number and resolution time of incidents. This results in less 
downtime and less disruption to business critical systems" (Office of Government Commerce, 2007; p.80). An example of this would be from JPMorgan Chase, where the implementation of the ITIL Problem Management process resulted in the elimination of 500,000 calls to the Service Desk (Dubie, 2007).

It should also be recognised that ITIL Problem Management does not only interact with Service Desk, Incident and Change Management. Figure 2.5.2 illustrates a practical process flow of Problem Management which includes multiple phases such incident matching, investigating, resolving and a number of other ITIL processes the Problem Management process interacts with. 


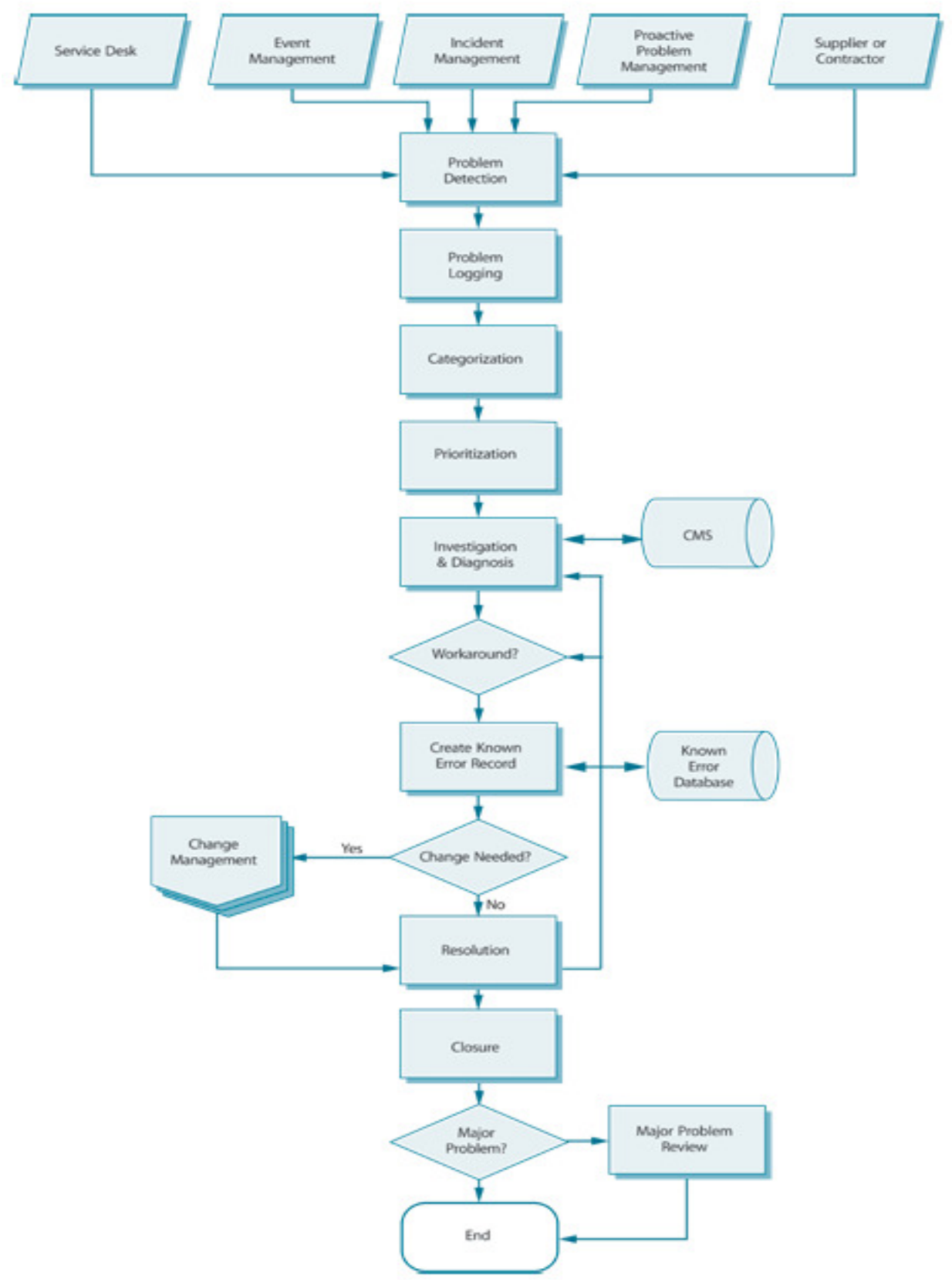

Figure 2.5.2 ITIL Problem Management process flow (Office of Government Commerce, 2007; p.82)

\subsection{ITIL Problem Management and IT Risk Management}

Risk Management is one of the five focus areas of IT Governance according to ITGI. Risks are commonly known to be associated with uncertainties. It is also important to understand that IT risks are not only associated with securing information systems or making an investment in IT developments or products. 
With the strategic importance of IT at the organisational environment, IT risks directly and indirectly impact the daily running of the businesses.

The Normal Accident Theory states that in a complex technological environment, accidents are not avoidable due to the tight coupling of technological systems and the complex or unpredictable interactions between them (Perrow, 1984). Risks can be regarded as embedded in the organisational IT operations, especially as the organisational technological environment becomes more complex and is increasingly companied by unpredictable interactions between various IT systems. The eventuation of risks in IT services and operations will inevitably impact the organisation as well as the IT service providers which manage and support the organisational IT operations. These risks are described in the following categories by Nazimoglu and Ozsen (2009):

Rework - The IT end-users raise repetitive or similar issues or disruptions to the Service Desk, or have to continuously apply workarounds when using certain IT functionalities. The IT support teams have to repetitively correct defective, failed, or non-conforming IT systems, undo or redo tasks which were not completed correctly.

Delayed solutions -solutions that are not applied in the required time to address underlying issues within IT systems or processes, or solutions which fail to minimize the impact of IT issues.

Fines and penalties - the consequences for IT service providers failing to meet Service Level Agreement for IT incidents or having other contractual breaches.

Service outages - any time the organisation as a service recipient does not receive service within the conditions set by a Service Level Agreement or preset expectations. Large scale service disruptions could seriously disrupt the functioning of organisations.

Waste - any activity that adds to the cost of IT services and operations, and to the running the organisational and business processes but does not generate revenue; or any activity that does not contribute to a more complete product or service as well as the ones that customers are not willing to pay for.

Dissatisfied customers - IT operation failures or service disruptions that may result in the loss of confidence and trust of the IT service providers by their customers and IT end-users who rely on the 
services provided; their own customers may also be dissatisfied if they fail to produce goods and services due to the IT failures or disruptions.

From an organisational IT governance perspective, the top of the organisational hierarchy should have the responsibility for an appropriate and effective risk management process, and such process depends on the interplay between the top management, operational and IT management (Wilkin and Chenhall, 2010). IT service providers, as they endeavor to meet their Service Level Agreements, align their services with their customers and create value, are often required to run risk management processes which include identifying risks, assessing risks, and taking steps to reduce risks to an acceptable level (Stoneburner et al., 2002, Nazimoglu and Ozsen, 2009).

"Problems", as defined by ITIL as the underlying causes for "service disruptions", can logically be seen as the risks to the IT services and operations. The ITIL Problem Management process, with detailed guidelines to identify underlying issues in IT operations, prevent them from eventuating and minimize their impact, essentially offers a systematic approach to address the risks in IT services and operations. By reaching objectives such as "Incident/outage avoidance", "Improve service reliability and performance to levels required by the business" and "Prevent recurrence of service disruptions", the ITIL Problem Management process directly contributes to the Risk Management area of the organisational IT governance.

The ITIL Problem Management process should therefore be regarded as the de facto risk management process in IT services and operations. Once the ITIL Problem Management process is implemented properly as part of the IT Service Management, it would essentially fulfill the risk management role and have strategic importance to the organisational IT governance. Corporate and IT executives, from an IT Governance perspective, should therefore oversee the resource commitment for the ITIL Problem Management process and review how well the process is being executed to prevent potential business disruptions. Compared to focusing on risks associated with new IT developments or investments, senior management's commitment for the implementation of the ITIL Problem Management process as part of IT Service Management may prove to be even more valuable in terms of return of investment and the prevention on monetary loss in the long run. 


\subsection{ITIL Problem Management process, major incident prevention and the improvement of IT services and operations}

ITIL defines an incident as service a disruptions, in reality, service disruptions are often the result of joint forces by a number of concurrent or sequential failures, which are in turn, caused by different root causes. Similar service disruptions happening at different times can be the manifestation of completely different set of root causes. More serious incidents, or incidents with disastrous impacts, may be the result of concurrent or sequential events or minor incidents should they fail to be investigated and prevented in the "chain of consequences" as illustrated by figure 2.7.1. For these major incidents, not the single root cause, but the causation relationships between each event and incident in the chain of consequences should be the focus of the investigation and the base for corrective and preventive actions.

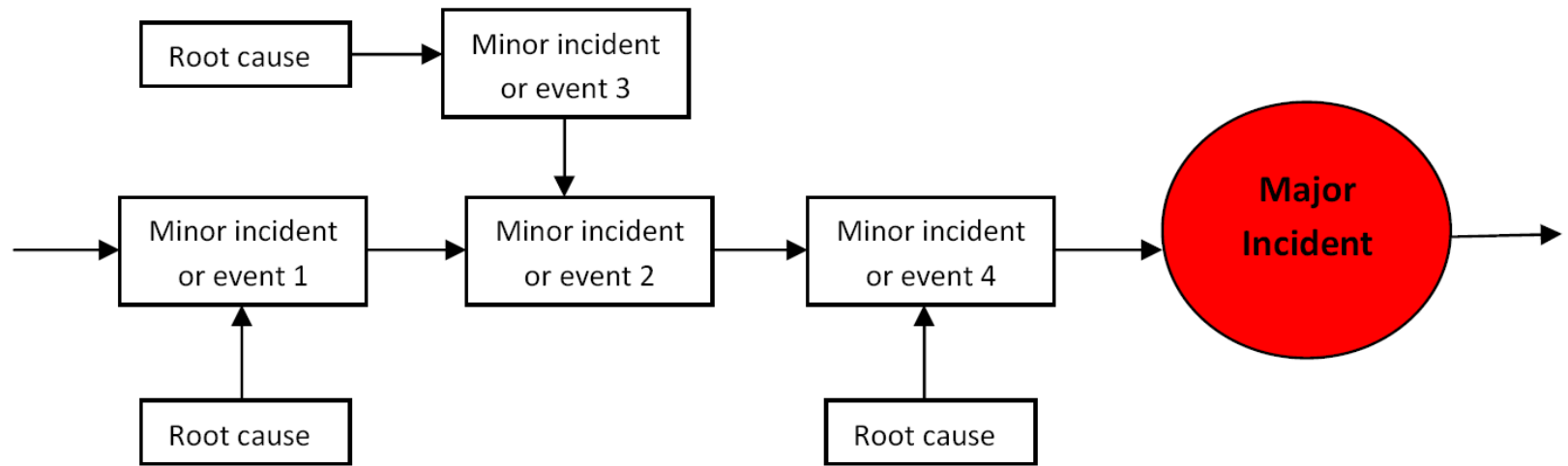

Figure 2.7.1 consequence chain leading to major incidents with disastrous impact; adapted from (Bullemer and Laberge, 2010).

As opposed to Normal Accident theory which states that accidents are not avoidable in an operational environment made of complex technological systems and the tight coupling and unpredictable interactions between these systems, a different organisational theory - High-reliability theory believes that "while accidents may be normal, serious ones can be prevented by implementing certain organisational practices" (Cooke and Rohleder, 2006; p.216). As prescribed by ITIL, one of the main objectives of the Problem Management process is to prevent incidents by eliminating their underlying causes. Applying High-reliability theory to organisational IT governance, it helps to understand that the ITIL Problem Management process can be and should be used as such organisational practice to break the chain that may lead to serious or disastrous IT incidents. 
The real power of the ITIL Problem Management process probably comes from its continuously learning activities within the IT Service Management and the IT operational environment as well as the management of the corrective and preventive actions based on these learning activities. The working relationship between the ITIL Problem Management process and Incident Management process fits into the description of the "incident learning system" as described by figure 2.7.2.

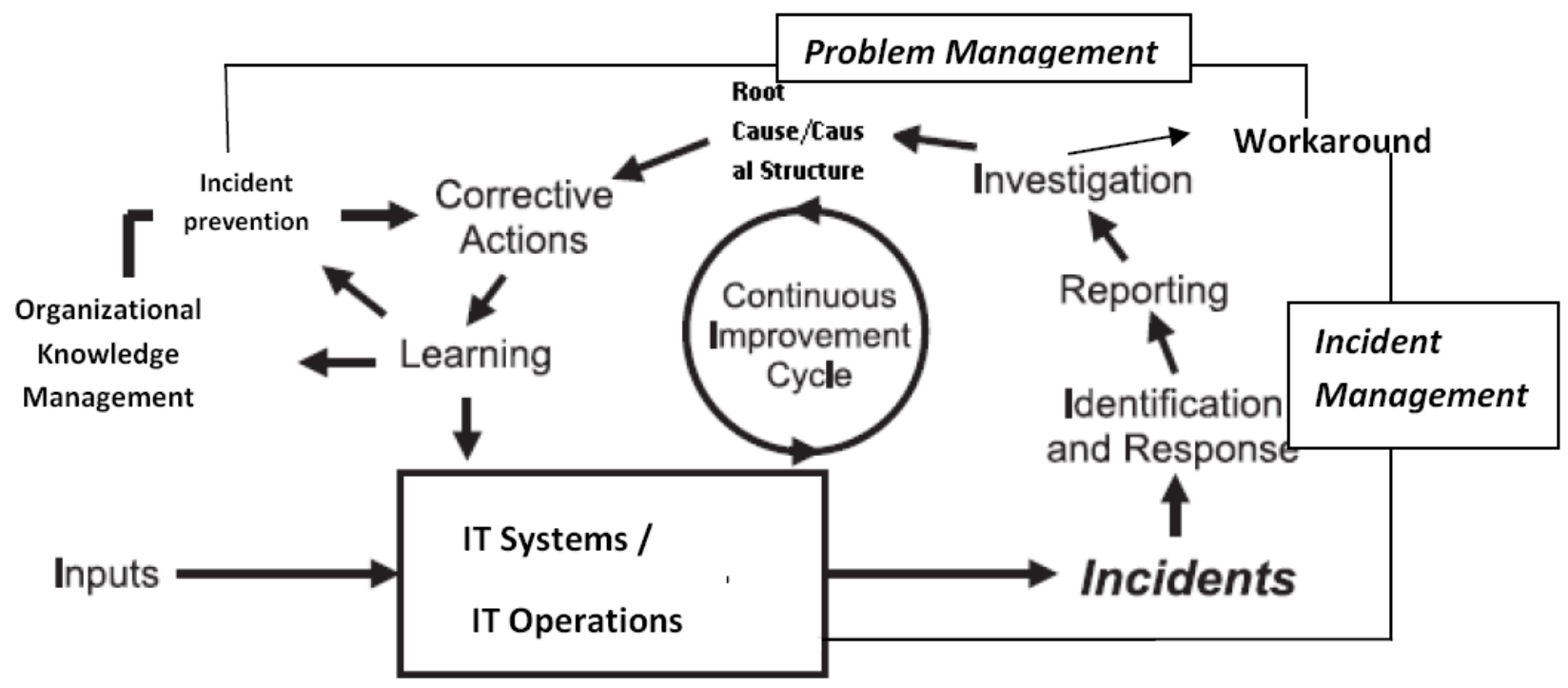

Figure 2.7.2 ITIL Problem Management process as part of an Incident learning system; adapted from Cooke and Rohleder (2006).

As the ITIL Problem Management process identifies, minimizes and prevents the impact of potential underlying issues in IT services and operations, it essentially facilitates such learning system and acts as a de facto Knowledge Management process for IT Service Management, and continuously examines, measures, improves IT services and operaions, and aligns IT services with the organisational requirements.

The ITIL Problem Management process can also benefit the organisational IT services and operations by adopting the "Operations Failure Modes" by Bullemer and Laberge (2010) as an alternative approach to achieve its objectives. As suggested by Bullemer and Laberge, whilst single incident focus may miss the "big picture" of the organisational IT services and operations, if the analysis is based on a sample of incidents, the conclusion may be vague and general. On the other hand, taking a systematic view towards the operational environment would mean that the focus would be on common underlying 
issues that cause operational failures; this approach would also bring better understanding of the vulnerabilities and their associated areas, which would ultimately help to achieve better quality of IT services and operations. Bullemer and Laberge (2010) further suggested the following systematic steps to examine the failures in order to continuously improve; these steps specified should be seen as essentially the practices and responsibilities of the ITIL Problem Management process as part of IT Service Management.

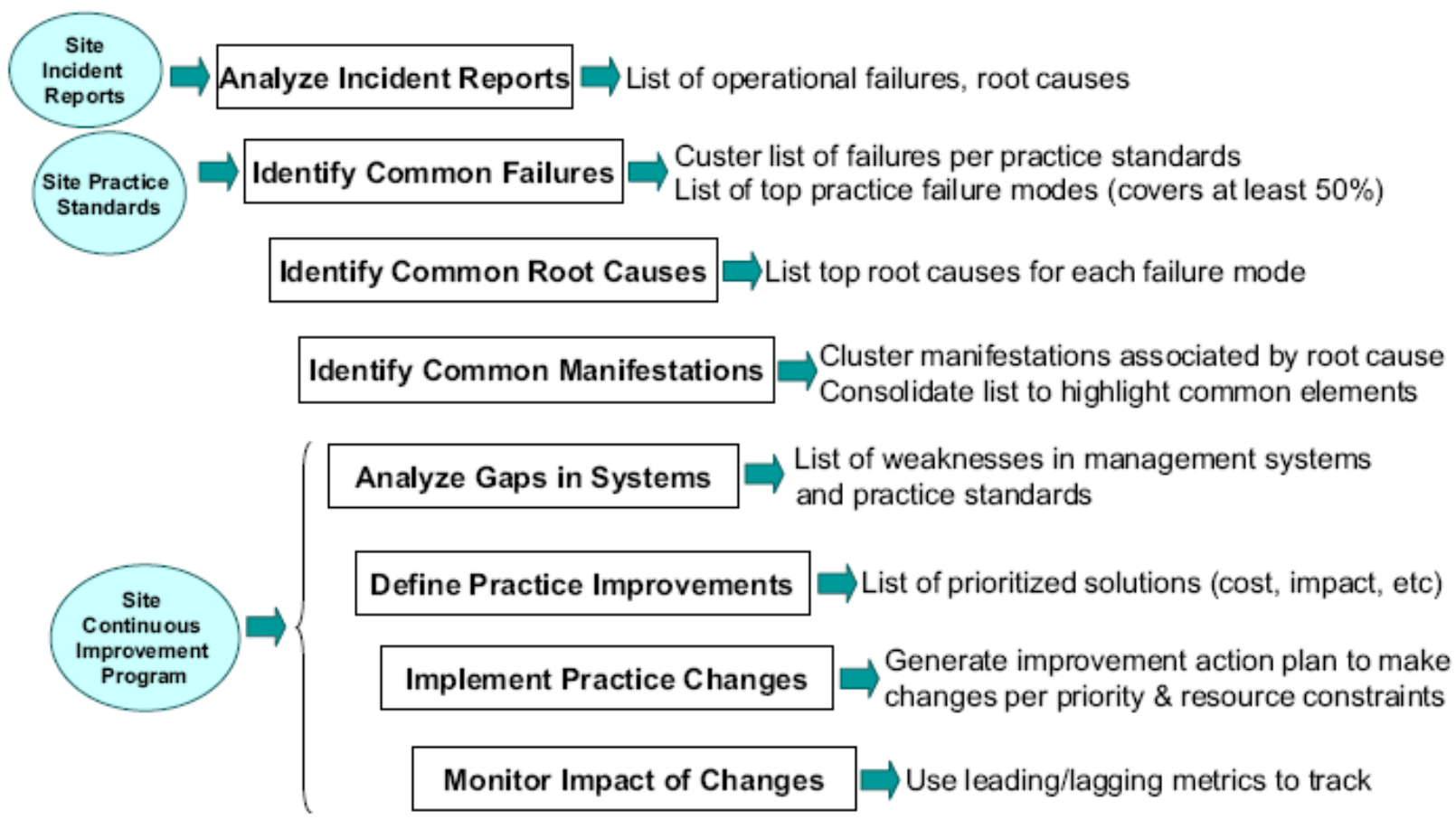

Figure 2.7.3 work progress for incident analysis and continuous improvement. Bullemer and Laberge (2010)

\subsection{ITIL Problem Management and the improvement of IT Governance}

Based on its learning power within IT services and also its focus on the IT operational environment, together with its ability to act as the de facto IT Risk Management process and drive continuous system and service improvements, the ITIL Problem Management process, both in principle and from a practical perspective, should be able to step up and make contributions to the rest of the organisational IT governance areas -

- Delivery of Value from IT Systems - address and remove underlying issues that may affect the operation of IT systems and improve their performance. 
- Management of IT Resources - optimize the investment of resources by facilitate proactive prevention of possible issues rather than firefighting.

- Measurement of the performance of IT Systems - monitor and trend existing issues and anticipate potential issues associated with IT systems and their operations.

- Strategic Alignment of Business and IT - assist organisational learning and knowledge management; and provide inputs to Service Design and Service Transition.

Gartner's "IT Management Process Maturity Model” (figure 2.8) was designed to assess IT organisation's process maturity in providing business-oriented IT Services Management (Gartner, 2005). Whilst not mentioning ITIL explicitly, the model uses terminologies similar to the ones from the ITIL framework such as the "Configuration", "Change", and "Asset" management processes. The "IT Management Process Maturity Model" specifically mentions "Problem Management" and related concepts such as "fight fires", "analyse trends" and "predict problems".

Level 4

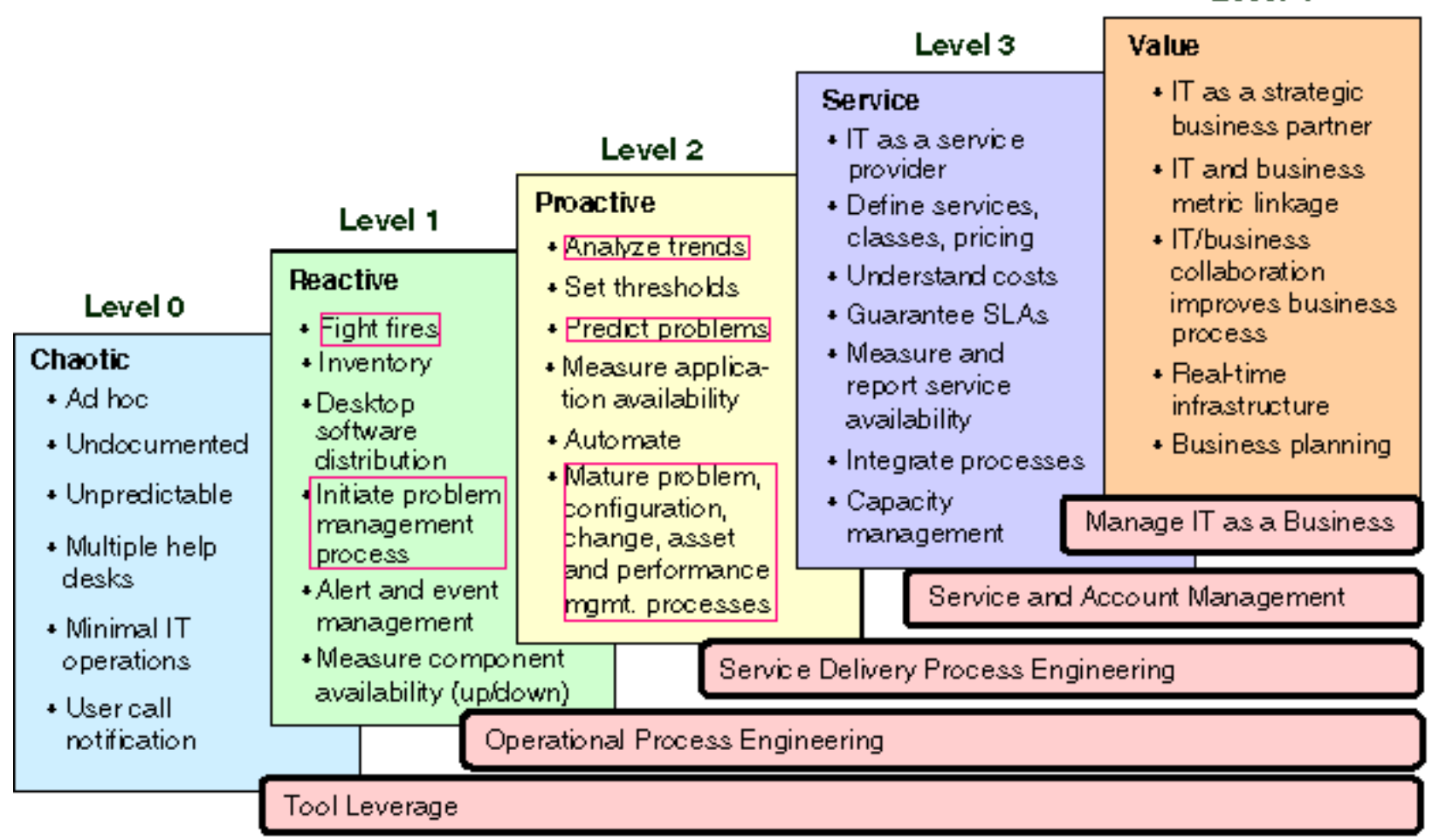

Figure 2.8 IT Management Process Maturity Model (Gartner, 2005) 
Whilst the adoption of the IT Service Management frameworks such as ITIL are supposed to benefit both the organisations which receive IT services and the IT support organisations which provide them, the implementation of the ITIL framework and related processes are largely left to the capability of the IT support organisations which can be both the internal IT departments or external IT service providers. Gartner's IT Management Process Maturity Model shows that the maturity of IT Service Management processes, such as the Problem Management process moving on from being reactive to being proactive, is a key indicator for the maturity of IT support organisations as they move towards delivering valueadded and strategically aligned IT services and improving their customers' organisational IT governance.

Unfortunately, Gartner also pointed out that as at late $2007,45 \%$ of IT organisations only had ad-hoc processes for IT Infrastructure and operations; only 30\% of IT organisations had "defined processes" for IT service support; the ones which had "repeatable and individually automated processes" only counted for $15 \%$ of all IT organisations (Gartner, 2007).The following two sections review some of the challenges identified by existing literature that IT support organisations may face when implementing the ITIL framework and the ITIL Problem Management process.

\subsection{The challenges of implementing the ITIL framework}

"ITIL framework does not offer clear-cut implementation techniques. The implementation mechanism is left for the implementer to decide upon" (Mohamed, Ribiere, O'Sullivan and Mohamed, 2008; p.316). The actual implementation of the framework and its processes requires careful analysis of the organisational requirements and priorities, and the design of an approach that suits the organisations' unique circumstances.

In recent years, a number of studies examined the ITIL implementation at various organisations. For the purpose of this paper, these studies are summarized in the following table; also listed are the challenges of implementing the ITIL framework as identified by these studies as well as the suggestions of overcoming these challenges. Some of the challenges were originally presented by these studies as "issues", "success factors" or "difficulties". 


\begin{tabular}{|c|c|c|c|}
\hline Author & Publication & Challenges identified & $\begin{array}{l}\text { Suggestions of overcoming the } \\
\text { challenges }\end{array}$ \\
\hline $\begin{array}{l}\text { Pereira } \\
\text { (2010) }\end{array}$ & $\begin{array}{l}\text { A Maturity model } \\
\text { for Implementing } \\
\text { ITIL }\end{array}$ & $\begin{array}{l}\text { - Organisational resistance to } \\
\text { change } \\
\text { - } \quad \text { Unproven business value } \\
\text { - Strong organisational } \\
\text { culture }\end{array}$ & $\begin{array}{l}\text { Pereira (2010) suggested in "A Maturity } \\
\text { model for Implementing ITIL" that to } \\
\text { overcome these challenges of ITIL } \\
\text { implementation, including the ones } \\
\text { listed by Sharifi et al (2008). According } \\
\text { to Pereira, organisations need to use a } \\
\text { maturity model such as CMM } \\
\text { (Capability Maturity Model) with five } \\
\text { maturity levels ("initial", "repeatable", } \\
\text { "defined", "managed" and "optimizing") } \\
\text { to assess its process capability by } \\
\text { measuring the degree to which } \\
\text { processes are defined and managed to } \\
\text { guide the implementation of the ITIL } \\
\text { Framework. }\end{array}$ \\
\hline $\begin{array}{l}\text { Shang and } \\
\text { Lin (2010) }\end{array}$ & $\begin{array}{l}\text { Barriers to } \\
\text { implementing } \\
\text { ITIL - A Multi- } \\
\text { Case Study on } \\
\text { the Service- } \\
\text { based Industry }\end{array}$ & $\begin{array}{l}\text { Dissatisfied customers due } \\
\text { to the gap between the } \\
\text { degree of improved service } \\
\text { quality and customers' } \\
\text { perception } \\
\text { - Unable to satisfy } \\
\text { customers' } \\
\text { specific needs in time } \\
\text { - } \text { Extra costs occurred in } \\
\text { education and } \\
\text { management } \\
\text { Time lag between } \\
\text { investment in ITIL project } \\
\text { and performance outcome } \\
\text { Conflicts between urgent } \\
\text { needs for quality } \\
\text { improvement and cost } \\
\text { consideration } \\
\text { Employee resistance } \\
\text { - } \text { Lack of integration ability } \\
\text { Conflict between different } \\
\text { interest group } \\
\text { Difficult to assess the } \\
\text { immediate effect of ITIL on } \\
\text { the continuous process of } \\
\text { improvement } \\
\text { Lack of collaboration }\end{array}$ & \\
\hline
\end{tabular}




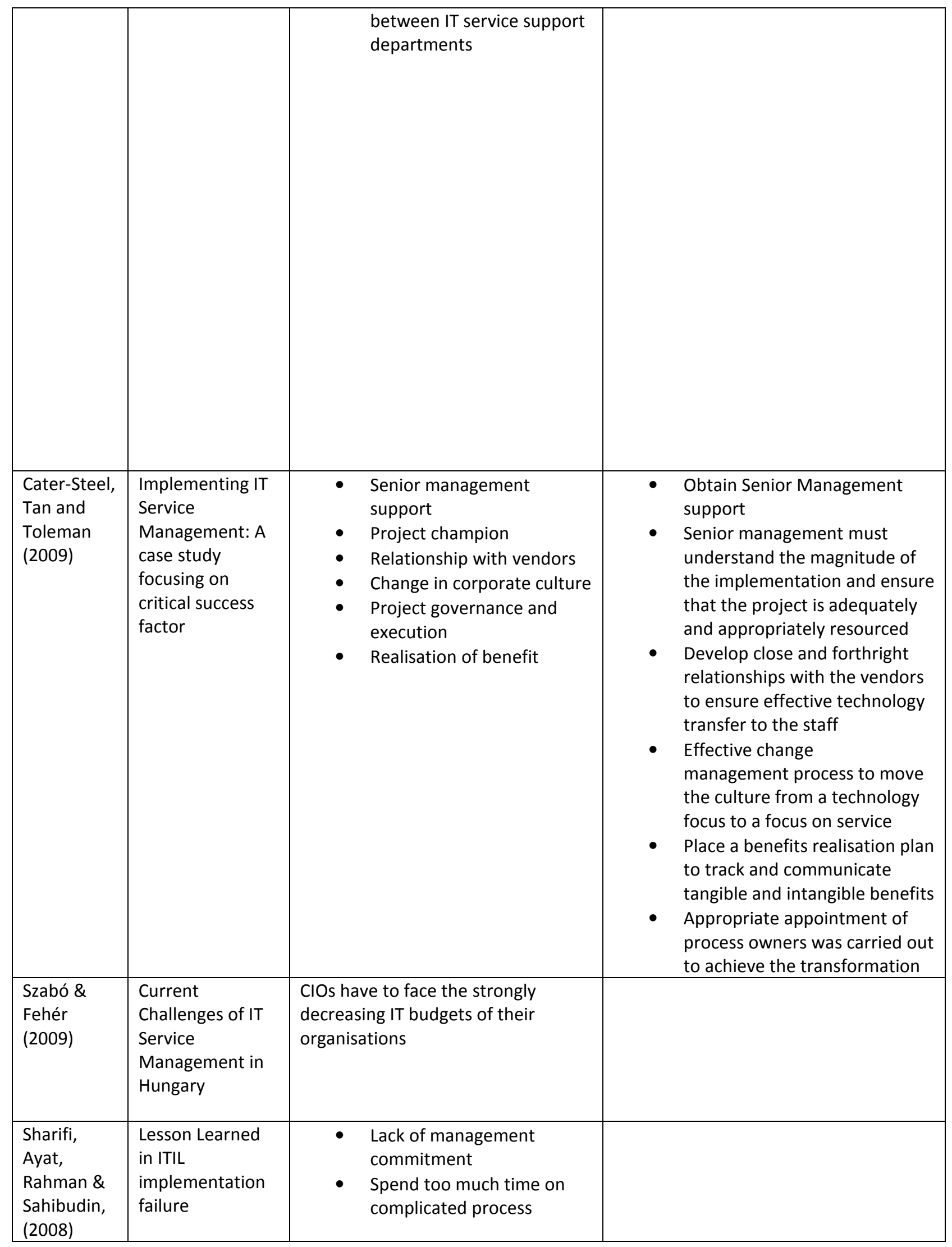




\begin{tabular}{|c|c|c|c|}
\hline & & $\begin{array}{ll} & \text { diagrams } \\
\text { - } & \text { Not creating work } \\
\text { - } & \text { Not assigning process } \\
\text { - } & \text { Conners } \\
\text { - } & \text { performancentrating too much on } \\
\text { - } & \text { Being too ambitious } \\
\text { - } & \text { Alloming to maintain } \\
\text { - } & \text { demarcation } \\
\text { - } & \text { of thoring constant reviewing } \\
\text { Not memorizing ITIL books }\end{array}$ & \\
\hline $\begin{array}{l}\text { Keel } \\
\text {, Orr } \\
\text {,Hernandez } \\
\text {, Patrocinio } \\
\& \\
\text { Bouchard } \\
\text { (2007) }\end{array}$ & $\begin{array}{l}\text { From a } \\
\text { technology- } \\
\text { oriented } \\
\text { to a service- } \\
\text { oriented } \\
\text { approach } \\
\text { to IT } \\
\text { management }\end{array}$ & $\begin{array}{l}\text { "One of the most difficult challenges } \\
\text { in implementing an ITSM strategy is } \\
\text { the impact ITSM may have on the IT } \\
\text { organisation and staff....due to the } \\
\text { natural tendency of people to resist } \\
\text { change" }\end{array}$ & $\begin{array}{l}\text { - } \quad \text { Establishing process ownership } \\
\text { - } \text { Defining the scope of the } \\
\text { - } \\
\text { - } \\
\text { - } \quad \text { Decess } \\
\text { Designing a technical } \\
\text { - } \quad \text { Decidinfrastructure process } \\
\text { - } \quad \text { Planning on process } \\
\text { and associated infrastructure }\end{array}$ \\
\hline $\begin{array}{l}\text { Cater-Steel } \\
\& \text { McBride } \\
(2007)\end{array}$ & $\begin{array}{l}\text { IT Service } \\
\text { Management } \\
\text { Improvement - } \\
\text { Actor Network } \\
\text { perspective }\end{array}$ & $\begin{array}{l}\text { - Lack of acceptance of new } \\
\text { processes } \\
\text { Lack of understanding of } \\
\text { why such changes are } \\
\text { necessary }\end{array}$ & $\begin{array}{l}\text { - Managerial instruments such } \\
\text { as organisational restructuring } \\
\text { and the definition of new roles } \\
\text { and processes must be backed } \\
\text { up by appropriate } \\
\text { communication which provides } \\
\text { a rationale for the changes, } \\
\text { sets the context and draws } \\
\text { people in } \\
\text { - Develop a corporate mindset } \\
\text { - Win hearts and minds } \\
\text { "Strong ground and good soil" } \\
\text { - make sure messages from } \\
\text { top management is well } \\
\text { received, understood and } \\
\text { supported by staff members }\end{array}$ \\
\hline $\begin{array}{l}\text { Cater-Steel } \\
\& \\
\text { Tan (2006) }\end{array}$ & $\begin{array}{l}\text { Transforming IT } \\
\text { Service } \\
\text { Management - } \\
\text { the ITIL Impact }\end{array}$ & $\begin{array}{ll}\text { - } & \text { Lack of Management } \\
\text { Support } \\
\text { - } \\
\text { Resistance from technical } \\
\text { staff } \\
\text { - Delays in establishing an } \\
\text { appropriate toolset }\end{array}$ & $\begin{array}{l}\text { - Senior management does not } \\
\text { need an in-depth } \\
\text { understanding of ITIL but must } \\
\text { provide support in terms of } \\
\text { resources and authority to } \\
\text { enforce new policies }\end{array}$ \\
\hline
\end{tabular}




\begin{tabular}{|c|c|c|c|}
\hline & & $\begin{array}{l}\text { - The difficulty of quantifying } \\
\text { benefits } \\
\text { Resistance to adhering to } \\
\text { the new documentation } \\
\text { and communication } \\
\text { processes. } \\
\text { Changing the focus from } \\
\text { crisis management and } \\
\text { workarounds to } \\
\text { consideration of the 'real } \\
\text { problems' as defined by } \\
\text { ITIL, resolving the } \\
\text { important underlying } \\
\text { problems } \\
\text { Measure return on } \\
\text { investment } \\
\text { Communication and } \\
\text { coordination between the } \\
\text { various sections to provide } \\
\text { a seamless end-to-end } \\
\text { service }\end{array}$ & $\begin{array}{l}\text { - } \\
\text { the processes in actual use } \\
\text { - } \quad \text { Eliminate surprises } \\
\text { - } \quad \text { Initially look for quick wins } \\
\text { customer service and services } \\
\text { delivery } \\
\text { - } \text { Awareness campaign and } \\
\text { Educate staff members } \\
\text { Have open discussions with } \\
\text { affected staff, establish a } \\
\text { comfortable environment for } \\
\text { discussion }\end{array}$ \\
\hline $\begin{array}{l}\text { Cater-Steel } \\
\& \text { Tan } \\
(2005 a)\end{array}$ & $\begin{array}{l}\text { Implementation } \\
\text { of IT } \\
\text { Infrastructure } \\
\text { Library (ITIL) in } \\
\text { Australia: } \\
\text { Progress and } \\
\text { success factor }\end{array}$ & $\begin{array}{l}\text { - Commitment from senior } \\
\text { management } \\
\text { - Champion to advocate and } \\
\text { promote ITIL } \\
\text { - } \quad \text { Ability of IT staff to adapt to } \\
\text { change } \\
\text { - Quality of IT staff allocated } \\
\text { to ITIL } \\
\text { ITIL training for IT staff }\end{array}$ & \\
\hline $\begin{array}{l}\text { Hochstein, } \\
\text { Tamm \& } \\
\text { Brenner } \\
\text { (2005b) }\end{array}$ & $\begin{array}{l}\text { Service-oriented } \\
\text { it management: } \\
\text { Benefit, cost and } \\
\text { success factors }\end{array}$ & $\begin{array}{l}\text { - Lack of acceptance of new } \\
\text { processes } \\
\text { - Lack of understanding of } \\
\text { why such changes are } \\
\text { necessary }\end{array}$ & $\begin{array}{l}\text { - Showing of "quick wins" and } \\
\text { thereby demonstrating the } \\
\text { usefulness of service-oriented } \\
\text { IT management (aiming at } \\
\text { measurable project goals) } \\
\text { - Striving for continuous } \\
\text { improvement in order to } \\
\text { guarantee the sustainability of } \\
\text { success } \\
\text { Marketing campaigns (buy-in- } \\
\text { phase, management of } \\
\text { expectations, use of internal } \\
\text { publication media, road shows, } \\
\text { workshops, seminars et cetera) } \\
\text { in order to create acceptance } \\
\text { and understanding } \\
\text { Obtaining support of } \\
\text { management in order to be } \\
\text { able to exert pressure }\end{array}$ \\
\hline
\end{tabular}




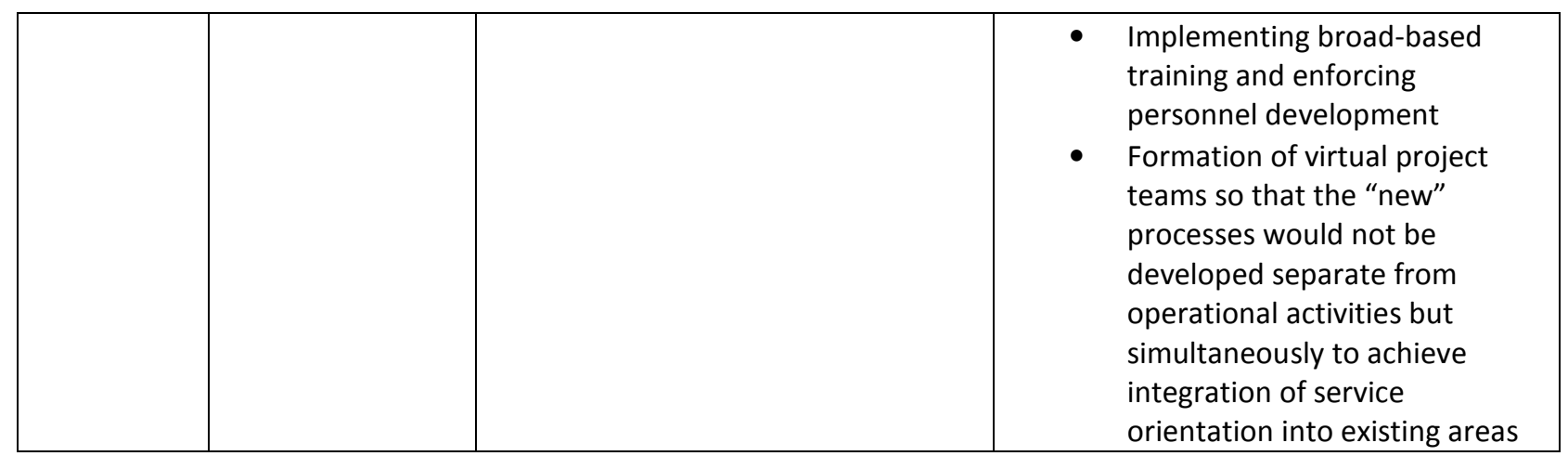

Table 2.9 summary of the challenges of implementing ITIL framework from literature review

The studies listed focused on the experiences of setting up the ITIL framework within IT support organisation from scratch. Most of them examined such implementation of the ITIL framework from a project management or organisational change management stand point. From a project management perspective, the management support, finance commitment, project execution and leadership, investment and return were regarded as the challenging areas for implementing the ITIL framework; from an organisational change perspective, challenges were also identified in regards to changing organisational culture, justifying the changes and overcoming employee resistance. According to these studies, having senior management support, developing an implementation strategy, careful planning and execution of the implementation projects as well as fostering an organisational cultural change were among the most appropriate method to meet the challenges of implementing the ITIL framework.

The aim of this research is to provide empirical evidence to verify whether some of the challenges for implementing the ITIL framework would also be associated with the implementation of the ITIL Problem Management process.

\subsection{The challenge of implementing the ITIL Problem Management process}

Among the very few empirical studies which covered the implementation of ITIL Problem Management process, Niessink and van Vliet (2006) assessed the quality of the ITIL Problem Management process run by a Dutch organisation responsible of the nation's social security system. This research concluded that the Problem Management process could not be executed properly due to the lack of sound Incident Management process - "30\% of the incidents were coded incorrectly" (Niessink and van Vliet, 2006; p.60). 
The book "ITIL Service Operation", one of the official publications of ITIL version 3, used only 160 words to describe the "challenges, critical success factors and risks" of the ITIL Problem Management process; among them, "the effective Incident Management process and tools" are pointed out as "a major dependency" because they will "ensure problems are identified and much work is done on the prequalification as soon as possible" (Office of Government Commerce, 2007; p.93). The "Formal interfaces and common working practices" between ITIL Problem Management process and Incident Management process are described as "critical". This piece of practitioner literature also mentions the training of technical staff in technology as well as business implications of the IT services and the processes; it further suggests that it is important for the Problem Management process to be able to "use all knowledge and Configuration Management resources available" (Office of Government Commerce, 2007; p.93). Such account of the challenges associated with the ITIL Problem Management process as offered by this official publication of the ITIL framework is rather vague or inadequate compared to what this process may encounter in reality.

Only very little literature offered the real case scenarios of implementation of the ITIL Problem Management process. In the "Problem Management" chapter of the book "Effective IT Service Management: To ITIL and Beyond" (Addy, 2008), the author pointed out the following common "issues":

- Insufficient focus and/or time and resources given to preventive action

- Lack of sufficient data for meaningful analysis

- Difficulty collecting the data necessary to facilitate analysis

- Poorly defined relationships between configuration items

- Relationship structure does not allow indirect cross object analysis

- Inappropriate resource allocation to preventive action efforts

- Limited involvement of appropriate technical specialists

- Unrealistic expectations that issues can be prevented easily

- Seemingly random events/undefined and/or unknown causal links prevent true causes being identified

- Control measures fail to prevent recurrence of incidents 
- Problem Management used as a means of determining/attributing blame for outages and/or incidents

- Reluctance on the part of employees to participate within the process (Addy, 2008; p.166).

The author Marko Jantti in his doctoral dissertation "Difficulties in managing software problems and defects" discussed the following challenges which he believes are related to ITIL Problem Management process -

- Terminology - ITIL terminologies were not widely or traditionally used in part of the IT industry.

- The lack of practical examples to show the distinctions of ITIL concepts such as incident, problem, service request and change request.

- The lack of guidelines as how knowledge management should interact with ITIL processes such as Problem Management. (Jantti, 2008)

Some ITIL training materials have also provided certain "problems" or challenges associated with the ITIL Problem Management process, such as -

- Wrong staff are assigned to Problem analysis

- Lack of overall discipline in carrying out the process

- Management doesn't want to hear bad news about weaknesses in either systems or people

- Overlapping resources between Incident Management and Problem Management

- No distinction is made between Incident Management and Problem Management

- The Incident Management process is too immature (Advanced Business Concepts, 2008)

- Lack of a good Incident Management process

- Failure to link Incident records with Problem and Known Error records

- Lack of management commitment

- Undermining the Service Desk role

- Failure to build and maintain a useful knowledge base

- An inability to determine the business impact of Incidents and Problems

- Confusing Incident and Problem Management goals (ITSM Academy Inc, 2005) 
The challenges or difficulties listed above focused mostly on the execution of the ITIL Problem Management process, such as the analysis of the impact, the resource and the information required, and also the interactions between the ITIL Problem Management process and other ITIL processes. Some challenges associated with the initial setup of the ITIL Problem Management process were also mentioned, such as the understanding of the ITIL Problem Management process and the management commitment and expectations. This study and its empirical research take into consideration of both of these two types of implementations and their associated challenges.

\subsection{Summary of the Literature Review}

The ITIL Problem Management process is the focus of this research paper; the study of this specific ITIL process cannot be done in isolation from the broad IT Service Management and organisational IT governance context. The literature review first examined the background of organisational IT governance, IT Service Management and the impact of IT services on organisational performances. The details of ITIL, which is one of the most widely adopted IT Service Management frameworks, were presented; the definitions of some of the ITIL Service Operation and Service Transition processes and a detailed description of the Problem Management process were also included.

It is established in the literature review that organisational IT support is increasingly being managed by processes instead of the traditional direct chain of command. IT support is also being provided with a service -orientated paradigm. These facts were reflected by IT support organisations' adoption of IT Service Management framework and best practices such as ITIL. IT Service Management drives the alignment between IT services and business, and by doing so, contributes to the overall success of organisational IT governance. The literature showed that IT Service Management is a strategic part of organisational IT governance. The ITIL framework, as an IT Service Management framework, is also compatible with IT Governance frameworks such as COBIT.

Although incidents or service disruptions may not be completely avoidable at a large and complex IT operational environment, with the learning power of the Problem Management process and its ability to take corrective and preventive actions, major IT incidents or incidents with disastrous impacts can be prevented. The ITIL Problem Management process can and should be used as a strategic process in many aspects of the organisational IT services and operations: from the IT service provider's perspective, this process provides key steps to facilitate continuous learning and improve the service quality. From 
the organisation's perspective, the ITIL Problem Management process can be used as an important organisational process to manage IT risks and address operational vulnerabilities. The implementation of the ITIL Problem Management process may also require an organisational cultural change in providing IT support which would shift the focus from performing reactive tasks such as break-fixes to proactively addressing potential underlying issues before they eventuate.

The challenges for IT support organisations in implementing the ITIL framework and the ITIL Problem Management process are also evident; after grouping the similar challenge items from the literature and removing the duplicate ones, the following summary can be made - 


\begin{tabular}{|c|c|c|}
\hline & $\begin{array}{l}\text { Challenges identified from literature review for } \\
\text { implementing ITIL Problem Management } \\
\text { process }\end{array}$ & $\begin{array}{l}\text { Challenges identified from literature review for } \\
\text { implementing the ITIL framework }\end{array}$ \\
\hline $\begin{array}{l}\text { Unique } \\
\text { items }\end{array}$ & $\begin{array}{l}\text { The availability, quality and expertise of the staff } \\
\text { resources that the process requires. } \\
\text { The maturity of other interrelated ITIL processes and } \\
\text { functions. } \\
\text { The data and information required to support the ITIL } \\
\text { Problem Management process and its analyses. } \\
\text { The relationship and collaboration between Problem } \\
\text { Management and other ITIL process and functions } \\
\text { such as incident management and the Service Desk. } \\
\text { The ability to reach some of the objectives of the ITIL } \\
\text { Problem Management process, such as to prevent } \\
\text { reoccurring incidents. } \\
\text { The interaction between Problem Management and } \\
\text { Knowledge Management } \\
\text { The expectation and understanding of this process by } \\
\text { the management }\end{array}$ & $\begin{array}{l}\text { The financial commitment. } \\
\text { The establishment of procedures, roles and } \\
\text { responsibilities. } \\
\text { The collaboration of IT support teams. } \\
\text { The toolset. } \\
\text { The measurement of return on long term and short } \\
\text { term business value. } \\
\text { The customer expectations and perceptions. } \\
\text { The return of investment in terms of service } \\
\text { improvement. } \\
\text { The resistance of the IT support teams. } \\
\text { Relationship with the external vendors and } \\
\text { consultants. } \\
\text { The management of the implementation project. }\end{array}$ \\
\hline $\begin{array}{l}\text { Common } \\
\text { items }\end{array}$ & \multicolumn{2}{|c|}{$\begin{array}{l}\text { The Management commitment and support. } \\
\text { The Understanding of the processes by IT support teams. } \\
\text { The resource committed to the implementation. } \\
\text { The motivation and willingness of the staff who participate in the ITIL processes. } \\
\text { The lack of practical examples to follow. } \\
\text { Change of culture, discipline and focus in providing IT support. }\end{array}$} \\
\hline
\end{tabular}

Table 2.11 summary of the challenges for implementing the ITIL framework and the ITIL Problem Management process as identified by literature review 


\section{Research Approach}

\subsection{Research objectives}

Given the limited literature and the lack of empirical enquiry into the implementation of the ITIL Problem Management process, this research aimed to conduct a rigorous investigation that would lead to the identification of the challenges associated with implementing the ITIL Problem Management process. This research also intended to collect insightful views and perspectives towards ITIL Problem Management process from IT professionals and to discover approaches, ways and methods for IT support organisations to overcome the challenges identified.

The overall question for this research can be described as: What are the challenges associated with the implementation of the ITIL Problem Management process by IT support organisations and how can IT support organisations overcome these challenges.

It was expected that this research would confirm some or all of the challenges concluded from literature review and possible provide additional ones. This research also aimed to order-rank the challenges according to their perceived importance by the participants, and to present them in the order of their ranking.

The objectives of the research can be summarized as to:

1. Explore and present IT professionals' views towards the ITIL Framework and the ITIL Problem Management process,

2. Identify the challenges of implementing the Problem Management process within IT support organisations,

3. Rank the identified challenges according to their importance,

4. Discover the possible ways, methods and approaches by which the IT support organisations can overcome the top-ranked challenges.

This research adds to academic literature on the ITIL Problem Management process and its implementation. It benefits IT support organisations and Problem Management practitioners; the challenges identified by this research and their importance ranking can be used as a priority list as they plan to implement the ITIL Problem Management process and improve their IT services. This research 
also offers guidance for implementing the ITIL Problem Management process and helps IT support organisations and Problem Management practitioners to develop their own implementation strategies that suit their organisational and business circumstances.

\subsection{Organisational Background}

This research was conducted in one IT company which is a major player in the ICT market place in both Australia and New Zealand. This company was established in the early 1970's, and as of September 2010, it employed around 5000 staff in both Australia and New Zealand and carries out work for over 2000 organisations. It provides managed IT services to large enterprise customers at various industries across both the public and private sector.

Over the years, this company has focused as much on methodologies as on technology in providing IT services. It has a track record of being customer-centric and has been proud to follow industry best practices such as the ITIL framework in delivering IT services to its customers. In late 2010, this company's operations at all major New Zealand sites were certified for ISO20000 IT Service Management standard; its operations at major Australia sites will also soon go through the certification process.

The company's Problem Management team, based in both Australia and New Zealand, has 20 staff members in total and manages the Problem Management process for over 30 enterprise customers as part of the "managed services" this company provides to these customers.

\subsection{Research Participants}

The researcher first recruited 23 IT professionals employed as permanent staff by this IT outsourcing company. The roles of participants and their geographical locations are listed in table 3.3. 


\begin{tabular}{|l|l|}
\hline New Zealand & Australia \\
\hline $\begin{array}{l}\text { 1X Problem Management team leader } \\
3 X \text { Service Desk team leader }\end{array}$ & $\begin{array}{l}\text { XX Problem Management manager } \\
\text { XX Problem Analyst } \\
\text { 1X Service Desk team manager }\end{array}$ \\
$\begin{array}{l}\text { 1X Service Improvement manager } \\
1 X \text { Change coordinator }\end{array}$ & $\begin{array}{l}1 X \text { Desktop Engineer } \\
1 X \text { Configuration analyst }\end{array}$ \\
$1 X$ Change and Configuration team leader & $1 X$ Senior Change manager \\
\end{tabular}

Table 3.3 the roles of the participants and their geographical locations

These participants were recruited based on their different involvements with the ITIL Problem Management process and were expected to provide diverse perspectives towards this ITIL process. The 8 members of the Problem Management team were considered as having the most in-depth knowledge and involvement of this process - each of the Problem Analysts was the manager and champion of this process for their designated enterprise customer, i.e. the organisation for which this process was implemented as part of the managed IT services. The Problem Management team leader and manager were the champions of this process within this IT support organisation and had main responsibilities for the initial setup of this process and overseeing the running of this process for all customers. Participants who worked for Service Desk, Change Management, Configuration Management and Service Delivery had been directly interacting with the Problem Management process from the perspectives of their own processes and daily tasks. The 4 engineers participated in this research all had direct involvement in the Problem Management process on regular basis. The Project Manager also worked with the Problem Management process particularly in managing and delivering projects that were considered as permanent solutions to certain problem cases or had the permanent solutions embedded.

All 23 participants represented a diverse background, knowledge and experiences in IT Service Management and in working with the ITIL framework. During the research interviews, at least 13 of the 23 participants specifically mentioned their previous work experiences with other IT support organisations, 2 of which were UK based IT companies. Two other participants left the current 
organisation in less than 3 months following the interviews in pursuit of employments in other IT service providers. Seventeen of the 23 participants had their roles in the organisation defined based on ITIL processes. All participants followed various ITIL processes for their daily tasks except for the Project Manager and one Engineer who were designated resource for IT projects. At least 9 participants had at least 1 ITIL certificate. Three of the participants had experiences initially setting up ITIL processes in the previous organisations they worked for. One participant, the Service Improvement manager, had the task of ensuring the organisation is running ITIL process according to international standards such as ISO 20000.

\subsection{Research Method}

This research aimed to answer the overall research question by analyzing and critically reflecting on how the ITIL Problem Management process and the challenges associated with its implementation were understood by the research participants. The research process can be described as:

1. The researcher used semi-structured interviews to collect data and analysed them qualitatively,

2. Following the qualitative data analysis, the research finalized a list of important challenges associated with implementing the Problem Management process as comprehensively identified by all the participants,

3. The researcher asked participants to rate each challenge identified according to their importance, and

4. The researcher then studied the rating of each challenge qualitatively to conclude the relative importance of the challenges and finalize their order-ranking.

Based on the analysis of the data collected during the interviews and also the challenges identified, the researcher also systematically identified the ways and methods to overcome these challenges.

The following open-ended questions were asked by the researcher in the semi-structured interviews to collect data from the participants -

1. What are your experiences working with the ITIL framework?

2. What is your view towards the ITIL Problem Management process?

3. What are the challenges in implementing ITIL Problem Management process in an IT support organisation?

4. What is the relative importance of these challenges? 
5. How can IT support organisations overcome the top challenges?

Follow-up questions were also used in the interview process to probe for participant's insights and knowledge. The researcher is based in New Zealand, the interviews with New Zealand participants were all conducted face to face and all interviews with Australian participants were conducted via telephone. The researcher also tape recorded all interviews with the participants' permission.

The researcher transcribed all 23 interviews for the qualitative content analysis. During the analysis, without referring to pre-existing knowledge of the research topic from either personal experiences or literature review, the researcher closely examined participants' answers and responses in the interview context. The meaning of the participants' answers and responses were constructed only with the participants' own words and the context of the interviews to ensure the maximal level of accuracy in reflecting the participants' understanding of the topic. The content analysis was conducted as a learning process without pre-assumptions; the researcher was the learner in this process and the participants' views were perceived by the researcher as of paramount importance. Overall, the researcher relied on the most accurate and objective interpretation and reflection of the participants' understanding to reach the conclusions.

During the content analysis process as described above, the researcher identified themes of the challenges for implementing the ITIL Problem Management process as they emerged. Based on these themes, the researcher built categories for the participants' answers and responses. The researcher then summarized all answers and responses in each category and removed duplicate items. This resulted in a list of the challenges for implementing the ITIL Problem Management process as being identified collectively by all participants' and exhaustive of all the answers and responses received in the interviews. The relationships between each category were also identified. For each challenge identified, the researcher kept a record of how many participants had mentioned it during the interviews. The content analysis steps taken to finalize the list of the challenges will be further elaborated in section 4.3. By following these content analysis steps, the researcher was also able to identify the participants' views on the ITIL framework and the ITIL Problem Management process, as well as comprehensively collected ideas and approaches suggested by the participants as how the challenges of implementing the ITIL Problem Management process can be overcome. 
The researcher originally planned to use Delphi method to order rank all the challenges and reach a consensus among the participants for the ranking order. To follow the Delphi method, the researcher would need to ask the participants to order rank all the challenges identified, and calculate an overall ranking for each individual challenge based on the ranking it received. The researcher would also need to calculate the Kendall's coefficient of concordance - if $n$ is the number of challenges identified and $m$ is the number of participants, $S$, the sum of the squared deviation of each challenge's ranking $R i$, would

be calculated by the formula $S=\sum_{i=1}^{n}\left(R_{i}-\bar{R}\right)^{2}$; the value of $\mathrm{S}$ would then determine the Kendall's coefficient of concordance, $W\left(W=\frac{12 S}{m^{2}\left(n^{3}-n\right)}\right)$ (Kendall and Smith, 1939).

The Kendall's coefficient of concordance varies between 0 and 1 ; if there is a "complete unanimity in the rankings", W would equal to 1 . "By using $\mathrm{W}$, one can make a realistic determination of whether any consensus has been reached, whether the consensus is increasing, and the relative strength of the consensus" (Schmidt, 1997; p. 765).

By following the Delphi method, if the Kendall's coefficient of concordance, W, is less than 0.5 following the first round of ranking, the researcher would need to present the ranking result to the participants and ask them to review their previous ranking decision and make a new ranking order if possible. The researcher would need to continue calculating Kendall's coefficient of concordance, W, based on the new ranking order from the participants until $\mathrm{W}$ becomes equal or larger than 0.5 , which means a moderate consensus had been reached among the participants in regards to the ranking order of the challenges; or until W becomes relatively steady or unchanged, which means that moderate consensus may never be reached. Previously this process was used by Singh, Keil and Kasi (2009) to come up with the importance ranking for the challenges associated with implementing a project management office (PMO) (Singh, Keil and Kasi, 2009).

The Delphi method was finally abandoned after a few rounds of ranking. The list of challenges as identified by the research was relatively long with 23 challenges in total; if the Delphi method had continued to be used, the Delphi process would inevitably become time-consuming and tedious. It was also not desirable to use Delphi method on just a number of selected challenges or just the top 10 
challenges based on the number of participants who mentioned them during the interviews. The momentum of the participants also dropped significantly after a few rounds of ranking; some participants expressed resistance to continue ranking the challenges. It was also observed that, as participants kept on reviewing the same list of challenges, their ranking became less objective and increasingly based only on their most recent experiences with the ITIL Problem Management process. Instead of continuing to follow the Delphi method, the researcher asked the participants to rate each challenge according to their importance; all ratings were done in a scale between 1 and 10, 1 being least important and 10 being most important. This step allowed the researcher to order-rank the challenge items according to the average importance rating each of them had received; challenges with higher average importance rating were given higher ranking, in case more than one challenge had the same average rating, the item which received ratings with smaller standard deviation was ranked higher. By following this process, the researcher finalized a ranked list of all the challenges associated with implementing the ITIL Problem Management process as identified by this research.

The researcher believed that the importance rating of each challenge was a valuable step for this research. Rather than selecting just a number of challenges for a Delphi study, this step ensured that the participants could review all the challenges collectively identified by all participants and assess their importance. There is one challenge which was only mentioned by one participant during the interview process, but was given the $3^{\text {rd }}$ highest importance rating at this step. This challenge item was obviously not been thought of by most participants during the interviews but was highly rated once the participants had the chance to evaluate its importance. This challenge would have been missed out if the researcher only took a number of most mentioned challenges for quantitative analysis. 


\section{Research Findings}

\subsection{Views towards the ITIL framework}

During each of the 23 interviews, the researcher asked the following question first to settle the participants and to establish rapport. It was also a way of getting their views on the ITIL Framework.

"Interview question 1: what are your experiences working with ITIL, what are your views and opinions about it?"

Except for the Project Manager, all participants had experiences working with the ITIL framework. The Project Manager's lack of experiences with the ITIL framework can be explained by the fact that Project Management is usually not considered as part of IT Service Management, and there are other designated methodologies for IT Project Management.

Throughout the interviews, the researcher found that the views towards ITIL as an IT Service Management framework were positive overall. Most of the participants expressed the view that ITIL was a framework that IT service providers should adopt; they also see this framework being in the process of being adopted by even more organisations. Two benefits of ITIL were highlighted in the interviews: first, internally for the IT service provider, ITIL defines roles and responsibilities for IT professionals and also how these different roles and functions should interact with one another, this helps to break down the functional silos in delivering IT services. Second, externally, ITIL provides an industry standard for managing and delivering IT services. The only negativity expressed towards ITIL is that the ten processes and one function in earlier versions of this framework may not be able to cover every aspect of IT services and operations; some participants believed that activities such as knowledge management or risk management were missed out by this framework, other participants thought that the framework left room for different interpretations, and as a result, how it was implemented and the extent of the implementation may vary between organisations. As mentioned earlier, "Implementation" stands for the actions to put a decision or plan into effect or to fulfill an undertaking; despite the overall confidence on the ITIL framework, most participants regarded the appropriate and successful implementation of this framework as crucial in realising its benefit.

The following is a summary of the themes that emerged from the answers and responses to this question. 


\begin{tabular}{|c|c|}
\hline Themes & Comments made for the ITIL framework during the interviews \\
\hline $\begin{array}{l}\text { The ITIL framework is } \\
\text { perceived overall } \\
\text { positively }\end{array}$ & $\begin{array}{l}\text { "I believe in it. I think it is a good thing, a very good thing" } \\
\text { "I think ITIL is something that is very good that we need to have in IT" } \\
\text { "it is a decent framework, it is logical" } \\
\text { "I think it is a good system; I don't see any other ways to manage a totally complex } \\
\text { environment" } \\
\text { "in terms of the system, it is a brilliant system" } \\
\text { "I am a strong advocate for ITIL and I think it is a very good framework" }\end{array}$ \\
\hline $\begin{array}{l}\text { ITIL is believed to be } \\
\text { in the process of } \\
\text { being adopted by } \\
\text { more organisations }\end{array}$ & $\begin{array}{l}\text { "From what I can see the government has embraced it and so private companies" } \\
\text { "It is a voice becoming universal" }\end{array}$ \\
\hline $\begin{array}{l}\text { ITIL is believed to } \\
\text { benefit the IT } \\
\text { support organisation } \\
\text { by defining IT } \\
\text { professionals' roles } \\
\text { and responsibilities } \\
\text { and working } \\
\text { relationships }\end{array}$ & $\begin{array}{l}\text { "It sets the line for demarcation quite clearly" } \\
\text { "...gives people some good guidelines to base themselves on and interlink those different } \\
\text { processes" } \\
\text { "...put emphasis on how the processes interlink and rely on each other" }\end{array}$ \\
\hline $\begin{array}{l}\text { ITIL is believed to } \\
\text { become a standard } \\
\text { way in providing IT } \\
\text { services }\end{array}$ & $\begin{array}{l}\text { "I think it's really useful because it is a standard way of doing things" } \\
\text { "it is kind of like standardized across the industry" } \\
\text { "ITIL very much integrated into all IT shops, service delivery" } \\
\text { "It just sort of gives the customer a bit of bench mark as where you were at" }\end{array}$ \\
\hline $\begin{array}{l}\text { The successful and } \\
\text { appropriate } \\
\text { implementation of } \\
\text { ITIL according to } \\
\text { organisational } \\
\text { environment was } \\
\text { seen crucial to } \\
\text { realise its benefit }\end{array}$ & $\begin{array}{l}\text { "You get to adopt, adapt it the way you wanted it to be" } \\
\text { "I like the adaptability of ITIL, I like the way that you can take a bit and piece of things and } \\
\text { implement them as what you need for your company, and expand on that, as your } \\
\text { company gets mature with ITIL processes or ITIL experiences" } \\
\text { "I find that when it is adhered to, it produces results" } \\
\text { "It is very effective if implemented properly" }\end{array}$ \\
\hline $\begin{array}{l}\text { The ITIL } \\
\text { implementation - } \\
\text { how the framework } \\
\text { is interpreted and } \\
\text { used - can vary and } \\
\text { there is room for } \\
\text { different } \\
\text { interpretations }\end{array}$ & $\begin{array}{l}\text { "It is common sense based approach and it is what you make of it" } \\
\text { "The only negative thing I see of ITIL would be the, it is up for interpretation...you can say } \\
\text { you are practicing ITIL but you are not really" }\end{array}$ \\
\hline
\end{tabular}




\begin{tabular}{|l|l|}
\hline & \\
\hline Earlier version of ITIL & "...some gaps stretching out there I think things they may not necessarily include as \\
may not cover all & functions for..." \\
aspects of IT services & "V3 is definitely a big step up comparing to what V2 was, and it would be interesting to see \\
and operations and it & V4 does if or when it happens" \\
is being addressed & "Especially with version 3, it is particularly comprehensive" \\
\hline
\end{tabular}

Table 4.1 themes emerged in relation to the views of ITIL framework

\subsection{Views towards the ITIL Problem Management process}

The second question the researcher asked during the interviews was the participants' view towards the ITIL Problem Management process.

\section{Interview Question two: “What is your view towards the ITIL Problem Management process?"}

Most participants understood the reduction of incidents as the main objective of the ITIL Problem Management process, and understood that the Problem Management process could achieve this objective by removing the root causes of incidents. The participants also had high expectations for Problem Management to reduce the workload of the support staff by achieving this objective. With such expectations, the participants also seemed to be primarily focused on reactive Problem Management rather than proactive Problem Management. There is a general positive perception towards the ITIL Problem Management process and the benefit it may bring to the IT support organisations as well as their customers. It was also generally seen as in IT service providers' as well as their customers' interest that the ITIL Problem Management process is implemented successfully.

Just as for the ITIL framework, the participants regarded the successful implementation of the Problem Management process as crucial in realising its benefits. Despite generally wanting to see the Problem Management process being better understood, better followed and more recognised in providing IT services, the participants also regarded the implementation of this process as less straightforward and more difficult than the implementation of other ITIL processes. Comparing to other ITIL processes, the participants saw more challenges that could influence the success of the Problem Management process, as well as the time and resources it may require to successfully realise its benefit and fully meet the high expectations held by various service teams in the IT support organisation. 
The participants expected that problem cases, as opposed to ordinary incidents, would require a lot more coordination between different IT skill sets. The Problem Managers were primarily expected to coordinate different expertise and keep the focus and momentum on finding and removing the root causes of incidents, and in the mean time, also proactively search for incidents that may occur in the future. The participants also believed that the implementation of the ITIL Problem Management process would need the support from the entire IT support organisation - from management to different internal teams as well as the customers. Ensuring the understanding of this process and its benefits was commonly seen as the first step in building such support. The participants also believed that a long-term or strategic view may be required to implement this process, and expected potential issues and challenges to be considered as the organisation prepares to implement the ITIL Problem Management process, such as the associated cost, the return of investment and the operational mindset, i.e. being proactive vs. being reactive.

The following is a summary of the themes emerged from the answers and responses to second question of the interview -

\begin{tabular}{|c|c|}
\hline Themes & Comments made for the ITIL framework during the interviews \\
\hline $\begin{array}{l}\text { The ITIL Problem } \\
\text { Management process is } \\
\text { generally viewed as being } \\
\text { valuable }\end{array}$ & $\begin{array}{l}\text { "There is great need for it" } \\
\text { "I can definitely see the importance and the value of it" } \\
\text { "I completely believe in it" } \\
\text { "I can see the advantages of Problem Management" }\end{array}$ \\
\hline $\begin{array}{l}\text { There are high expectations } \\
\text { from incident } \\
\text { management/Service Desk } \\
\text { for the Problem Management } \\
\text { process to reduce overall } \\
\text { workload }\end{array}$ & $\begin{array}{l}\text { "If they actually pick up these problems and run with it, they would actually be } \\
\text { reducing the number of incidents, and therefore, reducing the workload on them, } \\
\text { which would actually give them more time to work on more problems and work on } \\
\text { more preventative measures, which is what it should be." } \\
\text { "You put this thing in place to try to minimize the amount of time the service desk } \\
\text { for example, server team, windows team, anyone in the account is trying to reduce } \\
\text { the amount of time they have to work on things that happen all the time" }\end{array}$ \\
\hline $\begin{array}{l}\text { There are high expectations } \\
\text { from a service delivery } \\
\text { perspective for the Problem } \\
\text { Management process to be } \\
\text { proactive }\end{array}$ & $\begin{array}{l}\text { "if you take a look at the bigger picture, Problem Management is also responsible } \\
\text { for risk management, proactively checking all the things that may be wrong in the } \\
\text { future" } \\
\text { "I would like to see it bit more proactive" }\end{array}$ \\
\hline
\end{tabular}




\begin{tabular}{|c|c|}
\hline $\begin{array}{l}\text { There are expectations from } \\
\text { a technical problem solving } \\
\text { perspective for Problem } \\
\text { Management process to } \\
\text { resolve complicated technical } \\
\text { issues. }\end{array}$ & $\begin{array}{l}\text { "the problem manager used to take it away and the [support teams] didn't really } \\
\text { get that involved" } \\
\text { "a problem analyst should be more technical than the engineers ... he can really dig } \\
\text { into and understand what the problem is and how to resolve it rather than relying } \\
\text { on bits and pieces of information" }\end{array}$ \\
\hline $\begin{array}{l}\text { The implementation of the } \\
\text { Problem Management } \\
\text { process are understood to be } \\
\text { difficult }\end{array}$ & $\begin{array}{l}\text { "Problem Management is a particular difficult one I think" } \\
\text { "it takes a bit of maturity with the team as well as within the organisation to see } \\
\text { the true value of it" } \\
\text { "it is not a perfect world unfortunately" }\end{array}$ \\
\hline $\begin{array}{l}\text { The implementation of the } \\
\text { Problem Management } \\
\text { process requires financial and } \\
\text { resource investment }\end{array}$ & $\begin{array}{l}\text { "you need to do obviously the cost the financial implication of what resolves the } \\
\text { root cause or adopt a workaround" } \\
\text { "I think if an organisation can afford the resources, then it would be crazy not to do } \\
\text { it" } \\
\text { "The real challenge is to hire someone that is proactive and who has the } \\
\text { experiences or be able to analyse the risks within the environment, or within the } \\
\text { process, that is what I think as the most important thing we need to consider" } \\
\text { "I think a lot of the reasons for that were the higher level management team ... not } \\
\text { sure if they understood the benefit of it therefore remained uncommitted } \\
\text { financially for problem managers, the salary and the head count" }\end{array}$ \\
\hline
\end{tabular}

Table 4.2 theme emerged in relation to the views of the ITIL Problem Management process

\subsection{The challenges identified for IT Support organisation to implement the ITIL Problem Management process}

The researcher asked each of the participants the following two questions to get their insights on the challenges associated with the implementation of the ITIL Problem Management process and their importance -

Interview Question 3: What are the challenges you can identify for IT support organisations to implement the ITIL Problem Management process?

Interview Question 4: What is the relative importance of these challenges? 
The researcher identified the themes as they emerged from interpreting the participants' answers and responses and reflecting on the participants' understanding of the challenges; based on the themes identified, the following categories were built:

The understanding of the ITIL Problem Management process - It was highlighted by the participants that the ITIL Problem Management process was generally less well understood as compared to other ITIL processes among IT Service Management professionals; and it was also not commonly understood by the management of IT support organisations or their customers either. Not only does the concept of Problem Management require better understanding - i.e. the definitions of "problem", "underlying issues" and "incidents", the meaning of the terminologies such as "workaround", "root cause" and "permanent fixes" as well as their relationships, but also do the benefits of this process, especially that the benefits of the ITIL Problem Management process may not be visible immediately and are often long term or future-orientated. After summarizing the views belong to this category and removing duplicate ones, the following challenge items were listed -

Challenge 1: The IT support teams' understanding of the ITIL Problem Management process and its benefit

Challenge 2: The management's understanding of the ITIL Problem Management process and its benefit

Challenge 3: The customers' understanding of the ITIL Problem Management process and its benefit

The buy-in of the ITIL Problem Management process - it was pointed out by the participants that the buy-in of this process would be an important condition for the process to be properly followed or executed within the IT support organisation. The buy-in can be understood as the commitment for the process and the belief of its benefit. Not only is the buy-in required from the customers, it is also required from the IT professionals and the management of the IT support organisation. After summarizing the views belong to this category and removing duplicate views, the following challenge items were listed -

Challenge 4: The customer buy-in and support for the ITIL Problem Management process

Challenge 5: The management buy-in and support for the ITIL Problem Management process

Challenge 6: The IT support teams' buy-in and support for the ITIL Problem Management process 
The investment for the ITIL Problem Management process - the investment for this process, especially in terms of finance and resources, was seen by some participants as an important challenge; one participant mentioned that he had never seen adequate resources being committed to the Problem Management process as required. Some participants also pointed out that the investment would appear hard to justify especially the return of such investment may not be seen immediately. It was also pointed out that quite often it may cost the organisation less to simply apply workarounds to address certain issues in IT services and operations rather than investigating and removing their root causes. A number of participants also mentioned that experienced Problem Managers, as the manager of the process and a key resource for its implementation, are very hard to recruit; as a result, the hiring of a Problem Manager should be seen as an investment challenge for the IT support organisations. Other investments mentioned by the participants also included the tools purchased to implement the process. From this category, the following challenge items were listed -

Challenge 7: The finance and resource commitment for the ITIL Problem Management process

Challenge 8: The ability to achieve both short term and long term benefit of ITIL Problem Management process

Challenge 9: The cost-benefit justification for investigating, identifying and removing root causes of IT issues

Challenge 10: The capability, competency and skills of the Problem Manager

Challenge 11: The tools used for implementing the ITIL Problem Management process

The interrelation with other ITIL processes - many participants held the view that ITIL processes should interact with and rely on one another. A number of participants believed that the successful implementation of the ITIL Problem Management process would require a mature Incident Management process, Change Management process and Service Desk; and it would also be challenging to achieve the desired interactions and relationships between these processes. The following challenge items were listed for this category -

Challenge 12: The maturity of other ITIL processes and functions that interact with the ITIL Problem Management process 
Challenge 13: The relationships and interactions between ITIL Problem Management process and other ITIL processes and functions within the IT support organisation

The execution of the ITIL Problem Management process - some participants believed that the investigation of underlying issues would require focus, information, knowledge and collaborations of different support teams. All of these items would pose challenges to the successful running of the ITIL Problem Management process. In terms of the execution of the process, some participants also pointed out that the momentum would drop once the workaround has been applied, or when the investigation had been going on for quite some time. Two participants expected the problem manager to be highly technical himself in order to identify and resolve complicated technical issues. One other participant also pointed out that certain IT issues may happen intermittently which would make the investigation of the root causes very difficult. The following challenge items were listed for this category -

Challenge 14: The focus on the underlying causes of IT issues

Challenge 15: The collaboration of the support teams around problem cases

Challenge 16: The technical knowledge of the Problem Manager

Challenge 17: The technical knowledge of the IT support teams

Challenge 18: The quantity and quality of the information gathered for the ITIL Problem Management Process

Challenge 19: The nature and complications of the issues the IT support organisation's customer is facing

The organisational factors - some participants believed organisational factors such as the organisational structure or culture may impact the implementation of the ITIL Problem Management process. One participant mentioned that members of the IT support organisations may be reluctant to change the way they provide IT support and therefore pose challenges to the implementation of new support processes. Some also saw the adaption of this process and the design of related policies in the organisational environment being challenging. After summarizing the views, the following challenge items were listed -

Challenge 20: The focus of being proactive in providing IT support 
Challenge 21: The organisational structure of the IT support organisation related to the ITIL Problem Management process

Challenge 22: The IT support organisation's readiness to change in alignment with best practice guidelines

Challenge 23: The adaption, customization and governance of the ITIL Problem Management process within the IT support organisation

As the result of the data analysis process, the researcher identified a total number of 23 challenge items in 6 categories; the researcher then listed these items by random order and produced the following list:

\begin{tabular}{|c|c|c|}
\hline Challenges for implementing the ITIL Problem Management process & $\begin{array}{l}\text { No. of } \\
\text { participants } \\
\text { who } \\
\text { mentioned }\end{array}$ & $\begin{array}{l}\% \text { of } \\
\text { participants } \\
\text { who } \\
\text { mentioned }\end{array}$ \\
\hline The IT support teams' understanding of the ITIL Problem Management process and its benefit & 14 & $60.87 \%$ \\
\hline $\begin{array}{l}\text { The relationships and interactions between ITIL Problem Management process and other ITIL } \\
\text { processes and function within the IT support organisation }\end{array}$ & 15 & $65.22 \%$ \\
\hline The focus of being proactive in providing IT support & 5 & $21.74 \%$ \\
\hline The management's understanding of the ITIL Problem Management process and its benefit & 6 & $26.09 \%$ \\
\hline The maturity of other ITIL processes that interact with the ITIL Problem Management process & 7 & $30.43 \%$ \\
\hline $\begin{array}{l}\text { The quantity and quality of the information gathered for the ITIL Problem Management } \\
\text { Process }\end{array}$ & 7 & $30.438 \%$ \\
\hline The finance and resource commitment for the ITIL Problem Management process & 10 & $43.48 \%$ \\
\hline The customer buy-in and support for the ITIL Problem Management process & 5 & $21.74 \%$ \\
\hline The focus on the underlying causes of IT issues & 6 & $26.09 \%$ \\
\hline The customer's understanding of the ITIL Problem Management process and its benefit & 5 & $21.74 \%$ \\
\hline The nature and complications of the issues the IT support organisation's customer is facing & 1 & $4.35 \%$ \\
\hline The capability, competency and skills of the Problem Manager & 5 & $21.74 \%$ \\
\hline $\begin{array}{l}\text { The organisational structure of the IT support organisation related to the ITIL Problem } \\
\text { Management process }\end{array}$ & 1 & $4.35 \%$ \\
\hline The tools used for implementing the ITIL Problem Management process & 4 & $17.39 \%$ \\
\hline The management buy-in and support for the ITIL Problem Management process & 6 & $26.09 \%$ \\
\hline The IT support organisation's readiness to change in alignment with best practice guidelines & 1 & $4.35 \%$ \\
\hline The collaboration of the support teams around problem cases & 5 & $21.74 \%$ \\
\hline $\begin{array}{l}\text { The cost-benefit justification for investigating, identifying and removing root causes of IT } \\
\text { Problems }\end{array}$ & 7 & $30.43 \%$ \\
\hline $\begin{array}{l}\text { The adaption, customization and governance of the ITIL Problem Management process within } \\
\text { the IT support organisation }\end{array}$ & 5 & $21.74 \%$ \\
\hline The IT support teams' buy-in and support for the ITIL Problem Management process & 11 & $47.83 \%$ \\
\hline The technical knowledge of the Problem Manager & 2 & $8.70 \%$ \\
\hline
\end{tabular}




\begin{tabular}{|l|c|c|}
\hline $\begin{array}{l}\text { The ability to achieve both short term and long term benefit of ITIL Problem Management } \\
\text { process }\end{array}$ & 6 & $26.09 \%$ \\
\hline The technical knowledge of the IT support teams & 1 & $4.35 \%$ \\
\hline
\end{tabular}

Table 4.3 - challenges for implementing the ITIL Problem Management process

\subsection{Ways and methods to overcome the challenges}

The researcher asked each participant the following question during the interview to get the participant's insights as how the challenges of implementing the ITIL Problem Management process can be overcome by IT support organisations.

\section{Interview Question 5: How can IT support organisations overcome the top challenges?}

Whilst the participants offered suggestions to overcome challenges in all 6 categories, most of their answers and responses to this question were surrounding the "understanding" and "buy-in" of the ITIL Problem Management process. Most participants held the view that once the challenges in these two areas are successfully overcome, challenges in other areas such as "investment", "execution" and "organisational factors" could be addressed successfully as natural steps afterwards.

As suggested by the participants, it is essential to achieve the understanding of the objectives and requirements of the ITIL Problem Management process as well as how this process can benefit the IT support organisation and its customers. Whilst formal learning such as taking ITIL training courses was generally seen as the preferred method to achieve the understanding, the comprehension of this process should also be achieved by communications within the IT support organisation. The understanding achieved by the organisational communications based on real case scenarios may be more effective than formal learning as such communications can be more constant and more related to the issues that the IT support organisation is dealing with. One participant also pointed out that certain tools such as online references or knowledge management functionalities could also assist with the understanding of ITIL processes.

The following are some of the remarks made as the participants offered their suggestions on overcoming the challenge of understanding the Problem Management process - 
The understanding of the ITIL Problem Management process

"There should be more training, more strategic training on how to implement the Problem Management process and other ITIL processes"

"You need to communicate ...everyone Problem Management works with got to understand why the process is being there and what the goal is"

"Train people properly, put them through a week or day's training"

"You constantly having people coming in and have different ideas of ITIL and things, so the monitoring side is important"

"Education, education is the answer"

"You should definitely communicate that, it is more like getting the understanding as well"

"Most of the organisations need to drive the soft skills training having something like a knowledge base or so on, like an online referencing"

"More investment in staff and educating them"

"You need to communicate to business, why you are doing it and what kind of benefit they can expect."

"Through awareness campaign, through presentation to all the support groups"

The "buy-in" of the ITIL Problem Management process from the internal IT support teams, the management of the IT support organisation and also the customers are seen by the participants as crucial challenges. To overcome the buy-in challenge, some participants held the view that not only the understanding of the ITIL Problem Management process is required, but also real-life examples or quantifiable data are also needed to show how this process works as well as the results and the benefits it can bring. In terms of seeking buy-in from the customers, IT professionals such as Service Delivery Managers and account directors were believed to be able to assist.

The following are some of the comments made as the participants were offering suggestions to meet the buy-in challenge - 


\section{The buy-in of the ITIL Problem Management process}

"Presenting case studies from the previous implementations"

"You need to understand what drives the business, understand what is important to them... have the business engage with you and support you"

"It needs to have Service Delivery Management or Account Director's support to sell the benefit of that to the client"

"They [the customer] need to know their product, you need to take them on to the process, and the benefit and advantages and how they can reduce their...make saving, reduce the amount of, you know, incidents"

"If we can build business cases, show how well it has improved the quality of stuff like...by looking at the quantitative"

"If you could relate by Problem Management processes back to these goals and objectives"

"Show that we can be more proactive, preventing incidents from happening rather than the reactive mode, focusing on the proactive of dealing with incidents so you save a lot amount of workloads on people"

"Having real life example or proof of concept...not proof of concept but proof that it worked"

"You need to talk to the business"

"From the GM level, I think that is what would really appeal to them that there is a significant overhead saving or improving efficiencies or both"

"That is really where you got to check with your SDM, your customer relationship management. They need to drive that, you can't."

It was suggested that the "understanding" and "buy-in" of the ITIL Problem Management process would also help to overcome the challenges of making investments on appropriate tools and resources. Most participants believed that both the initial setup of the Problem Management process and the execution of this process would benefit from these investments. To overcome the challenges and to justify the cost of long term solutions and permanent fixes, some participants suggested that it would be essential for the Problem Management process to align its objectives with the strategic goals of the IT support organisation and its customers, and show how the permanent fixes could improve the end-user experiences and achieve long term cost savings. 
Throughout the interviews, the communications within the IT support organisation and the communications with the customers were highlighted as the method to overcome not just the "understanding" and "buy-in" challenges, but also the challenges in other categories. During the interviews, most participants also expressed the view that the implementation of the ITIL Problem Management process would require the drive from the top of IT support organisation; a top-down approach was seen by many participants as being required to show the vision and direction, create the momentum, provide resources, specify the steps, and foster an appropriate organisational culture and environment for the implementation of the ITIL Problem Management process. The results of the ranking of each challenge item following the data analysis also confirmed this view. The following quote from one participant can be used to summarize this approach which was suggested by many participants.

"It needs to come from the top down; it needs to be owned by ... you know, from the CEO down. They need to demonstrate they believe in it, because, you lead by example in my option. It is all about passing down the direction but if you don't give the staff the opportunity of progressing whichever field you are trying to push, and, by that, I mean, give them the tool sets, give them the training, and start banging the ITIL drum, you know, and then it is never going to work, you have to have buy-in from your management, at all levels."

\subsection{The order ranking of the challenges}

In order to produce the ranking order of the challenges, the researcher provided the participants with the list of all the challenges identified as seen in table 4.3; the researcher then asked the participants to consider the importance of these challenges and rate each challenge on a scale between 1 and 10 . No other details or information were provided for the rating exercise; 18 of the 23 participants took part in this step.

The overall order ranking of the challenges were finalized after compiling the participants' rating of each challenge. The order ranking was primarily based on the average importance rating each item received. For each challenge, the standard deviation of the ratings it received was also calculated to give an indication as how widely the participants' rating varied. The smaller the deviation of the ratings, the closer the ratings the item received which could indicate a higher level of consensus among the 
participants. For items with the same average importance rating, the researcher gave the one with ratings of smaller deviation the higher ranking. The table below shows the overall ranking of the challenges following this step -

\begin{tabular}{|c|c|c|c|c|}
\hline $\begin{array}{l}\text { Overall } \\
\text { Ranking }\end{array}$ & Challenges for implementing the ITIL Problem Management process & $\begin{array}{l}\text { Average } \\
\text { Importance } \\
\text { rating }\end{array}$ & $\begin{array}{l}\text { Standard } \\
\text { deviation } \\
\text { of the } \\
\text { rating }\end{array}$ & $\begin{array}{l}\text { Number of } \\
\text { people } \\
\text { mentioned } \\
\text { in } \\
\text { interviews }\end{array}$ \\
\hline 1 & $\begin{array}{l}\text { The quantity and quality of the information gathered for the ITIL } \\
\text { Problem Management Process }\end{array}$ & 8.5 & 1.12 & 7 \\
\hline 2 & $\begin{array}{l}\text { The management buy-in and support for the ITIL Problem } \\
\text { Management process }\end{array}$ & 8.5 & 1.38 & 6 \\
\hline 3 & $\begin{array}{l}\text { The IT support organisation's readiness to change in alignment } \\
\text { with best practice guidelines }\end{array}$ & 8.39 & 1.25 & 1 \\
\hline 4 & $\begin{array}{l}\text { The cost-benefit justification for investigating, identifying and } \\
\text { removing root causes of IT Problems }\end{array}$ & 8.33 & 1.49 & 7 \\
\hline 5 & The focus on the underlying causes of IT issues & 8.28 & 2.02 & 6 \\
\hline 6 & The collaboration of the support teams around problem cases & 8.22 & 1.84 & 5 \\
\hline 7 & $\begin{array}{l}\text { The management's understanding of the ITIL Problem } \\
\text { Management process and its benefit }\end{array}$ & 8.17 & 1.38 & 6 \\
\hline 8 & The capability, competency and skills of the Problem Manager & 8.06 & 1.47 & 5 \\
\hline 9 & $\begin{array}{l}\text { The IT support teams' buy-in and support for the ITIL Problem } \\
\text { Management process }\end{array}$ & 8.06 & 1.61 & 11 \\
\hline 10 & $\begin{array}{l}\text { The relationships and interactions between ITIL Problem } \\
\text { Management process and other ITIL processes and function within } \\
\text { the IT support organisation }\end{array}$ & 7.94 & 1.31 & 15 \\
\hline 11 & $\begin{array}{l}\text { The ability to achieve both short term and long term benefit of ITIL } \\
\text { Problem Management process }\end{array}$ & 7.72 & 1.99 & 6 \\
\hline 12 & $\begin{array}{l}\text { The IT support teams' understanding of the ITIL Problem } \\
\text { Management process and its benefit }\end{array}$ & 7.72 & 2.16 & 14 \\
\hline 13 & The technical knowledge of the IT support teams & 7.5 & 2.59 & 1 \\
\hline 14 & The focus of being proactive in providing IT support & 7.44 & 2.17 & 5 \\
\hline 15 & $\begin{array}{l}\text { The maturity of other ITIL processes that interact with the ITIL } \\
\text { Problem Management process }\end{array}$ & 7.22 & 1.65 & 7 \\
\hline 16 & $\begin{array}{l}\text { The nature and complications of the issues the IT support } \\
\text { organisation's customer is facing }\end{array}$ & 7.17 & 1.60 & 1 \\
\hline 17 & $\begin{array}{l}\text { The adaption, customization and governance of the ITIL Problem } \\
\text { Management process within the IT support organisation }\end{array}$ & 7 & 1.94 & 5 \\
\hline 18 & $\begin{array}{l}\text { The customer buy-in and support for the ITIL Problem } \\
\text { Management process }\end{array}$ & 7 & 2.69 & 5 \\
\hline 19 & $\begin{array}{l}\text { The customer's understanding of the ITIL Problem Management } \\
\text { process and its benefit }\end{array}$ & 6.94 & 2.41 & 5 \\
\hline 20 & $\begin{array}{l}\text { The organisational structure of the IT support organisation related } \\
\text { to the ITIL Problem Management process }\end{array}$ & 6.78 & 1.58 & 1 \\
\hline 21 & $\begin{array}{l}\text { The finance and resource commitment for the ITIL Problem } \\
\text { Management process }\end{array}$ & 6.72 & 1.97 & 10 \\
\hline 22 & $\begin{array}{l}\text { The tools used for implementing the ITIL Problem Management } \\
\text { process }\end{array}$ & 6.67 & 2.21 & 4 \\
\hline
\end{tabular}


23 The technical knowledge of the Problem Manager

6.06

2.32

Table 4.5.1 - the overall ranking order of all the challenges identified

The following tables show the ranking order of the challenge items in their designated categories -

\begin{tabular}{|c|c|c|c|c|c|}
\hline \multicolumn{2}{|r|}{ The understanding of the ITIL Problem Management process } & \multirow{2}{*}{$\begin{array}{l}\begin{array}{l}\text { Average } \\
\text { Importance } \\
\text { rating }\end{array} \\
8.17\end{array}$} & \multirow{2}{*}{$\begin{array}{l}\begin{array}{l}\text { Standard } \\
\text { deviation } \\
\text { of the } \\
\text { rating }\end{array} \\
1.38\end{array}$} & \multirow{2}{*}{\begin{tabular}{l} 
Number of \\
people \\
mentioned \\
in \\
interviews \\
\multicolumn{1}{c}{6}
\end{tabular}} & \multirow{2}{*}{$\begin{array}{l}\begin{array}{l}\text { Overall } \\
\text { ranking } \\
\text { among all } \\
\text { challenges }\end{array} \\
7\end{array}$} \\
\hline 1 & $\begin{array}{l}\text { The management's understanding of the ITIL Problem } \\
\text { Management process and its benefit }\end{array}$ & & & & \\
\hline 2 & $\begin{array}{l}\text { The IT support teams' understanding of the ITIL Problem } \\
\text { Management process and its benefit }\end{array}$ & 7.72 & 2.16 & 14 & 12 \\
\hline 3 & $\begin{array}{l}\text { The customer's understanding of the ITIL Problem } \\
\text { Management process and its benefit }\end{array}$ & 6.94 & 2.41 & 5 & 19 \\
\hline
\end{tabular}

Table 4.5.2 -ranking order of the challenges identified in the category of "the understanding of the ITIL Problem Management process"

\begin{tabular}{|c|c|c|c|c|c|}
\hline \multicolumn{2}{|r|}{ The buy-in of the ITIL Problem Management process } & \multirow{2}{*}{$\begin{array}{l}\text { Average } \\
\text { Importance } \\
\text { rating } \\
8.5\end{array}$} & \multirow{2}{*}{$\begin{array}{c}\begin{array}{c}\text { Standard } \\
\text { deviation } \\
\text { of the } \\
\text { rating }\end{array} \\
1.38\end{array}$} & \multirow{2}{*}{\begin{tabular}{l} 
Number of \\
people \\
mentioned \\
in \\
interviews \\
\multicolumn{1}{c}{7}
\end{tabular}} & \multirow{2}{*}{$\begin{array}{l}\begin{array}{l}\text { Overall } \\
\text { ranking } \\
\text { among all } \\
\text { challenges }\end{array} \\
2\end{array}$} \\
\hline 1 & $\begin{array}{l}\text { The management buy-in and support for the ITIL Problem } \\
\text { Management process }\end{array}$ & & & & \\
\hline 2 & $\begin{array}{l}\text { The IT support teams' buy-in and support for the ITIL Problem } \\
\text { Management process }\end{array}$ & 8.06 & 1.61 & 12 & 9 \\
\hline 3 & $\begin{array}{l}\text { The customer buy-in and support for the ITIL Problem } \\
\text { Management process }\end{array}$ & 7 & 2.69 & 19 & 18 \\
\hline
\end{tabular}

Table 4.5.3 -ranking order of the challenges identified in the category of "the buy-in of the ITIL Problem Management process"

\begin{tabular}{|c|l|c|c|c|c|}
\hline \multicolumn{2}{|l|}{ The investment for the ITIL Problem Management process } & $\begin{array}{l}\text { Average } \\
\text { Importance } \\
\text { rating }\end{array}$ & $\begin{array}{l}\text { Standard } \\
\text { deviation } \\
\text { of the } \\
\text { rating }\end{array}$ & $\begin{array}{l}\text { Number of } \\
\text { people } \\
\text { mentioned } \\
\text { in } \\
\text { interviews }\end{array}$ & $\begin{array}{l}\text { Overall } \\
\text { ranking } \\
\text { among all } \\
\text { challenges }\end{array}$ \\
\hline 1 & $\begin{array}{l}\text { The cost-benefit justification for investigating, identifying and } \\
\text { removing root causes of IT Problems }\end{array}$ & 8.33 & 1.49 & 7 & 4 \\
\hline 2 & The capability, competency and skills of the Problem Manager & 8.06 & 1.47 & 5 & 8 \\
\hline 3 & $\begin{array}{l}\text { The ability to achieve both short term and long term benefit of } \\
\text { ITIL Problem Management process }\end{array}$ & 7.72 & 1.99 & 6 & 11 \\
\hline 4 & $\begin{array}{l}\text { The finance and resource commitment for the ITIL Problem } \\
\text { Management process }\end{array}$ & 6.72 & 1.97 & 10 & 21 \\
\hline 5 & $\begin{array}{l}\text { The tools used for implementing the ITIL Problem } \\
\text { Management process }\end{array}$ & 6.67 & 2.21 & 4 & 22 \\
\hline
\end{tabular}

Table 4.5.4 -ranking order of the challenges identified in the category of "the investment for the ITIL Problem Management process" 


\begin{tabular}{|c|c|c|c|c|c|}
\hline \multicolumn{2}{|r|}{ The interrelation with other ITIL processes } & \multirow{2}{*}{$\begin{array}{l}\begin{array}{l}\text { Average } \\
\text { Importance } \\
\text { rating }\end{array} \\
7.94\end{array}$} & \multirow{2}{*}{$\begin{array}{c}\begin{array}{c}\text { Standard } \\
\text { deviation } \\
\text { of the } \\
\text { rating }\end{array} \\
1.31\end{array}$} & \multirow{2}{*}{\begin{tabular}{l}
$\begin{array}{l}\text { Number of } \\
\text { people } \\
\text { mentioned } \\
\text { in } \\
\text { interviews }\end{array}$ \\
\multicolumn{1}{c}{15}
\end{tabular}} & \multirow{2}{*}{$\begin{array}{l}\begin{array}{l}\text { Overall } \\
\text { ranking } \\
\text { among all } \\
\text { challenges }\end{array} \\
10\end{array}$} \\
\hline 1 & $\begin{array}{l}\text { The relationships and interactions between ITIL Problem } \\
\text { Management process and other ITIL processes and function } \\
\text { within the IT support organisation }\end{array}$ & & & & \\
\hline 2 & $\begin{array}{l}\text { The maturity of other ITIL processes that interact with the ITIL } \\
\text { Problem Management process }\end{array}$ & 7.22 & 1.65 & 7 & 15 \\
\hline
\end{tabular}

Table 4.5.5 -ranking order of the challenges identified in the category of "the interrelation with other ITIL processes"

\begin{tabular}{|l|l|c|c|c|c|}
\hline \multicolumn{2}{|l|}{ The execution of the ITIL Problem Management process } & $\begin{array}{l}\text { Average } \\
\text { Importance } \\
\text { rating }\end{array}$ & $\begin{array}{l}\text { Standard } \\
\text { deviation } \\
\text { of the } \\
\text { rating }\end{array}$ & $\begin{array}{l}\text { Number of } \\
\text { people } \\
\text { mentioned } \\
\text { in } \\
\text { interviews }\end{array}$ & $\begin{array}{l}\text { Overall } \\
\text { ranking } \\
\text { among all } \\
\text { challenges }\end{array}$ \\
\hline 1 & $\begin{array}{l}\text { The quantity and quality of the information gathered for the } \\
\text { ITIL Problem Management Process }\end{array}$ & 8.5 & 1.12 & 7 & 1 \\
\hline 2 & The focus on the underlying causes of IT issues & 8.28 & 2.02 & 6 & 5 \\
\hline 3 & The collaboration of the support teams around problem cases & 8.22 & 1.84 & 5 & 6 \\
\hline 4 & The technical knowledge of the IT support teams & 7.5 & 2.59 & 1 & 13 \\
\hline 5 & $\begin{array}{l}\text { The nature and complications of the issues the IT support } \\
\text { organisation's customer is facing }\end{array}$ & 7.17 & 1.60 & 1 & 16 \\
\hline 6 & The technical knowledge of the Problem Manager & 6.06 & 2.32 & 2 & 23 \\
\hline
\end{tabular}

Table 4.5.6 -ranking order of the challenges identified in the category of "the execution of the ITIL Problem Management process"

\begin{tabular}{|c|c|c|c|c|c|}
\hline \multicolumn{2}{|c|}{ The organisational factors } & \multirow{2}{*}{ 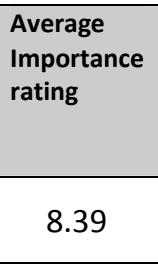 } & \multirow{2}{*}{$\begin{array}{c}\begin{array}{c}\text { Standard } \\
\text { deviation } \\
\text { of the } \\
\text { rating }\end{array} \\
1.25\end{array}$} & \multirow{2}{*}{\begin{tabular}{l} 
Number of \\
people \\
mentioned \\
in \\
interviews \\
\multicolumn{1}{c}{1}
\end{tabular}} & \multirow{2}{*}{$\begin{array}{l}\text { Overall } \\
\text { ranking } \\
\text { among all } \\
\text { challenges }\end{array}$} \\
\hline 1 & $\begin{array}{l}\text { The IT support organisation's readiness to change in alignment } \\
\text { with best practice guidelines }\end{array}$ & & & & \\
\hline 2 & The focus of being proactive in providing IT support & 7.44 & 2.17 & 5 & 14 \\
\hline 3 & $\begin{array}{l}\text { The adaption, customization and governance of the ITIL } \\
\text { Problem Management process within the IT support } \\
\text { organisation }\end{array}$ & 7 & 1.94 & 5 & 17 \\
\hline 4 & $\begin{array}{l}\text { The organisational structure of the IT support organisation } \\
\text { related to the ITIL Problem Management process }\end{array}$ & 6.78 & 1.58 & 1 & 20 \\
\hline
\end{tabular}

Table 4.5.7 -ranking order of the challenges identified in the category of "the organisational factors"

If considering the challenge items related to the Management, IT support teams, Problem Manager and the customer as "human factors", the following list can also be made - 


\begin{tabular}{|c|c|c|c|c|c|}
\hline \multicolumn{2}{|c|}{ Human factors } & \multirow{2}{*}{$\begin{array}{l}\begin{array}{l}\text { Average } \\
\text { Importance } \\
\text { rating }\end{array} \\
8.5\end{array}$} & \multirow{2}{*}{$\begin{array}{c}\begin{array}{c}\text { Standard } \\
\text { deviation } \\
\text { of the } \\
\text { rating }\end{array} \\
1.38\end{array}$} & \multirow{2}{*}{\begin{tabular}{l} 
Number of \\
people \\
mentioned \\
in \\
interviews \\
\multicolumn{1}{c}{6}
\end{tabular}} & \multirow{2}{*}{$\begin{array}{l}\begin{array}{l}\text { Overall } \\
\text { ranking } \\
\text { among all } \\
\text { challenges }\end{array} \\
2\end{array}$} \\
\hline 1 & $\begin{array}{l}\text { The management buy-in and support for the ITIL Problem } \\
\text { Management process }\end{array}$ & & & & \\
\hline 2 & The focus on the underlying causes of IT issues & 8.28 & 2.02 & 6 & 5 \\
\hline 3 & The collaboration of the support teams around problem cases & 8.22 & 1.84 & 5 & 6 \\
\hline 4 & $\begin{array}{l}\text { The management's understanding of the ITIL Problem } \\
\text { Management process and its benefit }\end{array}$ & 8.17 & 1.38 & 6 & 7 \\
\hline 5 & The capability, competency and skills of the Problem Manager & 8.06 & 1.47 & 5 & 8 \\
\hline 6 & $\begin{array}{l}\text { The IT support teams' buy-in and support for the ITIL Problem } \\
\text { Management process }\end{array}$ & 8.06 & 1.61 & 11 & 9 \\
\hline 7 & $\begin{array}{l}\text { The IT support teams' understanding of the ITIL Problem } \\
\text { Management process and its benefit }\end{array}$ & 7.72 & 2.16 & 14 & 12 \\
\hline 8 & The technical knowledge of the IT support teams & 7.5 & 2.59 & 1 & 13 \\
\hline 9 & $\begin{array}{l}\text { The customer buy-in and support for the ITIL Problem } \\
\text { Management process }\end{array}$ & 7 & 2.69 & 5 & 18 \\
\hline 10 & $\begin{array}{l}\text { The customer's understanding of the ITIL Problem } \\
\text { Management process and its benefit }\end{array}$ & 6.94 & 2.41 & 5 & 19 \\
\hline 11 & The technical knowledge of the Problem Manager & 6.06 & 2.32 & 2 & 23 \\
\hline
\end{tabular}

Table 4.5.8 -ranking order of the challenges related to "human factors" 


\section{Discussion}

\subsection{The understanding of the ITIL Problem Management process}

A number of participants in this research pointed out that ITIL framework is a "logical" and "common sense" approach to manage and deliver IT services. The same can be said about the ITIL Problem Management process. When a service disruption happens, it is common sense to restore services as quickly as possible and then start investigating the cause of such disruption and take corrective and preventive measures following the investigation. In this regard, Problem Management is often compared to the arson investigation that follows a fire outbreak.

Although it may appear that there is nothing too difficult for IT professionals and users to understand the principle of ITIL Problem Management process and its objectives and benefits, a few issues may just cause confusions. First of all, as mentioned by Jantti (2008), ITIL terminologies were not widely or traditionally used in IT industry. This was particularly the case for terminologies such as "Problem". The word "Problem" is commonly used in everyday life and is associated with a high level of ambiguity and negativity. In relation to Information Technology, "Problem" is often used to refer to technical issues or difficulties experienced by IT professionals or the user of IT services. In the ITIL dictionary, "Problem" means "the underlying cause for one or more incident" which is highly specific and is almost incompatible with how it is generally used in everyday life. It is almost impossible for IT professionals or the users to abandon the general meaning of "Problem" and strictly use this word as an ITIL terminology. "Known error" as an ITIL terminology also does not simply mean that the error is well known or documented, but specifically for an underlying issue which has a "documented root cause" and a "workaround".

Not just the terminologies such as "Problem" and "Known error" that may cause confusions, as pointed out by the literature review, "the lack of practical example to follow" may also cause challenges to the understanding of ITIL processes. In daily IT service operations, it is much more straightforward to communicate about "incident" or specific technical faults and failures as opposed to the "underlying cause". The meaning of "root cause" is also hard to grasp when facing complicated technical issues, people many have different opinions as how many levels of technical details the IT support teams would have to go through to reveal the true "root cause" and not just be satisfied with the manifestations of it. 
As a result, the understanding of the ITIL Problem Management process may often be hindered by the gap between the specific meanings of its terminologies and how the same words are used in daily lives; the understanding may be further prevented by the lack of the communications of real-case scenarios in daily IT service operations to show what a "Problem" really is according to its ITIL definition. Due to these, it would certainly require not just formal learning and education, but also constant communications to ensure the correct and consistent understanding of the Problem Management process by all parties involved.

\subsection{The quantity and quality of the information gathered for the ITIL Problem Management Process and the execution of the Problem Management process}

As a challenge item identified, the "quantity and quality of the information gathered for the ITIL Problem Management process" received the highest rating of importance in this research. It is believed that a complex technological environment would present enormous difficulties in finding all the relevant information required to diagnose the underlying causes of IT issues. At the time when incidents are reported or detected, what is usually observed is often the manifestation of the root cause whilst all relevant information about the underlying issue is often much harder to gather. Often an "incident" is the symptom of a number of related issues; the symptom can be exactly the same but with very different causes. This phenomenon can create the impression that Problem Management has not been effective in reducing the repetitive incidents, particularly, in the case where incidents are reported following the closure of a problem case addressing different underlying issues but caused the same symptoms. It is also the reality that, more often than not, the need to restore the services as quickly as possible gets in the way of retrieving all relevant information which may be extremely valuable in determining the root causes; for example, a very quick manual recovery of a failing devices may cause the loss of vital information that can be used to diagnose the root cause of the failure.

The incidents which happen intermittently over time without an obvious pattern are also common in a complex and tightly interlinked technological environment and often pose the most significant challenge for root cause diagnoses. Often due to their un-replicable nature, which means IT support teams are not able to reproduce them on demand or simulate them, it can be extremely difficult to gather all relevant information, or to know where to search for relevant information in the first place. At least one research participant pointed out in the interview that, following actions taken to address possible root causes of 
this kind of issues, IT support teams often needed to wait to see if they happen again to know for sure that the root cause had in fact been addressed properly. The intermittent, unpredictable and unreplicable nature of the IT issues is also one of the new challenges identified by this study for the implementation of the ITIL Problem Management process.

The Service Desk, as the first point of contact for the users of IT services, is often seen as the main source of incident related information, particularly the information of the incidents from the users' perspective. However, a number of factors may prevent the Service Desk getting all the relevant information for root cause diagnosis: first, the Service Desk often does not have the visibility or access to gather the information from all related technical systems or components; second, when incidents take place, the Service Desk mostly relies on the users to provide relevant information, which may often be inadequate; often incidents with minor impacts may not even be reported by the users in the first place; and also, as the first point of contact by the end-users when incidents take place, the Service Desk often focuses primarily on finding and applying the workarounds to resolve the incidents and restore the services as quickly as possible. Relying on Service Desk to gather all information to assist the diagnose of the root cause of the incidents, in this regard, can be similar to asking firefighters to gather information for arson investigation in the middle of putting out a fire.

It is clear from both the literature review and the research that information related to IT issues is critical to the problem investigation and root cause analysis. The implementation of the ITIL Problem Management process would benefit from increased visibility in the technical environment, which can come from technologies such as monitoring tools, event logs and alerts. Critical information can also come from effective communications between different IT support teams and the users. The IT professionals' ability to determine the specific information required and how to obtain and interpret such information would certainly prove valuable to the ITIL Problem Management process.

\subsection{The management buy-in and support for the ITIL Problem Management process}

This research concluded that the buy-in and support from the management of the IT support organisation is one of the most crucial and influential elements for the implementation of the ITIL Problem Management process. This result confirms the same proposition as seen in much of the existing literature for the implementation of the ITIL framework. 
By both the literature review and the research, the understanding of the ITIL process, the value provided by the process and the customer buy-in are regarded as the essential elements to obtain the support from the management. Management support is believed to be able to pave the way for finance and resource commitment, provide the process with more recognition and status and influence the entire organisation to follow the process. However, the management support for implementing the ITIL Problem Management process becomes a challenge if the process is not well understood, not commonly implemented or unable to clearly demonstrate the value it can add to the management and delivery of the IT services. With less management support, the process is less likely to be implemented properly and more likely to produce poor results.

It was suggested by the literature review that often a "quick win" can break such deadlock. The "quick wins" can be understood as the realisation of the benefit of the ITIL processes by implementing them initially in the most ideal conditions. With similar incidents commonly taking place within IT services and operations, the initial implementation of the ITIL Problem Management process can achieve the "quick win" by being able to identify and explain the causes of these service disruptions or operational failures. Problem cases created to highlight certain aspects of IT services and operations also focus attentions on vulnerabilities and risks. The identification of the root causes, underlying issues, vulnerabilities and risks would enable both the customer and the management of the IT support organisation to make informed decisions about the IT services and Infrastructure. By achieving these "quick wins", even without completing the entire problem life cycle or justifying for the cost of the permanent solutions, the ITIL Problem Management process may build up more management support which would allow the process to be further established and interrelated with other existing ITIL processes.

The management support for the ITIL Problem Management process in IT Service Management and delivery may also be achieved by an increase of customer satisfaction as the result of the implementation of this process. The customers' business priority and their genuine interest in knowing the underlying issues in their IT operations could play an important part in winning customer satisfaction and also increasing the demand for the ITIL Problem Management process. Whilst the customer may be satisfied with workarounds in place to minimize the impact of existing IT issues, their satisfaction could be improved if they also know what caused the issues in the first place and what needs to be done to prevent them. 


\subsection{The investment and cost-benefit justification for implementing the ITIL Problem Management process}

Existing literature suggests that the implementation of the ITIL framework is often seen as an investment by the adopting IT support organisations, as it requires financial commitment and also the consideration of the return in terms of service improvement and other organisational benefits. This view was also shared by the participants of this research as challenges associated with the investment category received most nominations during the interviews; among these challenges, the "cost-benefit justification" received the highest rating in term of importance.

The cost-benefit justification for the implementation of the ITIL Problem Management process may be even more relevant compared to other ITIL processes, particularly in terms of the financial considerations in making the decision to resolve an underlying issue permanently or simply to continue the services with available workarounds. The cost to permanently remove a root cause for incidents in IT services and operations are often more than the IT support organisation or its customer is willing to commit; as a result, a workaround with lower cost may be more affordable and become the favorable option. This dilemma may render the effort of investigating and diagnosing root causes less recognised within the IT support organisation or by the customers.

However, as suggested in the literature review, by identifying the risks and systematically analyzing their potential impacts to the IT services and operations, the ITIL Problem Management process would be in the position to improve IT performance and the use of existing IT infrastructure. By reaching this objective, the ITIL Problem Management process should provide value to the overall organisational IT governance as a cost saving measure as opposed to being an additional cost centre.

Even for certain underlying issues the permanent fixes may be deemed as too expensive to implement, often the creation of a problem case would bring well deserved attention to particular IT operational areas and reveal underlying vulnerabilities; the ITIL Problem Management process could also add value to the IT support organisation and its customers by providing the root cause information and discovering workarounds which are not only more affordable, but are also more long-term orientated and involve less manual intervention. Not only would the Problem Management be in the position to negotiate for realistic measures and strike the balance between expensive permanent fix options and workarounds with lower cost; it may also engage Project Management and incorporate structural and permanent 
fixes in the scope of upcoming infrastructural projects, and by doing so, getting the permanent fixes applied with lower cost comparing to applying them separately or on an ad-hoc basis.

\subsection{The relationships and interactions between ITIL Problem Management process and other ITIL processes and functions within the IT support organisation}

As seen in the literature review and also reaffirmed by the participants of this empirical research, all ITIL Service management processes are expected to interrelate with each other as they support the delivery and management of IT services. Problem Management and Incident Management are seen in particularly close working relationship. IT support organisations which implement Problem Management process often establish criteria for Problem Management process to be initialized based on the regularity, similarity or impact of the incidents experienced by the end-users. However, this practice should by no means imply how incident "becomes" a problem as they are two very different concepts one means service disruption and the other is defined by ITIL as the causes of the service disruption.

In reality the demarcation between Problem Management and Incident Management may not be entirely clear for several reasons; first, with limited technical resources, the same engineer or engineers may be the resources responsible for restoring the services as quickly as possible as well as for diagnosing the underlying cause of the service disruptions. In this situation, it may be inevitable that Incident Management would take priority of the resources. Also as suggested by both the literature review and this research, once a service disruption or incident has been resolved and the service has resumed with workarounds, the sense of urgency and momentum to continue to identify the root cause may drop significantly. Problem Management activities being executed in these circumstances would likely to be given lower priority or recognitions, and may find themselves getting deferred when the IT support organisation faces new incidents being raised.

There are several other scenarios in IT services and operations which often contribute to the some-what unclear demarcation between Incident Management and Problem Management: first of all, not all services can be restored by workarounds once they have been disrupted; for some incidents, workarounds may not be successfully identified or implemented, therefore, in order to resolve these incidents and restore services, the root cause must be found and removed. On the other hand, it is also common that during incident investigation, that not only are possible workarounds discovered, but the 
root cause is also revealed. In some cases, the removal of the root case may also turn out to be the best option to restore services comparing to other available workarounds. The Incident Management process, in these cases, cannot be strictly separated from the Problem Management activities.

The situations like the above may create the impression that most of the Problem Management process and its activities can be covered as part of Incident Management process, or the Problem Management process would only need to be implemented on a selective or ad-hoc basis; some participants of this research also mentioned that they observed the ITIL Problem Management process being incorrectly implemented as a "too hard basket" for Incident Management or as a "second level Incident Management process". With these kind of implementations, not only do the demarcations and interactions between Incident Management and Problem Management become unclear, the focus on the broad IT operational environment may also be lost and the objectives of the Problem Management process may be comprised; both the IT support organisations and their customers may also sacrifice the benefits and full potential of the ITIL Problem Management process.

Problem Management and Incident Management often need to look at the same IT issues from different angles. In reality, Incident Management is usually put to the front line since it is responsible to address service disruptions which usually come with greater urgency; also due to the often blurred demarcation line and the less straightforward concepts, the Problem Management process may be less recognised, less likely to be implemented to its full extent or reach its full potential. When facing these challenges, the IT support organisation would need to establish constructive and flexible engagement between the Problem Management and Incident Management process; focus must be given to how these processes can benefit each other and the entire IT services and operations.

One participant of the research called for "complete separation" between Problem Management and Incident Management in order for the Problem Management process to achieve its full potential. The literature review also suggests that the focus on single incidents or a sample of incidents may not be helpful to prevent operation failures or major incidents. In this regard, to achieve its objectives and become more proactive, Problem Management process may benefit from certain separations from the day-to-day management of incidents and focusing on the organisational wide IT services and operations, as well as its risks, vulnerabilities and the relationships and correlations of common underlying issues. In the mean time, Problem Management can assist Incident Management by providing background or 
historical information, by coordinating resources and facilitating incident learning and categorization, and by smoothly transitioning the focus from being reactive to preventive.

\subsection{The implementation of the ITIL Problem Management and the change of IT support organisations}

"The organisation's readiness to change in alignment with best practice guidelines" was rated by the participants of the research as the third most important challenge for implementing the ITIL Problem Management process. With a process-orientated IT Service Management, IT support is more integrated in the forms of various Service Management processes and is increasingly provided across many of the traditional technological function silos; this fact is also often reflected on and reinforced by the changes within the IT support organisation.

Organisational changes are often structural changes driven in a top-down fashion. They often depend on acceptance and corporation of the IT professionals; it is particularly the case when IT support organisations are not only adopting possible new organisational structures to better implement the IT Service Management framework, but also need the IT support professionals to follow these processes and interact with each other across various technological territories and beyond the traditional chain of commands.

Existing literature often viewed the implementation of the ITIL framework in line with organisational change and suggested that "the resistance of IT support teams" was one of the challenges for implementing this framework. As IT support is increasingly managed by process managers, the traditional line managers may view the process managers as a threat to their authority (Hewlett-Packard, 2003); the IT experts may also view the compliance with IT Service Management processes as an unnecessary overhead to their daily routines. At least one participant of this research pointed out that, even with the ITIL Problem Management processes established, when IT professionals from different technical groups of the organisation were asked to collaborate and diagnose the root causes of complex IT issues, they often intend to only focus on their own technical areas and first confirm that the problem or underlying issue didn't exist there. Such approach prevents meaningful interactions and collaborations between different expertises across different technical areas and often brings negative impact on the execution of the ITIL Problem Management process in a large and complex technical environment made of multiple technical dimensions. 
As IT support organisations are continuing the journey to become more service-centric and base their services on processes, a strong culture in the organisations, such as to be proactive in providing IT support and willing to learn from incidents and take the ownership of the underlying issues, is needed to foster the change not just for the organisational structure, but also for the attitude and mindset of IT professionals who have to interact across different functional silos. A strong culture like the ones just mentioned would help to build the common goals as well as the desired behaviors and social norms within the organisation. It is particularly relevant in terms of the implementation of the ITIL Problem Management process, as the implementation requires even tighter collaborations of various IT support teams. Also the proactive Problem Management aims to take the IT Service Management towards a more mature level and shift the focus from addressing IT issues as they arise to identifying and removing the risks or underlying causes before they eventuate. The implementation of the ITIL Problem Management process and the fulfillment of its responsibilities for the organisational IT governance would particularly require this process to be executed successfully by relying primarily on the organisational culture rather than the hierarchical authority.

\subsection{The ITIL Problem Management implementation strategy}

Based on the findings of this research, the following model was formulated. This model shows how each challenging area could influence one and other and increase or decrease the chances of the overall success of the implementation of the ITIL Problem Management process in an IT support organisation. The challenging areas are represented by the 6 of the 7 boxes in this model (apart from "the result of the process").

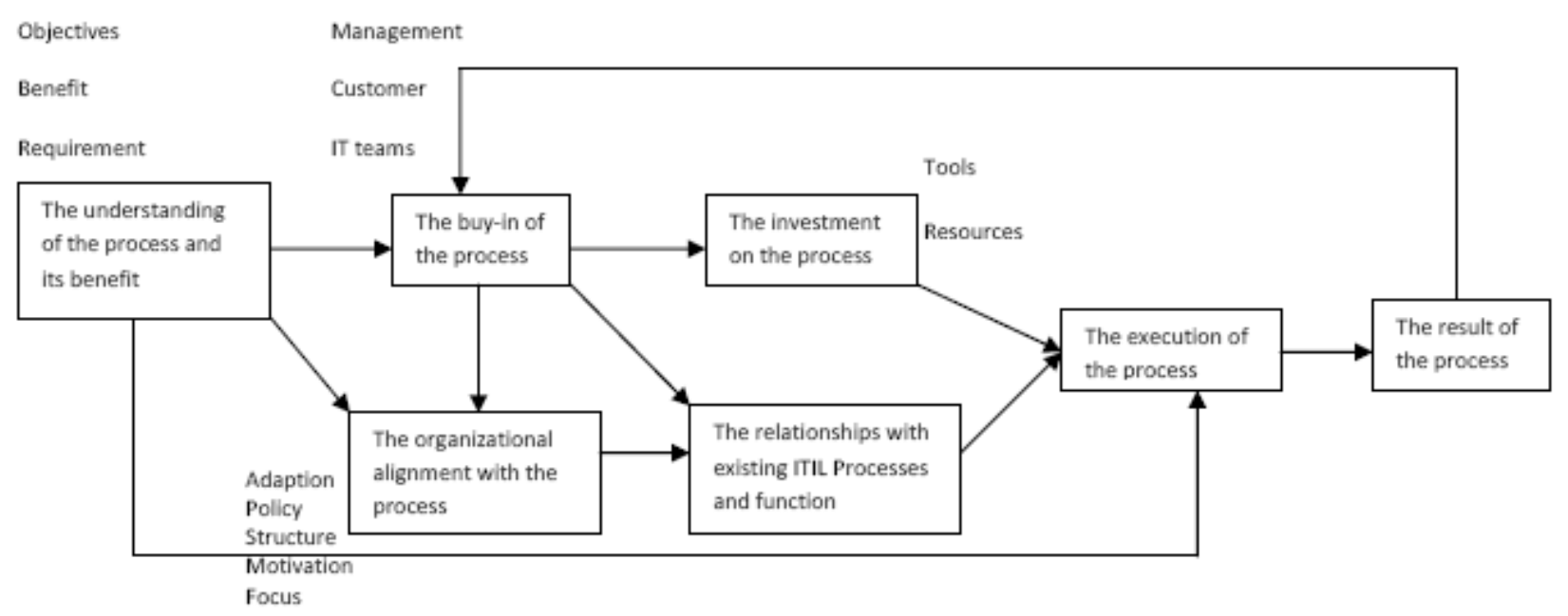


Figure 5.7 ITIL Problem Management process implementation model

According to this model, for an IT support organisation implementing the ITIL Problem Management process, particularly with very few examples as how this process had been implemented elsewhere, it is essential that the Management, the customers and the internal IT teams can understand this process and also perceive or project its benefit in order to build the buy-in. For an IT support organisation which has already started running the ITIL Problem Management process, it is essential to be able to constantly and clearly show its value to increase the buy-in overtime which would in turn have significant follow-on effects and increase the chances of its further successes in the future.

With the running of existing ITIL processes and functions such as Incident Management, Configuration Management, Change Management and Service Desk, both internal IT support groups and external IT service providers can use this model to introduce and implement the Problem Management process to form the base for managing and delivering IT services; this model is suitable for IT support organisations with different levels of maturity for running ITIL Processes and can be used to continuously improve the running of the ITIL Problem Management process along with other ITIL processes.

Communication stands at the centre of each of the 6 challenging areas as shown in this model and should be regarded as the most crucial element to formulate any strategies to implement the ITIL Problem Management process in order to meet the challenges identified by this research.

Communication within the IT support organisation is vital to promote the understanding of the process, increase buy-in, build relationships with other ITIL Processes and foster an organisational cultural change in order to align with the ITIL framework; it is also extremely important for the collaboration of different IT support teams around problem cases and the effort to minimize and prevent the impact caused by underlying issues within IT infrastructure and operations, and keep all stakeholders informed and updated in the problem life cycle.

The Problem Management process implementation strategy should therefore be essentially understood as an organisational communication strategy - a strategy that uses the transactional power of organisational communications to create the best possible organisational conditions to address each of the challenging areas described in the model above and interrelate organisational factors in such way so they can enhance one another and move together towards the overall objectives of the ITIL Problem Management process and to create value for both the customers and also the IT support organisation 
itself. The communication not only needs to be top-down or programmatic from a management perspective, but also participatory among IT professionals in the IT support organisation.

The importance of organisational communication to the implementation of the ITIL Problem Management process cannot be overstated. The implementation of the ITIL Problem Management process requires careful planning and execution of purposeful, constant and consistent communication events and activities that suit the targeted audiences as well as the unique circumstances and experiences of IT support organisations and their customers. The communication events need to have clear inputs, outputs, methods and forums designed, and may also need to be assessed constantly. For example, in order to increase the understanding of the ITIL Problem Management process, formal learning and education is one type of the communication event that can take place for the IT support teams; however, formal learning and education tend to be one-off and focus only on the concepts so they need to be accompanied by constant communication of real-life scenarios of problem cases and how the concepts are reflected in the daily operation of the IT support organisation. Such communication events may be required on weekly basis if not daily, and can be done electronically for efficiency or face to face for effectiveness. The communication events aiming to increase the management buy-in would need to be conducted in a bottom-up fashion and based on the clear demonstration of the positive impact of this process on both the IT support organisation and its customers. The communication events to coordinate resources to execute the ITIL Problem Management process need to take into consideration of the organisational culture and hierarchy and focus on information gathering and sharing as well as the underlying cause of IT issues. The communication events to build relationships with other ITIL processes need to focus on establishing and sustaining the interactions towards common objectives.

\subsection{The quality of the Problem Manager}

As the management and delivery of IT services are increasingly based on interrelated processes such as the ones prescribed by the ITIL framework, the role of process managers within IT support organisation is also becoming more influential to the quality of the IT services. As opposed to managers in a traditional vertical command chain, process managers are required to manage resource, information and activities across different technical dimensions and functional silos; more often than not, such horizontal chains would also need to go beyond the organisational boundaries and extend to external vendors and suppliers. 
The role of the process managers in IT Service Management differs from the role of IT project managers; as opposed to IT project managers who need to plan and execute efforts to bring desirable end-results or products to the customers within designated time frame and under budget, IT process managers generally need to embed their processes with the IT services and meet customers' IT services and operations' requirements on a more constant or on-going basis. Although IT Service Management may seem to be more routinised when compared to IT project management, and the IT Service Management processes may seem capable of being well structured according to best practice guidelines, the management of the problem cases rarely has routinised steps or workflows. This is mostly due to the fact that IT service disruptions and their underlying causes often come with unique circumstances and would often require the collaborations of various expertise and knowledge to address.

As both the champion and manager of the ITIL Problem Management process, not only does the problem manager need to coordinate efforts and progress through the life cycle of problems, he/she would also need to be the key resource to overcome the associated challenges, and execute the implementation strategy to ensure the benefit of this process is fully realised.

Based on these requirements and the also the challenges identified by this research, the following qualities should be expected from the manager of the ITIL Problem Management process to overcome these challenges -

Operational focus and proactive mindset - the problem life cycle begins with the detection and identification of IT service disruptions or risks and vulnerabilities that may lead to potential service disruptions. Problem managers should be able to exercise oversight on the organisational wide IT operational environment, have knowledge of common and severe service disruptions as well as their causes and relationships. Based on these understanding, the problem managers should also be able to anticipate potential service disruptions or operational failures and act on the preventive measures in a timely manner.

Relationship building abilities - the problem managers should be able to build relationships and engage with key Service Management functions and processes based on common objectives and mutual benefits. The problem managers also need to have close working relationships with the customer, the line managers of various IT teams and also the third party vendors and suppliers. 
Coordination abilities - collaboration between different IT skill sets and support groups are the key to the success of root cause investigation in order to address underlying issues that may impact the IT services and operations. The problem managers need to coordinate the support teams in a way that various competencies can be combined, and organize them to carry out related activities in a planned and controlled manner.

Facilitation skills - the problem manager needs to fulfill a supporting role in a problem life cycle. They need to be able to create the best possible conditions and environment for executing the Problem Management process; the problem managers also need to keep the communication channels open between all parties involved and provide assistances by providing information, documentations and tools, schedules, updates and etc.

Leadership - as well as being facilitators, the problem managers need to maintain the momentum of the IT support teams, keep the focus on the underlying issues, and drive the effort in progressing through the problem life cycle. As the champion of the ITIL Problem Management process, they also need to be able to promote the understanding of the ITIL Problem Management process and becoming the leading force in fostering an organisational cultural change which will see the organisation being more proactive and preventive in providing IT services.

Analysis and reporting skills - the problem managers need to be familiar with various root cause analysis techniques and be able to analyse information related to service disruptions; they also need to effectively report critical information and the progress of problem life cycle to the management and the customers on regular bases.

As discussed, communication is crucial to both the initial set up of the Problem Management process and the execution of this process and its related activities. Most of the qualities listed above can be regarded as being based on solid communication skills. Communication ability and skills should be regarded as one of the most desirable quality for the manager of the ITIL Problem Management process. It is essential for problem managers to be an organisational communicator who perform communication tasks in various forms in order to build relationships, facilitate incident learning, manage risks, coordinate resources, promote the understanding of the Problem Management process and influence the behavior of IT professionals. 


\section{Conclusion}

\subsection{Summary of the challenges for implementing the ITIL and Problem Management process}

This study is one of the first ones to examine the rather rarely implemented ITIL Problem Management process and explore its huge potential not just within IT Service Management, but also in the overall IT Governance of the organisations which consume IT services based on the ITIL framework. This study began with a broad perspective towards the use of Information Technology in organisational life and reviewed the relationships between organisational IT governance, IT Service Management and their associated concepts and frameworks.

This study recognises that the power of the ITIL Problem Management process are essentially from its learning ability within the IT services and operations, and its ability to manage and take corrective and preventive actions based on its knowledge of the IT services and operational environment and by interacting with other ITIL processes. From the literature review, this study established the unique and strategic position held by the ITIL Problem Management process in an organisational IT governance context and how this process could contribute to the IT Governance areas such as "Risk Management", "Value Delivery", "Performance Management", "Resource Management", "Strategic Alignment".

This study first summarized the challenges that the implementation of the ITIL Problem Management process may encounter according to existing literature. The empirical research at a major international IT company further identified 23 unique challenges that may impact the successful implementation of this process; this research also rated the importance of each challenge identified and the order-ranked these challenges according to their importance rating. These challenges and their ranking are presented in the following 6 categories -

\begin{tabular}{|l|c|c|}
\hline The understanding of the ITIL Problem Management process & $\begin{array}{l}\text { Ranking in } \\
\text { category }\end{array}$ & $\begin{array}{l}\text { Overall } \\
\text { ranking }\end{array}$ \\
\hline $\begin{array}{l}\text { The management's understanding of the ITIL Problem Management process and its } \\
\text { benefit }\end{array}$ & 1 & 7 \\
\hline $\begin{array}{l}\text { The IT support teams' understanding of the ITIL Problem Management process and } \\
\text { its benefit }\end{array}$ & 2 & 12 \\
\hline $\begin{array}{l}\text { The customer's understanding of the ITIL Problem Management process and its } \\
\text { benefit }\end{array}$ & 3 & 19 \\
\hline
\end{tabular}




\begin{tabular}{|c|c|c|}
\hline The buy-in of the ITIL Problem Management process & $\begin{array}{l}\text { Ranking in } \\
\text { category }\end{array}$ & $\begin{array}{l}\text { Overall } \\
\text { ranking }\end{array}$ \\
\hline The management buy-in and support for the ITIL Problem Management process & 1 & 2 \\
\hline The IT support teams' buy-in and support for the ITIL Problem Management process & 2 & 9 \\
\hline The customer buy-in and support for the ITIL Problem Management process & 3 & 18 \\
\hline
\end{tabular}

\begin{tabular}{|c|c|c|}
\hline The investment for the ITIL Problem Management process & $\begin{array}{l}\text { Ranking in } \\
\text { category }\end{array}$ & $\begin{array}{l}\text { Overall } \\
\text { ranking }\end{array}$ \\
\hline $\begin{array}{l}\text { The cost-benefit justification for investigating, identifying and removing root causes } \\
\text { of IT Problems }\end{array}$ & 1 & 4 \\
\hline The capability, competency and skills of the Problem Manager & 2 & 8 \\
\hline $\begin{array}{l}\text { The ability to achieve both short term and long term benefit of ITIL Problem } \\
\text { Management process }\end{array}$ & 3 & 11 \\
\hline The finance and resource commitment for the ITIL Problem Management process & 4 & 21 \\
\hline The tools used for implementing the ITIL Problem Management process & 5 & 22 \\
\hline
\end{tabular}

\begin{tabular}{|l|c|c|}
\hline The interrelation with other ITIL processes & $\begin{array}{l}\text { Ranking in } \\
\text { category }\end{array}$ & $\begin{array}{l}\text { Overall } \\
\text { ranking }\end{array}$ \\
\hline $\begin{array}{l}\text { The relationships and interactions between ITIL Problem Management process and } \\
\text { other ITIL processes and function within the IT support organisation }\end{array}$ & 1 & 10 \\
\hline $\begin{array}{l}\text { The maturity of other ITIL processes that interact with the ITIL Problem } \\
\text { Management process }\end{array}$ & 2 & 15 \\
\hline
\end{tabular}

\begin{tabular}{|c|c|c|}
\hline The execution of Problem Management process & $\begin{array}{l}\text { Ranking in } \\
\text { category }\end{array}$ & $\begin{array}{l}\text { Overall } \\
\text { ranking }\end{array}$ \\
\hline $\begin{array}{l}\text { The quantity and quality of the information gathered for the ITIL Problem } \\
\text { Management Process }\end{array}$ & 1 & 1 \\
\hline The focus on the underlying causes of IT issues & 2 & 5 \\
\hline The collaboration of the support teams around problem cases & 3 & 6 \\
\hline The technical knowledge of the IT support teams & 4 & 13 \\
\hline $\begin{array}{l}\text { The nature and complications of the issues the IT support organisation's customer is } \\
\text { facing }\end{array}$ & 5 & 16 \\
\hline The technical knowledge of the Problem Manager & 6 & 23 \\
\hline
\end{tabular}

\begin{tabular}{|c|c|c|}
\hline The organisational factors & $\begin{array}{l}\text { Ranking in } \\
\text { category }\end{array}$ & $\begin{array}{l}\text { Overall } \\
\text { ranking }\end{array}$ \\
\hline $\begin{array}{l}\text { The IT support organisation's readiness to change in alignment with best practice } \\
\text { guidelines }\end{array}$ & 1 & 3 \\
\hline The focus of being proactive in providing IT support & 2 & 14 \\
\hline $\begin{array}{l}\text { The adaption, customization and governance of the ITIL Problem Management } \\
\text { process within the IT support organisation }\end{array}$ & 3 & 17 \\
\hline $\begin{array}{l}\text { The organisational structure of the IT support organisation related to the ITIL } \\
\text { Problem Management process }\end{array}$ & 4 & 20 \\
\hline
\end{tabular}


This empirical research made the following contributions: first, it validated the challenges associated with the implementation of the ITIL Problem Management process as suggested by existing literature. Second, it verified that all the challenges associated with the implementation of the ITIL framework as seen in existing literature also apply to the implementation of the ITIL Problem Management process, and some of the challenges, such as the collaboration of the IT support teams, are even more closely associated with the implementation of the ITIL Problem Management process compared to other processes or the entire ITIL framework. Third, it identified additional challenges to the implementation of the ITIL Problem Management process, such as the cost-benefit justification of investigating and removing root causes, being proactive in providing IT support, the technical knowledge of problem manager and the support teams and also the nature and complications of the underlying issues. Fourth, it presented all the challenges in meaningful and interrelated categories and provided the ranking order for these challenges. The relationships among the categories were also explored as part of this study.

\subsection{Overcome the challenges to implement the ITIL Problem Management process}

Although the implementation of the ITIL Problem Management process often aims to benefit both the IT support organisations which manage and deliver IT services and the organisations which receive them, the challenges associated with the implementation would mostly need to be managed and overcome by the IT support organisations. To begin with, the IT support organisations need to ensure the ITIL Problem Management process and its benefit are understood by all parties involved; it would then need to invest on tools and resources, facilitate collaborations of IT teams and build constructive working relationships between the Problem Management process and other ITIL processes. The successful implementation of the ITIL Problem Management would also require the appropriate focus on underlying issues within the entire organisational IT services and operations. Last but not least, there would need to be regular measurements and demonstrations of its value and benefits to ensure there is continuous support for this process from both within the IT support organisation and also its customers.

At a practical level, this study offered an in-depth discussion of the ITIL Problem Management process and the critical challenges associated with its implementation. Not only did this study provide advices on how these challenges can be overcome, it also provided a theoretical framework which can be utilized to address these challenges systematically. This framework focuses on the understanding of the ITIL Problem Management process and the buy-in of this process, and shows how the organisational 
conditions created by these two factors can be utilized to influence other organisational factors and assist with the successful execution of this process which would in turn increase the buy-in.

This study also highlights the effective organisational communication as a key method to overcome challenges identified in each category and particularly to promote the understanding, increase the buyin and foster a strong organisational culture that would enable the ITIL Problem Management process to achieve its full potential. The careful planning and execution of organisational communication events in various forms are recommended by this study to be the centre of any strategies designed to implement the ITIL Problem Management process within the IT support organisations.

This study recognises the importance of the problem manager role in implementing the ITIL Problem Management process; it views the problem manager being an overall organisational communicator who focuses on organisation-wide IT services and operations, has a proactive mindset as well as coordination, analysis and facilitation skills to lead the effort to progress through the problem life cycle.

This study provides the much needed literature and empirical evidence on the implementation of the ITIL Problem Management process; IT support organisations and ITIL Problem Management practitioners would be able to benefit from this study as they implement the ITIL Problem Management process at their own organisational environment.

\subsection{The view towards the ITIL framework and the ITIL Problem Management process}

Amongst the studies of ITIL as the IT Service Management framework, this study is one of the very few which focuses on the implementation of its individual processes. It also made a rare effort to gather insights and views towards the ITIL framework and the ITIL Problem Management process from the IT professionals who routinely worked with them. Despite the overall positive views towards the ITIL framework and the Problem Management process, this study found that that their successful implementation by the IT support organisation is seen as crucial for realising their benefits.

Although the ITIL Problem Management process is seen as being less understood compared to other ITIL processes, there are relatively high expectations for this process, particularly in terms of minimizing service disruptions and also the associated workloads. On the other hand, more factors are seen as may influence the success of the ITIL Problem Management process. The strength of the ITIL framework is 
believed to come from the interactions between all of its processes. Close and constructive working relationships between the ITIL Problem Management process and other ITIL processes are also regarded as vital.

This study also points out that, in a complex technical environment, disruptions of IT services are hard to prevent, however major disastrous impacts can be avoided. The avoidance of these incidents and their impacts would require an appropriate organisational process to exercise oversight on the IT services and operations, facilitate learning of the incidents, continuously improve IT performance and proactively identify and remove risks. The ITIL Problem Management process, once implemented and supported appropriately, would be able to fulfill this strategic role.

\subsection{Limitations and future research}

The empirical research of this study was conducted with IT professionals from one single IT support organisation; despite this organisation operating in two different countries and the diverse backgrounds of the participants, the organisational culture, standards and challenges are largely shared by all participants. The fact that the ITIL framework is well regarded and actively followed by this organisation and its employees can be beneficial to this research but may also prevent alternative views. It is therefore recommended that the empirical research of this paper is replicated at different organisational environments in the future, especially in internal IT support groups or in organisations with different maturity level in regards to the implementation of the ITIL framework.

It is also necessary for the challenge items and their categories presented by this paper to be quantitatively examined in order to shed further lights on their relationships and associations. The model recommended by this paper for implementing the ITIL Problem Management and overcoming the associated challenges should also be quantitatively verified.

This study primarily focused on the principles and objectives of the ITIL Problem Management process within the IT Service Management and organisational IT operations and governance, and also the implementation and practice of this process in such context. More work needs to be done to explore the structures of the ITIL framework in both ITIL version 2 and version 3, and how the structures offered by each version may influence the interaction between the Problem Management process and other ITIL processes as well as the outcome of the implementation of the Problem Management process. 


\section{Bibliography}

Addy, R. (2008). Effective IT Service Management: To ITIL and Beyond. Boston, MA: Morgan Kaufmann Publishers.

Advanced Business Concepts. (2008). IT Service Management Problem Management: Problem Management. Retrieved from www.adbizco.com.

Ayat, M., Sharifi, M., Sahibudin, S., \& Ibrahim, S. (2009). Adoption Factors and Implementation Steps of ITSM in the Target. In: Modelling and Simulation. AMS '09. Third Asia International Conference, pp. 369 - 374. IEEE Press.

Barney, J. B. (1991). Firm resources and sustained competitive advantage. Journal of Management, Vol. 17, pp. 99-120.

Bartolini, C., \& Salle, M. (2005). Business Driven Prioritization of Service Incidents IFIP International. Federation for Information Processing 2004.

Barua, A., Kriebel, C.H., \& Mukhopadhyay, T. (1995). Information technologies and business value: an analytic and empirical investigation. Information Systems Research, Vol. 6, pp. 3-23.

Bullemer, P., \& Laberge, J. (2010). Common operations failure modes in the process industries. Journal of loss prevention in the process industries, Vol.23, pp.928-935.

Braun, C., \& Winter, R. (2007). Integration of IT Service Management into Enterprise Architecture.ACM, pp.1215-1219. Proceedings of the 2007 ACM symposium on applied computing.

Brenner, M. (2006). Classifying ITIL Processes: A Taxonomy under Tool Support Aspects. The First IEEE/IFIP International Workshop, pp. 19 - 28. IEEE Press.

Brenner, M.,Rodosek, G.D.,Hanemann, A.,Hegering, H-G., \& Koenig, R. (2007). Service Provisioning: Challenges, Process Alignment and Tool Support. In: Bergstra, J., and Murgess, M (ED) Handbook of network and system administration. Elsevier B.V.

Buckby, S., Best, P., \& Stewart, J. (2008). The current state of Information Technology governance literature. In: Cater-Steel, Aileen (Ed) Information Technology Governance and Service Management Frameworks and Adaptions. Information Science Reference (IGI Global). Hershey PA USA, pp. 1-43.

CA Technologies. (2010). Research Report: the avoidable cost of downtime. Retrieved from http://arcserve.com/us/lpg/cost-of-downtime.aspx.

Carr, N.G. (2005). The end of corporate computing. MIT Sloan Management Review, Vol.46, pp. 66-73. 
Cater-Steel, A., \& McBride, N. (2007). IT Service Management Improvement - an Actor Network Perspective. Paper presented at the European Conference on Information Systems. St. Gallen, Switzerland.

Cater-Steel, A., \& Tan, W.-G. (2005a). Implementation of IT Infrastructure Library (ITIL) in Australia: Progress and Success Factors. Paper presented at the IT Governance International Conference. Auckland, New Zealand.

Cater-Steel, A., \& Tan, W.-G. (2005b). Summary of Responses to itSMF Conference Survey. Retrieved from http://www.usq.edu.au/users/caterst/.

Cater-Steel, A., Tan, W.-G., \& Toleman, M. (2006). Challenge of adopting multiple process improvement frameworks. Paper presented at the European Conference on Information Systems, Goteborg, Sweden.

Cater-Steel, A. P., \& Toleman, M. (2007). Education for IT Service Management. International Journal of ITStandards and Standardization Research, Vol.5, pp. 27-42.

Cater-Steel, A., Toleman, M., \& Tan, W.-G. (2006). "Transforming IT Service Management - the ITIL impact". Proceedings of the 17th Australasian Conference on Information Systems, Adelaide, Australia.

Cater-Steel, A., Toleman, M., \& Tan, W.-G. (2009). “Using Institutionalism as a lens to examine ITIL adoption and diffison". Proceedings of the 20th Australasian Conference on Information Systems, Melbourn, Australia.

Conger, S., Winniford, M. A., \& Erickson-Harris, L. (2007). Service Management in Operations. Proceedings of the Fourteenth Americas Conference on Information Systems, Toronto, Canada.

Cooke.D., \& Rohleder, T. (2006). Learning from incidents: from normal accidents to high reliability. System Dynamics Review, Vol.22, pp. 213-239.

Davenport, T.H. (1993). Process Innovation; reengineering work through Information Technology. Harvard Business School Press.

Demirkan,H., Kauffman, RJ., Vayghan.JA., Fill, H, Karaiannis.D \& Maglio.PP. (2008). Service Orientated Management and technology. Electronic Commerce Research and Applications, Vol.7, pp. 356-376.

Deverson, T., \& Kennedy, G.D.(Ed). (2005). The New Zealand Oxford dictionary. South Melbourne, Victoria, Australia: Oxford University Press.

DiMaggio, P. J., \& Powell, W. W. (1983). The Iron Cage Revisited: Institutional Isomorphism and Collective Rationality in Organisational Fields. American Sociological Review, Vol.48, pp.147-160.

Dubie, D. (2007). Ten ways to make ITIL work for you. NetworkWorld.com. Retrieved from: www. networkworld.com/news/2006/071006-itil-package.html .

Freedman, R. (2004). Standards-based IT Consulting. Consulting to Management, Vol. 15, pp. 31-34. 
Gartner, INC. (2005). New Technologies Attempt to Meet ITSM Demands of IT Operations Group. Retrieved from www.gartner.com.

Gartner, INC. (2007). IT infrastructure and operations maturity model. Retrieved from www.gartner.com.

Gartner, INC. (2007). Gartner survey shows 85 percent of organisations anticipate spending on external service providers will increase or stay the same when economy recovers. Retrieved from www.gartner.com.

Gorla, N., Somer,T., \& Wong, B. (2010). Organisational impact of system quality, information quality, and service quality. Journal of strategic information systems, Vol.19, pp. 207-228.

Gray,P. (2006). Managers guide to making decisions about information systems. Hoboken, NJ: John Wiley \& Sons.

Goldkuhl, G., \& Lind, M. (2008). Coordination and transformation in business processes: towards an integrated view. Business Process Management Journal, Vol. 14, pp. 761-77.

Grewell, S., McDonald, C. (2006) Issues in IT Governance \& IT Service Management - A study in their adoption in Australian Universities. European Conference on IT Evaluation, September 2006, Genoa, Italy.

Hewlwtt-Packard. (2003). HP IT Service Management (ITSM): Transforming IT organisations into service providers. Retrieved from www.hp.com.

Hill, M., \& Hupe, P. (2002). Implementing Public Policy, London, Thousand Oaks, CA and New Delhi, India: Sage, 223-233.

Hochstein, A., Zarnekow, R., \& Brenner, W. (2005a). ITIL as Common Practice Reference Model for IT Service Management: Formal Assessment and Implications for Practice. e-Technology, e-Commerce and e-Service, 2005. EEE '05. Proceedings of the 2005 IEEE International Conference, pp. $704-710$. IEEE Press.

Hochstein, A., Tamm, G., Brenner, W. (2005b). Service-oriented it management: Benefit, cost and success factors. Proceedings of the Thirteenth European Conference on Information Systems, Regensburg, Germany, University of Regensburg.

IBM. (2008). IBM IT Facilities Consolidation and Relocation Services - data centre consolidation and relocation. Retrieved from www.ibm.com.

Information Technology Governance Institute (ITGI). (2000). IT Governance roundtable - Sponsored by the IT Governance institute. Information Systems Control Journal, Vol. 4, pp.27-28.

Information Technology Governance Institution (ITGI). (2004).IT Control objectives for SARBANES-OXLEY. Retrieved from www.itgi.org. 
Information Technology Governance Institution (ITGI). (2007). COBIT 4.1. Rolling Meadows, IL: ISACA.

Jantti, M. (2008). Difficulties in Managing Software Problems and Defects. Doctoral dissertation, University of Kuopio, Kuopio, Finland.

Kashanchi, R., \& Toland, J. (2006). Can ITIL Contribute to IT/business Alignment? An Initial Investigation. WIRTSCHAFTSINFORMATIK. pp.340-348.

Keel, A. J., Orr, M. A., Hernandez, R.R., Patrocinio, E.A., \& Bouchard, J. (2007). From a technologyoriented to a service-orientated approach to IT management. IBM Systems Journal, Vol.3, pp. 549-564.

Kendall,M.G., \& Smith, B. (1939). The problem of $m$ rankings. The annals of mathematical statistics, Vol.10, pp.275-287.

Kettinger, W.J., Teng, J.T., \& Guha, S. (1997). Business process change: a study of methodologies, techniques, and tools. MIS Quarterly, Vol. 21, pp. 55-98.

KIM, G. (2003). Sarbanes-Oxley, Fraud Prevention, and IMCA: A Framework for Effective Controls Assurance. Computer Fraud and Security, September 2003, Vol.2003, pp.12-16.

Knahl,M.H. (2009). A Conceptual Framework for the Integration of IT Infrastructure Management, IT Service Management and IT Governance. World Academy of Science, Engineering and Technology, Vol. 52, pp. 438-443.

Ko,D., \& Fink,D. (2010). Information Technology governance: an evaluation of the theory-practice gap. Corporate Governance, Vol. 10, pp. 662-674.

Kumbakara, N. (2008). Managed IT services: the role of IT standards. Information Management and Computer Security, Vol.16, pp. 336-359.

Mohamed, M.S., Ribiere, V.M., O'Sullivan, K.J., \& Mohamed, M.A. (2008). The re-structuring of the Information Technology infrastructure library (ITIL) implementation using knowledge management framework, VINE: The journal of information and knowledge management systems, Vol.38, pp.315-333.

Munstermann, B., Eckhardt, A., \& Wetzel, T. (2010). The performance impact of business process standardization. Business Process Management Journal, Vol.16, pp. 29-56.

Nazimoglu, O., \& Ozsen, Y. (2009).Analysis of risk dynamic in Information Technology service delivery. Journal of enterprise information management, Vol. 23, pp. 350-364.

Nicewicz-Modrzewska, D., Stolarski, P. (2008). ITIL implementation roadmap based on process governance. EUNIS 2008. Adam Mickiewicz University Computer Centre.

Niessink, F.,\& Van Vliet, H. (2006). Towards mature IT services. Software Process - Improvement and Practice, Vol.4, pp. 55-71. 
Nordin, F. (2008). Linkages between service sourcing decisions and competitive advantage: A review, propositions, and illustrating cases. International Journal of production economics, Vol.114, pp. 40-55.

Office of Government Commerce. (2007). The Official Introduction to the ITIL Service Lifecycle. London, TSO.

Office of Government Commerce. (2008). ITIL Lifecycle Publication Suite. London, TSO.

Office of Government Commerce. (2007). ITIL Service Operation. London, TSO.

Office of Government Commerce. (2007). ITIL Service Strategy. London, TSO.

Office of Government Commerce. (2007). ITIL Definition List. London, TSO.

Office of Government Commerce. (2007). IT Service Management - An introduction. Zaltbommel, Van Haren Publishing.

Office of Government Commerce. (2000). Service Support. London, TSO.

Paim, R., Caulliraux, H.M., \& Cardoso, R. (2008). Process management tasks: a conceptual and practical view. Business Process Management Journal, Vol. 14, pp. 694-723.

Palmquist, M. (2003). A brief history of computer support for writing centres and writing across the curriculum programmes. Computers and Composition, Vol. 20, pp. 395-413.

Peppard, J. (2003). Managing IT as a portfolio of services. European Management Journal, Vol. 21, pp. 467-483.

Pereira, R. (2010). A Maturity model for implementing ITIL, MEIC Alameda, Intsituto Superior Tecnico, Lisboa, Portugal.

Perrow, C. (1984). Normal Accidents: Living With High-Risk Technologies. New York, Basic Books.

Pollard, C., \& Cater-Steel, A. (2009). Justifications, Strategies, and Critical Success Factors in Successful ITIL Implementations in U.S. and Australian Companies: An Exploratory Study. Information Systems Management, Vol.26, pp. 164-175.

Porra, J., Hirschheim, R., \& Parks, M.S. (2006). Forty Years of Corporate Information Technology Function at Texaco Inc.-a History. Information and Organisation, Vol. 16, pp. 82-107.

Reed,R.,Lemak,D.,Mero,N. (2000). Total quality management and sustainable competitive advantage. Journal of quality management, Vol.5, pp.5-26.

Regev,G., \& Wegmann, A. (2009). Why business process improvement might not bring customer satisfaction. Retrieved from www.scientificcommons.org. 
Rowe, G., \& Wright, G. (1999). The Delphi technique as a forecasting tool: issues and analysis. International Journal of Forecasting, Vol. 15, pp. 353-375.

Saxena, K.B.C., \& Bharadwaj, S.S. (2009). Managing business process through outsourcing: a strategic partnering perspective. Business Process Management Journal, Vol. 15, pp.687-715.

Shang,S., and Lin,.S.F. (2010). Barriers to Implementing ITIL-A Multi-Case Study on the Service-based Industry. Contemporary Management Research, Vol.6.pp.53-70.

Schmidt, R. C. (1997). Managing Delphi surveys using nonparametric statistical techniques. Decision Sciences, Vol. 28, pp. 763-774.

Scott, W. R. (2004). Institutional theory. Encyclopedia of Social Theory, George Ritzer, ed. Thousand Oaks, CA: Sage.

Sharifi, M., Ayat, M., Rahman, A.A., \& Sahibudin, S. (2008). Lessons Learned in ITIL Implementation Failure. Information Technology, 2008. ITSim 2008, pp. 1 - 4. IEEE

Spohrer J, Maglio pp, Bailey J, Gruhl D. (2007). Steps toward a science of service systems. Computer, Vol.40, pp. 71-77.

Singh, R.,Keil, M., \& Kasi, V. (2009). Identifying and overcoming the challenges of implementing a project management office. European Journal of Information Systems, Vol. 18, pp. 409-427.

Skrinjar, R., Bosilj-Vuksic, V., \& Indihar-Stemberger, M. (2008). The impact of business process orientation on financial and non-financial performance. Business Process Management Journal, Vol. 14 No. 5 , pp. $738-754$.

Stoneburner, G., Goguen, A., \& Feringa, A. (2002). Risk Management Guide for Information Technology Systems, National Institute of Standards and Technology, Gaithersburg, MD.

Tallon, P.P., Kraemer, K.L., \& Gurbaxani, V. (2000). Executives' perceptions of the business value of Information Technology: a process-oriented approach. Journal of Management Information Systems, Vol. 16, pp. 145-73.

Wessels, E., \& Loggerenberg, J. V. (2006). IT Governance: Theory and Practice. Paper presented at the Conference on Information Technology in Tertiary Education, Pretoria, South Africa.

Wilkin, C., \& Chenhall, RH. (2010). A review of IT Governance: A taxonomy to inform accounting information systems. Journal of Information Systems, Vol. 24, pp. 107-146.

Youtie, J.,Shapira, P., \& Laudeman,G. (2007). Supply, demand and ICT-based services: A local level perspective. Telecommunication Policy, Vol.31, pp.347-358. 


\section{Appendix 1: Human Ethics Committee application form 1}

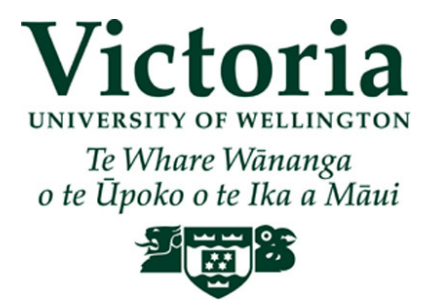

INFORMATICS HUMAN ETHICS COMMITTEE

Application for Approval of Research Projects

Please email applications to your supervisor, who will then email it to an Informatics HEC member for a preliminary review.

Note: The Human Ethics Committee attempts to have all applications approved within 6 working days, but a longer period may be necessary if applications require substantial revision.

1 NATURE OF PROPOSED RESEARCH:

(a) Student Research

(b) If Student Research Degree MMIM......... Course Code MMIM 592......

(c) Project Title: Identifying and overcoming the challenges of implementing the ITIL Problem Management process in IT support organizations

2 INVESTIGATORS:

(a) Principal Investigator

Name...Michael Hsu.

e-mail address hsumich@myvuw.ac.nz

School/Dept/Group School of Information Management

(b) Other Researchers Name Position

(a) Supervisor (in the case of student research projects)

Janet Toland (School of Information Management, Victoria University of Wellington, janet.toland@vuw.ac.nz, 463 6861) 
(a) Proposed starting date for data collection - June $\mathbf{2 0 1 0}$ or after HEC approval has been granted.

(Note: that NO part of the research requiring ethical approval may commence prior to approval being given)

(b) Proposed date of completion of project as a whole ...February $2011 . .$. CONSIDERATIONS

(a) Sources of funding for the project

Please indicate any ethical issues or conflicts of interest that may arise because of sources of funding

e.g. restrictions on publication of results

No Funding

(b) Is any professional code of ethics to be followed

$\mathbf{N}$

If yes, name

(c) Is ethical approval required from any other body

$\mathbf{N}$

If yes, name and indicate when/if approval will be given

\section{DETAILS OF PROJECT}

Briefly Outline:

(a) The objectives of the project

Information Technology Infrastructure Library (ITIL) framework is widely adopted and used by organizations for providing IT infrastructure support and managing IT services. Problem Management process is one of the 10 processes defined under the ITIL framework.

The ITIL Problem Management process is for identifying and removing the root causes of IT service disruptions, especially the repetitive and common incidents. It aims at proactively preventing possible future IT service disruptions within an organization and also minimizing the impact of service disruptions that can not be prevented.

This study seeks to explore IT professionals' views towards the Problem Management process and identify the challenges of implementing the Problem Management process within IT support organizations. It also aims at ranking these challenges according to their importance 
and discovering possible ways, methods and approaches by which the IT support organizations can overcome the top-ranked challenges.

(b) Method of data collection

The collection of data for this research will be based on semi-structured interviews. The interviewees (who are also the panel of experts for the data collection based on the Delphi method) will be the IT professionals from Fujitsu Australia and New Zealand. The following questions will be used in the semi-structured interviews:

1. What are your experiences of working with ITIL?

2. What is your view towards ITIL Problem Management process?

3. How can IT support organizations overcome the top challenges of implementing ITIL Problem Management process?

It is intended to conduct the interviews face-to-face when possible and via Teleconference when necessary for data collecting. All interviews will be held on the premises of Fujitsu Australia and New Zealand.

(c) The benefits and scientific value of the project

ITIL is a set of best practice guidance and specifies "what to do" but not "how to do" in providing IT infrastructure support and managing IT services. ITIL does not offer a clear-cut implementation techniques for IT support organizations.

This research hopes to offer insightful views and perspectives towards ITIL Problem Management process. It seeks to contribute to an understanding of the challenges for implementing ITIL Problem Management process for IT support organizations. This research is expected to benefit IT support organizations such as Fujitsu Australia and New Zealand by suggesting possible ways, methods and approaches to enable them to overcome the challenges and successfully implement the ITIL Problem Management process.

(b) Characteristics of the participants

For the purpose of this research around 20-25 members of Fujitsu Australia and New Zealand will be invited. The participants invited will be ITIL Problem Management practitioners, IT professionals who have experiences working with Problem Management process, or IT 
professionals who had experiences or involvement in implementing ITIL Problem Management process.

The researcher will first verbally invite the members of Problem Management, Change Management, Service Desk and various IT engineering teams based in both New Zealand and Australia to participate in this research. The formal recruitment letter will be sent to the team members who have verbally expressed interest to participate. The recruitment process is likely to commerce in early July 2010 and run in parallel with interviewing process.

(c) Method of recruitment

The recruitment process will commence with the development of a list of suitable IT professionals. The IT professionals' roles within Fujitsu Australia and New Zealand will be reviewed to identify their suitability to participate in this research. Suitable candidates will be short-listed and initial contacts will be made to verbally invite the candidates to participate in this research. Through the initial contact, the nature of the research, the objective of the research and the research methods and processes will be communicated with the potential participants. For the IT professionals who verbally expressed interest of participating in this study, a research information sheet and research consent letter will be sent to the candidate in seeking their permission to collect data from them.

(f) Payments that are to be made/expenses to be reimbursed to participants None

(g) Other assistance (e.g. meals, transport) that is to be given to participants None.

(h) Any special hazards and/or inconvenience (including deception) that participants will encounter

Inconvenience in terms of the time commitment required for the interviews.

(i) State whether consent is for: (Please indicate as many as it applies)
(i) the collection of data
Y
(ii) attribution of opinions or information
$\mathbf{N}$
(iii) release of data to others
$\mathbf{N}$
(iv) use for a conference report or a publication $\mathbf{Y}$
(v) use for some particular purpose (specify) $\quad \mathbf{N}$ MMIM 592 
Attach a copy of any questionnaire or interview schedule to the application Please see section $5($ b) for a list of interview questions.

(j) How is informed consent to be obtained (see paragraphs 4.31(g), 5.2, 5.5 and 5.61 of the Guidelines)

(i) the research is strictly anonymous, an information sheet is supplied and informed consent is implied by voluntary participation in filling out a questionnaire for example (include a copy of the information sheet)

\section{$\mathbf{N}$}

(ii) the research is not anonymous but is confidential and informed consent will be obtained through a signed consent form (include a copy of the consent form and information sheet)

$\mathbf{Y}$

(iii) the research is neither anonymous nor confidential and informed consent will be obtained through a signed consent form (include a copy of the consent form and information sheet)

$\mathbf{N}$

(iv) informed consent will be obtained by some other method (please specify and provide details)

$\mathbf{N}$

With the exception of anonymous research as in (i), if it is proposed that written consent will not be obtained, please explain why

N/A

(k) If the research will not be conducted on a strictly anonymous basis state how issues of confidentiality of participants are to be ensured if this is intended. (See paragraph 4.3.1(e) of the Guidelines). (e.g. who will listen to tapes, see questionnaires or have access to data). Please ensure that you distinguish clearly between anonymity and confidentiality. Indicate which of these are applicable.

(i) access to the research data will be restricted to the investigator

\section{$\mathbf{N}$}

(ii) access to the research data will be restricted to the investigator and their supervisor (student research)

$Y$

(iii) all opinions and data will be reported in aggregated form in such a way that individual persons or organisations are not identifiable

$Y$

(iv) Other (please specify) 
The research data will be stored in the $\mathrm{H}$ drive of the researcher's student computing account at the Victoria University of Wellington.

Any information and opinions that the research participants provide will not be attributed to the research participants, and the research participants will not be able to be identified in any way.

(I) Procedure for the storage of, access to and disposal of data, both during and at the conclusion of the research. (see section 7 of the guidelines). Indicate which are applicable:

(i) all written material (questionnaires, interview notes, etc) will be kept in a locked file and access is restricted to the investigator

(ii) all electronic information will be kept in a password-protected file and access will be restricted to the investigator Y

(iii) all questionnaires, interview notes and similar materials will be destroyed:
(a) at the conclusion of the research
$\mathbf{N}$

or (b) _ 2 _ years after the conclusion of the research

$Y$

(iv) any audio or video recordings will be returned to participants and/or electronically wiped

$\mathbf{Y}$

(v) other procedures (please specify):

If data and material are not to be destroyed please indicate why and the procedures envisaged for ongoing storage and security

N/A.

(m)Feedback procedures (See section 8 of the Guidelines). You should indicate whether feedback will be provided to participants and in what form. If feedback will not be given, indicate the reasons why.

A summary of key findings and a research report will be provided to all research participants as well as their employer Fujitsu Australia and New Zealand. 
(n)Reporting and publication of results. Please indicate which of the following are appropriate. The proposed form of publications should be indicated on the information sheet and/or consent form.

(i) publication in academic or professional journals

(ii) dissemination at academic or professional conferences

Y

(iii) deposit of the research paper or thesis in the University Library (student research)

Y

(iv) a case study used for teaching purposes

$\mathbf{N}$

(v) other (please specify)

......Employer of the researcher has requested the right to review any material before it is published or deposited in the university library (see attached email).

To respond to the employer's requirement, the researcher will present the research paper to the employer prior to depositing it to the university library or publishing. The researcher has guaranteed that the employer's name will not be mentioned in the research paper.

Signature of investigators as listed on page 1 (including supervisors) and Chair of Informatics HEC.

NB: All investigators and the Chair of Informatics HEC must sign the form, then send it to Perumal Pillai for filing in the University's Research Office once the electronic application has been approved.

Date...

Date.

Date...

Supervisors:

Date.

Date

Chair of Informatics HEC:

Date 


\section{Appendix 2: Human Ethics Committee application form 2 \\ Victoria \\ UNIVERSITY OF WELLINGTON \\ Te Whare Wānanga \\ o te Ūpoko o te Ika a Māui

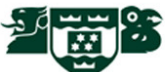

\section{INFORMATICS HUMAN ETHICS COMMITTEE}

Application for Approval of Research Projects

Please email applications to your supervisor, who will then email it to an Informatics HEC member for a preliminary review.

Note: The Human Ethics Committee attempts to have all applications approved within 6 working days, but a longer period may be necessary if applications require substantial revision.

1 NATURE OF PROPOSED RESEARCH:

(a) Student Research

(b) If Student Research Degree MMIM......... Course Code MMIM 592......

(c) Project Title: Identifying and overcoming the challenges of implementing the ITIL Problem Management process in IT support organizations

2 INVESTIGATORS:

(a) Principal Investigator

Name...Michael Hsu.

e-mail address hsumich@myvuw.ac.nz

School/Dept/Group School of Information Management

(b) Other Researchers Name Position

(c) Supervisor (in the case of student research projects)

Janet Toland (School of Information Management, Victoria University of Wellington, janet.toland@vuw.ac.nz, 463 6861) 
(a) Proposed starting date for data collection - June $\mathbf{2 0 1 0}$ or after HEC approval has been granted.

(Note: that NO part of the research requiring ethical approval may commence prior to approval being given)

(b) Proposed date of completion of project as a whole ...February 2011... CONSIDERATIONS

(a) Sources of funding for the project

Please indicate any ethical issues or conflicts of interest that may arise because of sources of funding

e.g. restrictions on publication of results

No Funding

(b) Is any professional code of ethics to be followed

$\mathbf{N}$

If yes, name

(c) Is ethical approval required from any other body

$\mathbf{N}$

If yes, name and indicate when/if approval will be given

Briefly Outline:

(d) The objectives of the project

Information Technology Infrastructure Library (ITIL) framework is widely adopted and used by organizations for providing IT infrastructure support and managing IT services. Problem Management process is one of the 10 processes defined under the ITIL framework.

The ITIL Problem Management process is for identifying and removing the root causes of IT service disruptions, especially the repetitive and common incidents. It aims at proactively preventing possible future IT service disruptions within an organization and also minimizing the impact of service disruptions that can not be prevented.

This study seeks to explore IT professionals' views towards the Problem Management process and identify the challenges of implementing the Problem Management process within IT support organizations. It also aims at ranking these challenges according to their importance and discovering possible ways, methods and approaches by which the IT support organizations can overcome the top-ranked challenges. 


\section{(b) Method of data collection}

The collection of data for this research will be based on the Delphi method. The Delphi method was developed to define important issues and reach consensus among a panel of experts through an iterative process of controlled feedback.

The panel of experts will be the IT professionals from Fujitsu Australia and New Zealand. The following questions will be asked to collect research data from the panel of experts based on the Delphi method.

1. What are the challenges in implementing ITIL Problem Management process in an IT support organization?

2. What is the relative importance of these challenges?

The questions will be asked face-to-face when possible and via Teleconference when necessary for data collecting. All interviews will be held on the premises of Fujitsu Australia and New Zealand.

(c) The benefits and scientific value of the project

ITIL is a set of best practice guidance and specifies "what to do" but not "how to do" in providing IT infrastructure support and managing IT services. ITIL does not offer a clear-cut implementation techniques for IT support organizations.

This research hopes to offer insightful views and perspectives towards ITIL Problem Management process. It seeks to contribute to an understanding of the challenges for implementing ITIL Problem Management process for IT support organizations. This research is expected to benefit IT support organizations such as Fujitsu Australia and New Zealand by suggesting possible ways, methods and approaches to enable them to overcome the challenges and successfully implement the ITIL Problem Management process.

\section{(d) Characteristics of the participants}

For the purpose of this research around 20-25 members of Fujitsu Australia and New Zealand will be invited as the experts on the panel. The participants invited will be ITIL Problem Management practitioners, IT professionals who have experiences working with Problem Management process, or IT professionals who had experiences or involvement in implementing ITIL Problem Management process. 
The researcher will first verbally invite the members of Problem Management, Change Management, Service Desk and various IT engineering teams based in both New Zealand and Australia to participate in this research. The formal recruitment letter will be sent to the team members who have verbally expressed interest to participate. The recruitment process is likely to commerce in early July 2010 and run in parallel with interviewing process.

\section{(e) Method of recruitment}

The recruitment process will commence with the development of a list of suitable IT professionals. The IT professionals' roles within Fujitsu Australia and New Zealand will be reviewed to identify their suitability to participate in this research. Suitable candidates will be short-listed and initial contacts will be made to verbally invite the candidates to participate in this research. Through the initial contact, the nature of the research, the objective of the research and the research methods and processes will be communicated with the potential participants. For the IT professionals who verbally expressed interest of participating in this study, a research information sheet and research consent letter will be sent to the candidate in seeking their permission to collect data from them.

(f) Payments that are to be made/expenses to be reimbursed to participants None

(g) Other assistance (e.g. meals, transport) that is to be given to participants None.

(h) Any special hazards and/or inconvenience (including deception) that participants will encounter

Inconvenience in terms of the time commitment required for the interviews.

(i) State whether consent is for: (Please indicate as many as it applies)
(i) the collection of data
Y
(ii) attribution of opinions or information
$\mathbf{N}$
(iii) release of data to others
$\mathbf{N}$
(iv) use for a conference report or a publication $\mathbf{Y}$
(v) use for some particular purpose (specify) $\quad \mathbf{N}$ 
Attach a copy of any questionnaire or interview schedule to the application

Please see section $5(b)$ for a list of interview questions.

(j) How is informed consent to be obtained (see paragraphs 4.31(g), 5.2, 5.5 and 5.61 of the Guidelines)

(i) the research is strictly anonymous, an information sheet is supplied and informed consent is implied by voluntary participation in filling out a questionnaire for example (include a copy of the information sheet)

\section{$\mathbf{N}$}

(ii) the research is not anonymous but is confidential and informed consent will be obtained through a signed consent form (include a copy of the consent form and information sheet)

(iii) the research is neither anonymous nor confidential and informed consent will be obtained through a signed consent form (include a copy of the consent form and information sheet)

$\mathbf{N}$

(iv) informed consent will be obtained by some other method (please specify and provide details)

$\mathbf{N}$

With the exception of anonymous research as in (i), if it is proposed that written consent will not be obtained, please explain why

N/A

(k) If the research will not be conducted on a strictly anonymous basis state how issues of confidentiality of participants are to be ensured if this is intended. (See paragraph 4.3.1(e) of the Guidelines). (e.g. who will listen to tapes, see questionnaires or have access to data). Please ensure that you distinguish clearly between anonymity and confidentiality. Indicate which of these are applicable.

(i) access to the research data will be restricted to the investigator

$\mathbf{N}$

(ii) access to the research data will be restricted to the investigator and their supervisor (student research) $\mathbf{Y}$

(iii) all opinions and data will be reported in aggregated form in such a way that individual persons or organisations are not identifiable $\quad \mathbf{Y}$

(iv) Other (please specify)

The research data will be stored in the $\mathrm{H}$ drive of the researcher's student computing account at the Victoria University of Wellington. 
Any information and opinions that the research participants provide will not be attributed to the research participants, and the research participants will not be able to be identified in any way

(I) Procedure for the storage of, access to and disposal of data, both during and at the conclusion of the research. (see section 7 of the guidelines). Indicate which are applicable:

(i) all written material (questionnaires, interview notes, etc) will be kept in a locked file and access is restricted to the investigator

(ii) all electronic information will be kept in a password-protected file and access will be restricted to the investigator

(iii) all questionnaires, interview notes and similar materials will be destroyed:
(a) at the conclusion of the research

$\mathbf{N}$

or (b) _ 2 _ years after the conclusion of the research

$Y$

(iv) any audio or video recordings will be returned to participants and/or electronically wiped

(v) other procedures (please specify):

If data and material are not to be destroyed please indicate why and the procedures envisaged for ongoing storage and security

N/A

(m)Feedback procedures (See section 8 of the Guidelines). You should indicate whether feedback will be provided to participants and in what form. If feedback will not be given, indicate the reasons why.

A summary of key findings and a research report will be provided to all research participants as well as their employer Fujitsu Australia and New Zealand.

(n)Reporting and publication of results. Please indicate which of the following are appropriate. The proposed form of publications should be indicated on the information sheet and/or consent form.

(i) publication in academic or professional journals

(ii) dissemination at academic or professional conferences 
(iii) deposit of the research paper or thesis in the University Library (student research)

\section{Y}

(iv) a case study used for teaching purposes

$\mathbf{N}$

(vi) other (please specify)

......Employer of the researcher has requested the right to review any material before it is published or deposited in the university library (see attached email).

To respond to the employer's requirement, the researcher will present the research paper to the employer prior to depositing it to the university library or publishing. It is also guaranteed that the employer's name will not be mentioned in the research paper.

Signature of investigators as listed on page 1 (including supervisors) and Chair of Informatics HEC.

NB: All investigators and the Chair of Informatics HEC must sign the form, then send it to Perumal Pillai for filing in the University's Research Office once the electronic application has been approved.

Date.

Date

Date...

\section{Supervisors:}

Date

Date...

Chair of Informatics HEC:

Date 


\title{
Appendix 3: Letter seeking permission to carry out the proposed research at Fujitsu Australia and New Zealand
}

\author{
VICTORIA UNIVERSITY OF WELLINGTON
}

Te Whare Wananga o te Upoko o te Ika a Maui

General Manager

Managed Services

Fujitsu Australia and New Zealand

Dear Paul,

I am writing to you in order to seek permission to interview several staff members from your organisation for my research project 'Identifying and overcoming the challenges of implementing the ITIL Problem Management process in IT support organizations'.

The research is carried out as part of my Master's degree in Information Management at the Victoria University of Wellington, New Zealand. The proposed research project seeks to identify the challenges of implementing ITIL Problem Management process and discover how IT support organizations can approach and overcome these challenges. The implementation of ITIL processes is an area that has not received much attention in the Information Management literature and therefore has the potential to break new ground. Of particular interest are questions such as: what are the challenges of implementing ITIL Problem Management process in an IT support organization, what are the relative importance of the challenges of implementing ITIL Problem Management process, and how IT support organisations can approach and overcome these challenges?

Victoria University has rigorous standards in place which address the standard of the research and protect the participants. All material collected in your organisation will be kept confidential. Only my supervisor and I will have access to the data, and neither your organisation nor individuals being interviewed can be identified at any stage of the research. The proposed interviews with selected employees will be kept as brief as possible in order to keep the time expenditure of participants to a minimum. At any time during the research the organisation maintains the right to withdraw from the project. At the end of this research, a report will be provided to you. You will also be able to review any research results, or request removal of any information from the research paper before it is published or deposited to the university library.

If you have further questions with regard to the proposed research, or concerns about confidentiality, please feel free to contact me anytime at 642102192778 or via email to hsumich@ myvuw.ac.nz. You can also contact my supervisor Janet Toland at 6444636861 or via email to janet.toland@ vuw.ac.nz.

Kind regards,

Michael Hsu 
Fujitsu New Zealand

149 Taranaki Street

Wellington, New Zealand, 6011

M: 642102192778 


\section{Appendix 4: Letter to SIM Human Ethic Committee}

\section{Jun 10}

Re: Identifying and overcoming the challenges of implementing the ITIL Problem Management process in IT support organizations

Principle Researcher: Michael Hsu

Supervisor (student research): Janet Toland

Ref No: \#17768

To Whom It May Concern:

Thanks for reviewing my HEC application for my proposed research and the feedbacks provided. In light of the committee's requirement I have made the following changes in my HEC application.

1. I have attached my employer's email giving permission for the proposed research to be conducted in the organization that I am employed in.

2. I have attached two application forms seeking permission for two different forms of data collection - Delphi method and semi-structured interviews. The corresponding research questions have also been specified in these two HEC application forms.

3. I confirm that the Delphi expert panel and all interviewees for this research will be employees of Fujitsu Australia and New Zealand. A total number of 20-25 IT professionals working for this IT outsourcing company will be recruited for this research. The recruitment criteria and process have also been specified.

4. I have made it clear to the research participants and their employer that participating in this research is completely voluntary and the research data will not be released to others. The participants' names will not be used in this research, nor would their opinions be attributed to the participants in anyway that can identify the participants.

5. To address the employer's concerns, I have assured that the name of the employer's organization will not be mentioned in the research paper, and the employer will have the opportunity to review the research paper and request removal of any information from the research paper before it is published or deposited to the university library.

6. I have changed my email address in the application form to my student email address. I have also changed my contact phone number to my private one.

7. I have assured that the research data will be stored on the $\mathrm{H}$ drive of my student computing account provided by Victoria University of Wellington. 
8. I have also made changes to the attached Information Sheet, Consent Form, Recruitment Letter and Letter to Employer as advised by the HEC.

I would like to submit my revised HEC application forms. I am looking forward to further feedback from the HEC regarding this application and my proposed research.

\section{Best regards}

Michael Hsu

Fujitsu New Zealand

149 Taranaki Street

Wellington, New Zealand, 6011

M: 642102192778 


\title{
Appendix 5: Research recruitment letter to potential research participants at Fujitsu Australia and New Zealand
}

\author{
VICTORIA UNIVERSITY OF WELLINGTON
}

Te Whare Wananga o te Upoko o te Ika a Maui

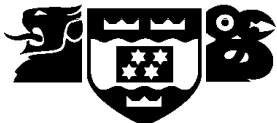

\section{Dear colleague,}

I am writing to you in order to invite you to participate in my research project on ITIL Problem Management process. The project seeks to identify the challenges of implementing ITIL Problem Management process and discover how IT support organizations should approach and overcome these challenges.

Fujitsu Australia and New Zealand has given me permission to carry out the research within the company and to interview selected staff with regard to aspects of ITIL Problem Management process. You are considered as an expert who has extensive experience in this area, and I would thus appreciate if you found the time to participate in my research, and to be interviewed as part of a focus group. The interview will be relatively brief and should not take longer than 30-45 minutes. Issues raised in the interviews may be followed up by email.

The interview could take place at a time and place of your convenience. Questions of particular interest are: what are your experiences in working with ITIL, what are the challenges of implementing ITIL Problem Management process in an IT support organization, what are the relative importance of the challenges of implementing ITIL Problem Management process, and how can IT support organisations approach and overcome these challenges?

Participation in this research is voluntary. You are not under any obligation to take part in this research. Victoria University has rigorous standards in place which address the standard of the research and protect the participants. All material collected during the interview will be kept confidential. No other people than me and my supervisors will have access to the data, and measures will be taken that neither you nor your organisation can be identified. At any time during the interview, you maintain the right to withdraw. I would appreciate the opportunity to talk with you about the proposed research and your potential role as a participant. Please feel free to contact me anytime at 642102192778 or via email to hsumich@myvuw.ac.nz. You can also contact my supervisor Janet Toland at 6444636861 or via email to janet.toland@vuw.ac.nz.

Kind regards,

Michael Hsu

Fujitsu New Zealand

149 Taranaki Street Wellington, New Zealand, 6011

M: 642102192778 


\title{
Appendix 6: Research Information Sheet
}

\author{
VICTORIA UNIVERSITY OF WELLINGTON \\ Te Whare Wananga o te Upoko o te Ika a Maui
}

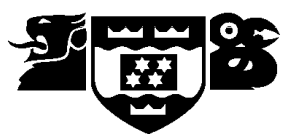

\section{Information Sheet}

\section{Project Title: Identifying and overcoming the challenges of implementing the ITIL Problem Management process in IT support organizations.}

\section{Purpose of the Research}

The purpose of the research is to explore IT professionals' views towards the ITIL Problem Management process and identify the challenges of implementing the Problem Management process within IT support organizations. It also aims at ranking these challenges according to their importance and discovering possible ways, methods and approaches by which the IT support organizations can overcome the topranked challenges.

This research has already been approved by the general manager of managed services at Fujitsu New Zealand and will be carried out by interviewing IT professionals from Fujitsu Australia and New Zealand. The interviews deal with general questions about the way in which the IT professionals see the ITIL Problem Management process, the challenges IT support organizations face in implementing ITIL Problem Management process and how to overcome these challenges. If necessary, issues from the interviews will be followed up by focus group meetings or email discussions. The insights gained will be used as part of my Master research in information management and may be published.

Apart from its objective to provide scientific insights and further the research of the ITIL Problem Management process and its implementation, this study also contributes towards the requirements for a course in the Master of Information Management programme.

\section{Confidentiality}

Victoria University requires ethical approval which has been granted for this research. All raw data will be kept confidential to the researcher and his supervisor. Throughout the project, raw data will be kept under password and/or lock protection and destroyed two years after the conclusion of the project. Collected, collated and analysed data may be published in case studies, academic journals and presented at conferences.

Participation in this research is voluntary. You are not under any obligation to take part in this research. Even after the interview is completed you have the right to withdraw from the study until 1st of 
September, 2010. Any information and opinions that you provide will not be attributed to you, and you will not be able to be identified in any way. A summary of the key findings and a research report will be provided to you and all other research participants.

Please feel free to contact my research supervisor Janet Toland on 4636861 or our Head of School (Dr Val Hooper) on 4635020 if you require further information about the project or the informed consent requirement.

The consent form is attached. It includes a request for permission to tape-record interviews. If you agree to participate, please complete the form, sign it and return it to me.

Thank you for your time.

Yours sincerely,

Michael Hsu

Phone: 642102192778

Email: hsumich@myvuw.ac.nz 


\section{Appendix 7: Consent to Participate in Research}

VICTORIA UNIVERSITY OF WELLINGTON

Te Whare Wananga o te Upoko o te Ika a Maui

\section{Consent to Participate in Research}

Project Title: Identifying and overcoming the challenges of implementing the ITIL Problem Management process in IT support organizations.

[Please mark each box with a $\sqrt{ }$ to indicate agreement]

I have been given and have understood an explanation of this research project. I have had an opportunity to ask questions and have them answered to my satisfaction. I understand that I may withdraw myself (or any information I have provided) from this project (before data collection and analysis is complete) without having to give reasons by e-mailing hsumich@myvuw.ac.nz or his supervisor at the email addresses given below by the $1^{\text {st }}$ of September, 2010 .

I understand that any information I provide will be kept confidential to the researcher and his supervisor, the published results will not use my name, and that no opinions will be attributed to me in any way that will identify me. I understand that the data I provide will not be used for any other purpose or released to others. I understand that, if this interview is audio recorded, the recording of interviews will be erased at the conclusion of the project.

I would like to receive a summary of the results of this research when it is completed.

I agree to take part in this research.

I agree to this interview being audio recorded.

Signed:

Name of participant:

Date:

Please feel free to contact Michael Hsu on 021-02192778 or via email at hsumich@ myvuw.ac.nz or his supervisor, Janet Toland on 4636861 or via email at janet.toland @ vuw.ac.nz for further information on the project or informed consent requirement. 


\section{Appendix 8: Importance Rating Questionnaire \\ The challenges for IT support organisations to implement ITIL Problem Management process}

Please rate $(\mathrm{V})$ the importance of the following challenges -

1...Least important challenge; 5 ... moderate important challenge;

10...most important challenge

A. The IT support teams' understanding of the ITIL Problem Management process and its benefit

\begin{tabular}{|l|l|l|l|l|l|l|l|l|l|}
\hline 1 & 2 & 3 & 4 & 5 & 6 & 7 & 8 & 9 & 10 \\
\hline & & & & & & & & & \\
\hline
\end{tabular}

B. The relationships and interactions between ITIL Problem Management process and other ITIL processes and function within the IT support organisation

\begin{tabular}{|l|l|l|l|l|l|l|l|l|l|}
\hline 1 & 2 & 3 & 4 & 5 & 6 & 7 & 8 & 9 & 10 \\
\hline & & & & & & & & & \\
\hline
\end{tabular}

C. The focus of being proactive in providing IT support

\begin{tabular}{|l|l|l|l|l|l|l|l|l|l|}
\hline 1 & 2 & 3 & 4 & 5 & 6 & 7 & 8 & 9 & 10 \\
\hline & & & & & & & & & \\
\hline
\end{tabular}

D. The management's understanding of the ITIL Problem Management process and its benefit

\begin{tabular}{|l|l|l|l|l|l|l|l|l|l|}
\hline 1 & 2 & 3 & 4 & 5 & 6 & 7 & 8 & 9 & 10 \\
\hline & & & & & & & & & \\
\hline
\end{tabular}

E. The maturity of other ITIL processes and function that interact with the ITIL Problem Management process

\begin{tabular}{|l|l|l|l|l|l|l|l|l|l|}
\hline 1 & 2 & 3 & 4 & 5 & 6 & 7 & 8 & 9 & 10 \\
\hline & & & & & & & & & \\
\hline
\end{tabular}


F. The quantity and quality of the information gathered for the ITIL Problem Management Process

\begin{tabular}{|l|l|l|l|l|l|l|l|l|l|}
\hline 1 & 2 & 3 & 4 & 5 & 6 & 7 & 8 & 9 & 10 \\
\hline & & & & & & & & & \\
\hline
\end{tabular}

G. The finance and resource commitment for the ITIL Problem Management process

\begin{tabular}{|l|l|l|l|l|l|l|l|l|l|}
\hline 1 & 2 & 3 & 4 & 5 & 6 & 7 & 8 & 9 & 10 \\
\hline & & & & & & & & & \\
\hline
\end{tabular}

H. The customer buy-in and support for the ITIL Problem Management process

\begin{tabular}{|l|l|l|l|l|l|l|l|l|l|}
\hline 1 & 2 & 3 & 4 & 5 & 6 & 7 & 8 & 9 & 10 \\
\hline & & & & & & & & & \\
\hline
\end{tabular}

I. The focus on the underlying causes of IT issues

\begin{tabular}{|l|l|l|l|l|l|l|l|l|l|}
\hline 1 & 2 & 3 & 4 & 5 & 6 & 7 & 8 & 9 & 10 \\
\hline & & & & & & & & & \\
\hline
\end{tabular}

J. The customers' understanding of the ITIL Problem Management process and its benefit

\begin{tabular}{|l|l|l|l|l|l|l|l|l|l|}
\hline 1 & 2 & 3 & 4 & 5 & 6 & 7 & 8 & 9 & 10 \\
\hline & & & & & & & & & \\
\hline
\end{tabular}

K. The nature and complications of the issues the IT support organisation's customer is facing

\begin{tabular}{|l|l|l|l|l|l|l|l|l|l|}
\hline 1 & 2 & 3 & 4 & 5 & 6 & 7 & 8 & 9 & 10 \\
\hline & & & & & & & & & \\
\hline
\end{tabular}

L. The capability, competency and skills of the Problem Manager

\begin{tabular}{|l|l|l|l|l|l|l|l|l|l|}
\hline 1 & 2 & 3 & 4 & 5 & 6 & 7 & 8 & 9 & 10 \\
\hline & & & & & & & & & \\
\hline
\end{tabular}


M. The organisational structure of the IT support organisation related to the ITIL Problem Management process

\begin{tabular}{|l|l|l|l|l|l|l|l|l|l|}
\hline 1 & 2 & 3 & 4 & 5 & 6 & 7 & 8 & 9 & 10 \\
\hline & & & & & & & & & \\
\hline
\end{tabular}

N. The tools used for implementing the ITIL Problem Management process

\begin{tabular}{|l|l|l|l|l|l|l|l|l|l|}
\hline 1 & 2 & 3 & 4 & 5 & 6 & 7 & 8 & 9 & 10 \\
\hline & & & & & & & & & \\
\hline
\end{tabular}

O. The management buy-in and support for the ITIL Problem Management process

\begin{tabular}{|l|l|l|l|l|l|l|l|l|l|}
\hline 1 & 2 & 3 & 4 & 5 & 6 & 7 & 8 & 9 & 10 \\
\hline & & & & & & & & & \\
\hline
\end{tabular}

P. The IT support organisation's readiness to change in alignment with best practice guidelines

\begin{tabular}{|l|l|l|l|l|l|l|l|l|l|}
\hline 1 & 2 & 3 & 4 & 5 & 6 & 7 & 8 & 9 & 10 \\
\hline & & & & & & & & & \\
\hline
\end{tabular}

Q. The collaboration of the support teams around problem cases

\begin{tabular}{|l|l|l|l|l|l|l|l|l|l|}
\hline 1 & 2 & 3 & 4 & 5 & 6 & 7 & 8 & 9 & 10 \\
\hline & & & & & & & & & \\
\hline
\end{tabular}

R. The cost-benefit justification for investigating, identifying and removing root causes of IT issues

\begin{tabular}{|l|l|l|l|l|l|l|l|l|l|}
\hline 1 & 2 & 3 & 4 & 5 & 6 & 7 & 8 & 9 & 10 \\
\hline & & & & & & & & & \\
\hline
\end{tabular}

S. The adaption, customization and governance of the ITIL Problem Management process within the IT support organisation

\begin{tabular}{|l|l|l|l|l|l|l|l|l|l|}
\hline 1 & 2 & 3 & 4 & 5 & 6 & 7 & 8 & 9 & 10 \\
\hline & & & & & & & & & \\
\hline
\end{tabular}


T. The IT support teams' buy-in and support for the ITIL Problem Management process

\begin{tabular}{|l|l|l|l|l|l|l|l|l|l|}
\hline 1 & 2 & 3 & 4 & 5 & 6 & 7 & 8 & 9 & 10 \\
\hline & & & & & & & & & \\
\hline
\end{tabular}

U. The technical knowledge of the Problem Manager

\begin{tabular}{|l|l|l|l|l|l|l|l|l|l|}
\hline 1 & 2 & 3 & 4 & 5 & 6 & 7 & 8 & 9 & 10 \\
\hline & & & & & & & & & \\
\hline
\end{tabular}

V. The ability to achieve both short term and long term benefit of ITIL Problem Management process

\begin{tabular}{|l|l|l|l|l|l|l|l|l|l|}
\hline 1 & 2 & 3 & 4 & 5 & 6 & 7 & 8 & 9 & 10 \\
\hline & & & & & & & & & \\
\hline
\end{tabular}

W. The technical knowledge of the IT support teams

\begin{tabular}{|l|l|l|l|l|l|l|l|l|l|}
\hline 1 & 2 & 3 & 4 & 5 & 6 & 7 & 8 & 9 & 10 \\
\hline & & & & & & & & & \\
\hline
\end{tabular}

